University of Tennessee Health Science Center

UTHSC Digital Commons

\title{
Anal Cancer Risk Factor Management Practices and the Barriers and Facilitators of Addressing Anal Health in the HIV Primary Care Setting
}

Crystal Martin Walker

University of Tennessee Health Science Center

Follow this and additional works at: https://dc.uthsc.edu/dissertations

Part of the Neoplasms Commons, Primary Care Commons, and the Virus Diseases Commons

\section{Recommended Citation}

Walker, Crystal Martin , "Anal Cancer Risk Factor Management Practices and the Barriers and Facilitators of Addressing Anal Health in the HIV Primary Care Setting" (2015). Theses and Dissertations (ETD). Paper 285. http://dx.doi.org/10.21007/etd.cghs.2015.0338.

This Dissertation is brought to you for free and open access by the College of Graduate Health Sciences at UTHSC Digital Commons. It has been accepted for inclusion in Theses and Dissertations (ETD) by an authorized administrator of UTHSC Digital Commons. For more information, please contact jwelch30@uthsc.edu. 


\title{
Anal Cancer Risk Factor Management Practices and the Barriers and Facilitators of Addressing Anal Health in the HIV Primary Care Setting
}

\begin{abstract}
Background: The incidence of anal cancer is only $1-2$ per 100,000 people in the general population, but in people living with HIV and AIDS (PLWHA), the incidence is far greater by about 80 times. This is a striking disproportion, and it is vital for the healthcare provider and healthcare system to become more attentive to the risk of anal cancer in high-risk populations such as PLWHA. There are a number of modifiable risk factors for anal cancer in PLWHA such as smoking, non-adherence to antiretroviral therapy (ART), and risky sexual behaviors. The HIV primary care provider (HIV PCP) plays a major role in working with patients to address those risk factors through anal cancer risk factor management (ACRFM). The issue is that anal cancer and anal health are rarely addressed in the HIV primary care setting, and with anal cancer being on the rise in high-risk populations, the lack of risk factor management could become a major healthcare issue. This study sought to understand HIV PCPs' current practices of screening for anal cancer risk factors and intervening to manage those risk factors. It also sought to understand their knowledge, confidence, and attitudes towards managing each risk factor in order to determine if there is a relationship between their knowledge, confidence, and attitude and their practices. Because anal health, a component of sexual health, is so poorly discussed in primary care, this study also sought to understand the factors that HIV PCPs see as facilitating or impeding their approach to discussing anal health with their patients. The overall purpose of the study was to understand ACRFM practices and the barriers and facilitators of addressing anal health in the HIV primary care setting.

Methods: In this exploratory study, a descriptive correlational design was used to assess ACRFM quantitatively. The barriers and facilitators of discussing anal health in the HIV primary care setting were explored qualitatively. A 20-question ACRFM survey was developed and administered to HIV PCPs in MS, TN, and AR. Data were analyzed using descriptive statistics, confidence interval hypothesis testing for mean values, and Spearman's correlation coefficients. HIV PCPs were then randomly selected from survey participants for individual interviews. Five interview questions were used to understand the barriers and facilitators of discussing anal health in the HIV primary care settings. Interview transcripts were analyzed for codes that would fall into two major categories: barriers and facilitators of discussing anal health.
\end{abstract}

Results: There were 20 HIV PCPs who participated in the quantitative portion of the study. HIV PCPs were less likely to practice towards managing risky sexual behaviors $(2.57 \pm 1.2)$ when compared to smoking and non-adherence to ART. Knowledge, confidence, and attitude (KCA) scores were statistically higher towards management of non-adherence to ART, but all KCA scores were high ( $\geq 4.0$ on a scale of 5.0). There was a moderate relationship between the knowledge of managing risky sexual behaviors and practices towards managing risky sexual behaviors $(r=.56699, p=.0091)$. There were 10 HIV PCPs randomly selected from the sample of survey participants, and 9 agreed to participate in brief one-on-one interviews. There were two major categories, barriers and facilitators of discussing anal health in the HIV primary care setting, and a total of ten codes. There were seven barrier codes: external issues, demand of other priorities, perception of patient embarrassment, lack of resources, provider embarrassment, lack of anal complaints, and gender discordance. There were 3 facilitator codes: awareness, advantageous circumstances, and the patient-provider relationship. Anal health was confirmed as a component of sexual health.

Conclusions: HIV PCPs were found to have high knowledge, confidence, and attitude scores towards managing all anal cancer risk factors. This finding indicated that other factors might have contributed to a lesser likelihood of managing risky sexual behaviors in the HIV primary care setting other than knowledge, confidence, and attitude. The lack of resources related to screening for risky sexual behaviors and 
intervening to reduce risky sexual behaviors was hypothesized as one reason to explain this finding. Barriers of addressing anal health such as lack of time, the demand of other issues, the lack of anal health complaints, personal embarrassment, and issues related to gender discordance were also identified as factors to explain this finding. An implication for future practice includes the development of resource guides specific to ACRFM. Another implication includes the implementation of preventative health visits for ACRFM in HIV primary care as an effort to reduce issues related to time constraints and competing demands. A nationwide improvement of sexual health and anal health education is also recommended in training programs for all healthcare professionals in order to reduce issues related to personal embarrassment.

\section{Document Type}

Dissertation

Degree Name

Doctor of Philosophy (PhD)

\section{Program}

Nursing Science

\section{Research Advisor}

Wendy M. Likes, Ph.D., D.N.Sc

\section{Keywords}

anal cancer, barriers, facilitators, HIV, PLWHA, sexual health

\section{Subject Categories}

Diseases | Medical Specialties | Medicine and Health Sciences | Neoplasms | Primary Care | Virus

Diseases 


\title{
Anal Cancer Risk Factor Management Practices and the Barriers and Facilitators of Addressing Anal Health in the HIV Primary Care Setting
}

\author{
A Dissertation \\ Presented for \\ The Graduate Studies Council \\ The University of Tennessee \\ Health Science Center
}

In Partial Fulfillment

Of the Requirements for the Degree

Doctor of Philosophy

From The University of Tennessee

By

Crystal Martin Walker

May 2015 
Copyright (C) 2015 by Crystal Martin Walker.

All rights reserved. 


\section{DEDICATION}

I dedicate this dissertation to my loving and caring husband Kenneth M. Walker II, my grandmother Elizabeth Camphor Martin, The Martin Family, and The Walker Family. Thank you for all for your love and support. 


\section{ACKNOWLEDGEMENTS}

I would like to acknowledge and share my deepest gratitude for Dr. Wendy Likes for accepting me as her graduate student. I am honored to know you and to be mentored by you. You are the epitome of hard work and dedication, and I hope to follow in your footsteps. I would also like to thank my committee members Drs. Marye Bernard, Satish Kedia, Cynthia Russell, and Elizabeth Tolley for your time and your expertise.

I would also like to acknowledge Dr. Carolyn Graff for your support, your input, and your time and Connie Burgess for your assistance.

Funding for this study was provided by the University of Tennessee Health Science Center's College of Nursing. 


\begin{abstract}
Background: The incidence of anal cancer is only 1-2 per 100,000 people in the general population, but in people living with HIV and AIDS (PLWHA), the incidence is far greater by about 80 times. This is a striking disproportion, and it is vital for the healthcare provider and healthcare system to become more attentive to the risk of anal cancer in high-risk populations such as PLWHA. There are a number of modifiable risk factors for anal cancer in PLWHA such as smoking, non-adherence to antiretroviral therapy (ART), and risky sexual behaviors. The HIV primary care provider (HIV PCP) plays a major role in working with patients to address those risk factors through anal cancer risk factor management (ACRFM). The issue is that anal cancer and anal health are rarely addressed in the HIV primary care setting, and with anal cancer being on the rise in high-risk populations, the lack of risk factor management could become a major healthcare issue. This study sought to understand HIV PCPs' current practices of screening for anal cancer risk factors and intervening to manage those risk factors. It also sought to understand their knowledge, confidence, and attitudes towards managing each risk factor in order to determine if there is a relationship between their knowledge, confidence, and attitude and their practices. Because anal health, a component of sexual health, is so poorly discussed in primary care, this study also sought to understand the factors that HIV PCPs see as facilitating or impeding their approach to discussing anal health with their patients. The overall purpose of the study was to understand ACRFM practices and the barriers and facilitators of addressing anal health in the HIV primary care setting.
\end{abstract}

Methods: In this exploratory study, a descriptive correlational design was used to assess ACRFM quantitatively. The barriers and facilitators of discussing anal health in the HIV primary care setting were explored qualitatively. A 20-question ACRFM survey was developed and administered to HIV PCPs in MS, TN, and AR. Data were analyzed using descriptive statistics, confidence interval hypothesis testing for mean values, and Spearman's correlation coefficients. HIV PCPs were then randomly selected from survey participants for individual interviews. Five interview questions were used to understand the barriers and facilitators of discussing anal health in the HIV primary care settings. Interview transcripts were analyzed for codes that would fall into two major categories: barriers and facilitators of discussing anal health.

Results: There were 20 HIV PCPs who participated in the quantitative portion of the study. HIV PCPs were less likely to practice towards managing risky sexual behaviors $(2.57 \pm 1.2)$ when compared to smoking and non-adherence to ART. Knowledge, confidence, and attitude (KCA) scores were statistically higher towards management of non-adherence to ART, but all KCA scores were high ( $\geq 4.0$ on a scale of 5.0). There was a moderate relationship between the knowledge of managing risky sexual behaviors and practices towards managing risky sexual behaviors $(\mathrm{r}=.56699, \mathrm{p}=.0091)$.

There were 10 HIV PCPs randomly selected from the sample of survey participants, and 9 agreed to participate in brief one-on-one interviews. There were two major categories, barriers and facilitators of discussing anal health in the HIV primary care setting, and a 
total of ten codes. There were seven barrier codes: external issues, demand of other priorities, perception of patient embarrassment, lack of resources, provider embarrassment, lack of anal complaints, and gender discordance. There were 3 facilitator codes: awareness, advantageous circumstances, and the patient-provider relationship. Anal health was confirmed as a component of sexual health.

Conclusions: HIV PCPs were found to have high knowledge, confidence, and attitude scores towards managing all anal cancer risk factors. This finding indicated that other factors might have contributed to a lesser likelihood of managing risky sexual behaviors in the HIV primary care setting other than knowledge, confidence, and attitude. The lack of resources related to screening for risky sexual behaviors and intervening to reduce risky sexual behaviors was hypothesized as one reason to explain this finding. Barriers of addressing anal health such as lack of time, the demand of other issues, the lack of anal health complaints, personal embarrassment, and issues related to gender discordance were also identified as factors to explain this finding. An implication for future practice includes the development of resource guides specific to ACRFM. Another implication includes the implementation of preventive health visits for ACRFM in HIV primary care as an effort to reduce issues related to time constraints and competing demands. A nationwide improvement of sexual health and anal health education is also recommended in training programs for all healthcare professionals in order to reduce issues related to personal embarrassment. 


\section{TABLE OF CONTENTS}

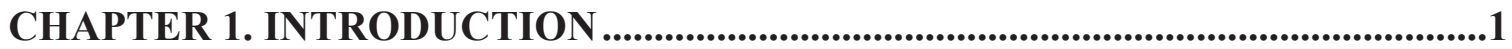

Anal Cancer and Anal Cancer Risk Factor Management ............................................ 1

Background and Significance ..............................................................................2

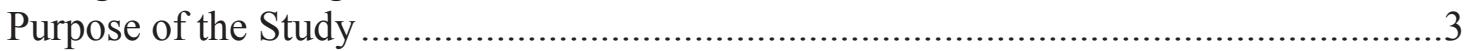

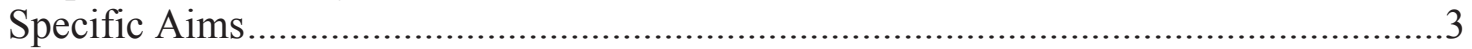

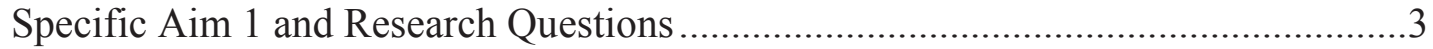

Specific Aim 2 and Research Questions .......................................................

Specific Aim 3 and Research Questions ...........................................................4

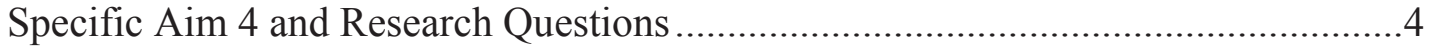

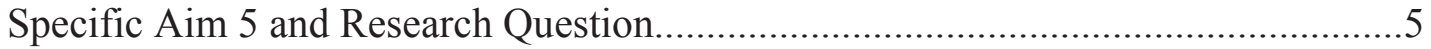

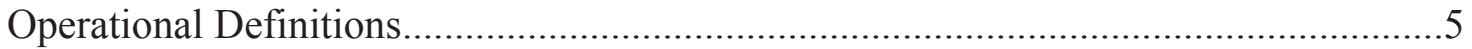

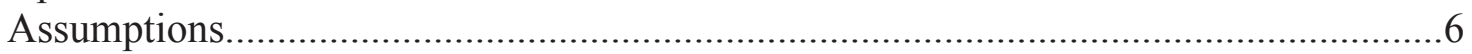

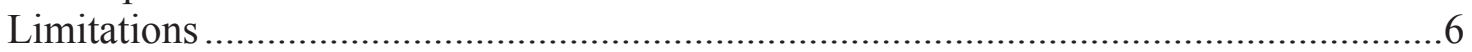

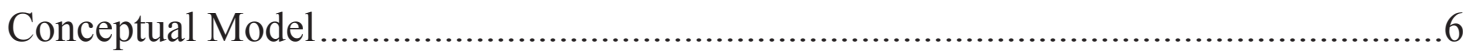

CHAPTER 2. REVIEW OF LITERATURE .......................................................10

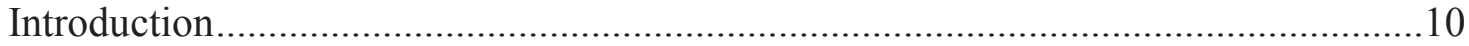

Barriers to Managing Sexual Health in Primary Care Settings ....................................11

Determinants of Health ......................................................................................... 13

Anal Cancer Screening, Diagnosis, and Management...........................................15

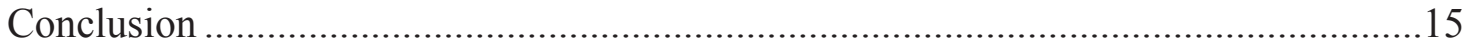

CHAPTER 3. METHODOLOGY .........................................................................17

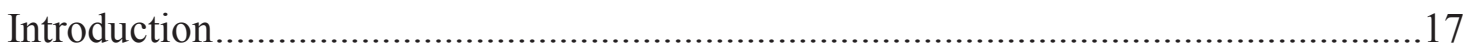

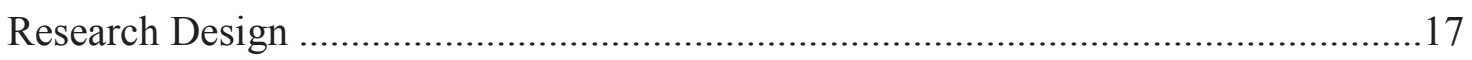

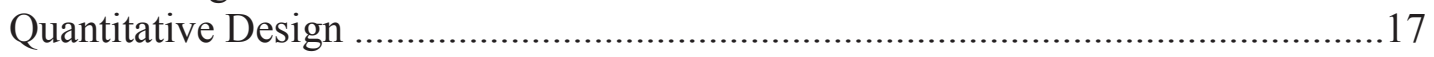

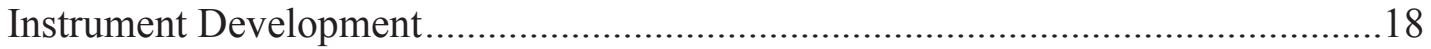

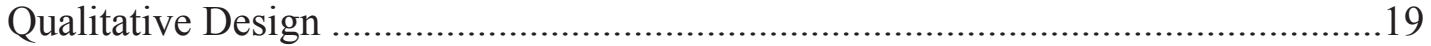

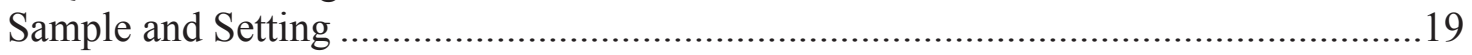

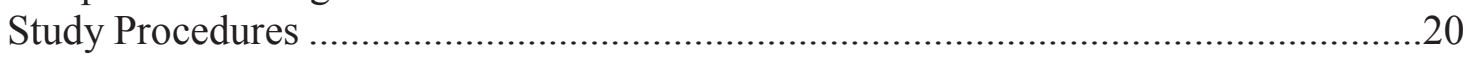

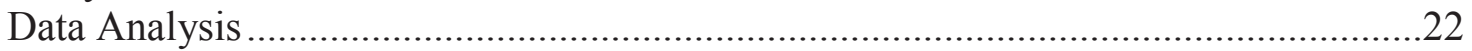

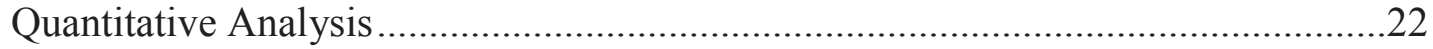

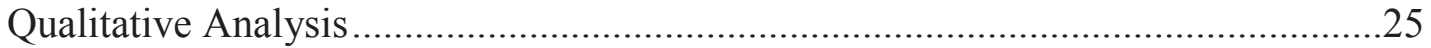

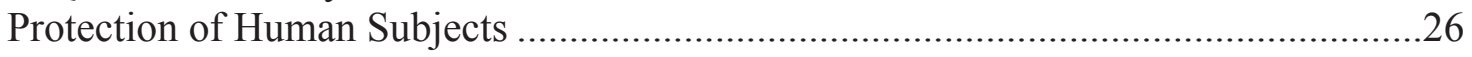

CHAPTER 4. ANALYSIS........................................................................................27

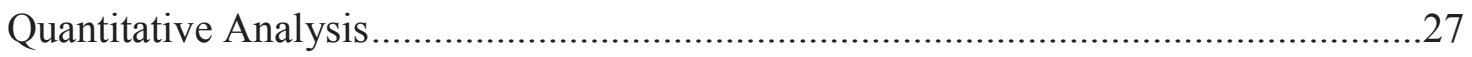

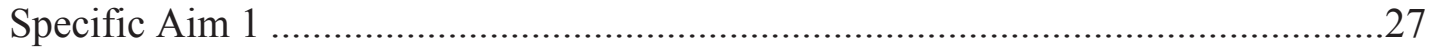

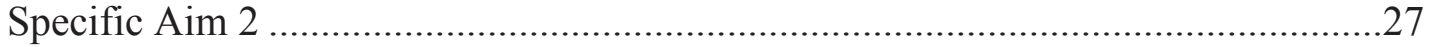

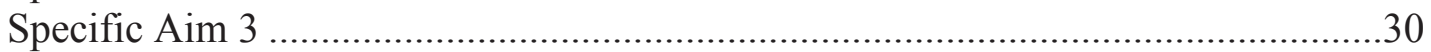

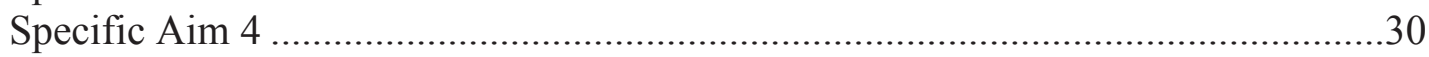

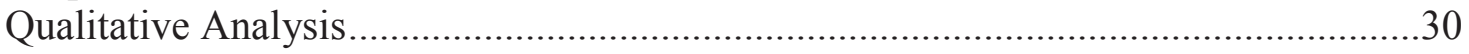




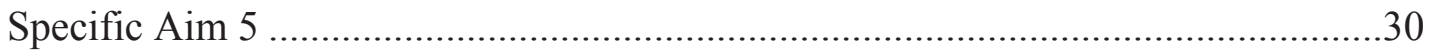

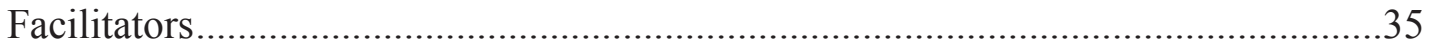

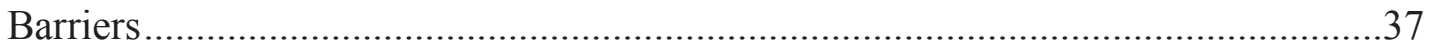

CHAPTER 5. DISCUSSION .................................................................................. 41

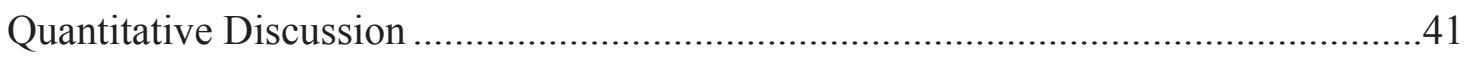

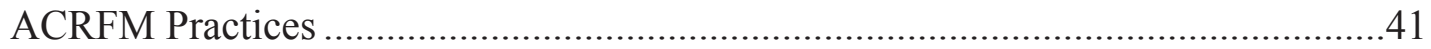

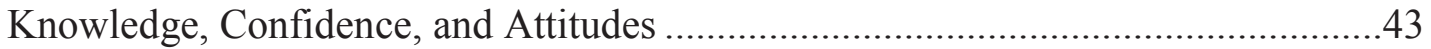

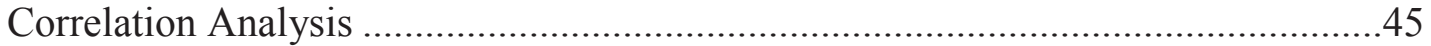

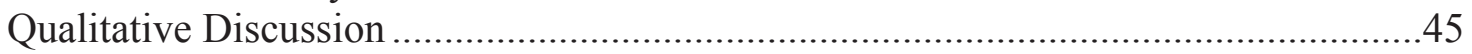

Perception of Patient Embarrassment and Provider Embarrassment.........................46

External Issues and the Demand of Other Priorities ..............................................47

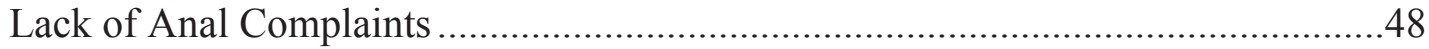

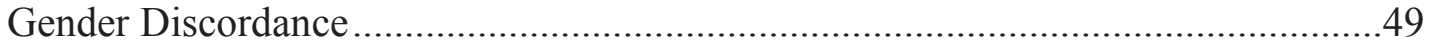

Lack of Resources .......................................................................................49

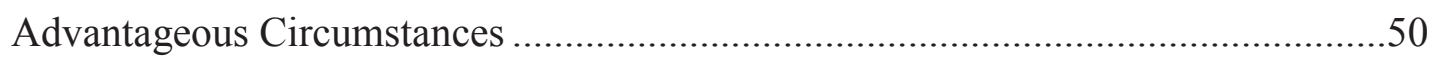

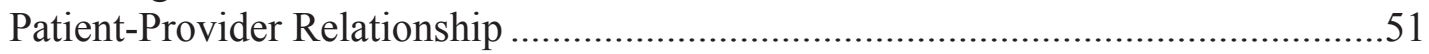

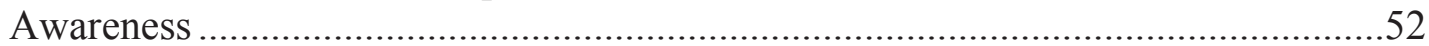

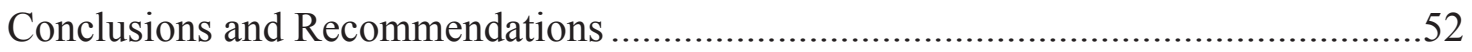

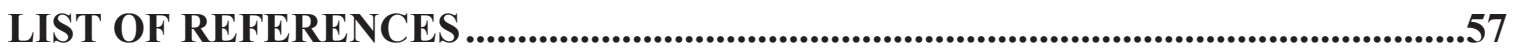

APPENDIX A. LIFESTYLE RISK FACTOR SURVEY .....................................67

APPENDIX B. ANAL CANCER RISK FACTOR MANAGEMENT SURVEY ......72

APPENDIX C. INSTITUTIONAL REVIEW BOARD APPROVAL ........................79

APPENDIX D. ONLINE SURVEY CONSENT FORM .........................................81

APPENDIX E. MAIN CONSENT FORM...................................................................82

VITA 


\section{LIST OF TABLES}

Table 4.1. Demographic Information for 20 Participating Primary Care Providers.......28

Table 4.2. Average Practice Scores by Anal Cancer Risk Factor of 20 HIV Primary

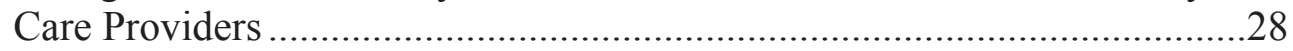

Table 4.3. Average Practice Scores and 95\% Confidence Intervals of 20 HIV

Primary Care Providers .........................................................................29

Table 4.4. Average Knowledge, Confidence, and Attitude Scores of 20 HIV

Primary Care Providers .........................................................................29

Table 4.5. Interpretations of Average Knowledge, Confidence, and Attitude Scores

of 20 HIV Primary Care Providers...........................................................29

Table 4.6. Average Knowledge, Confidence, and Attitude Scores and 95\%

Confidence Intervals of 20 HIV Primary Care Providers

Table 4.7. Estimated Spearman Correlation Coefficients between Total Score for ACRFM Practices and Scores for Knowledge, Confidence, and Attitudes towards ACRFM based on 20 HIV Primary Care Providers.........31

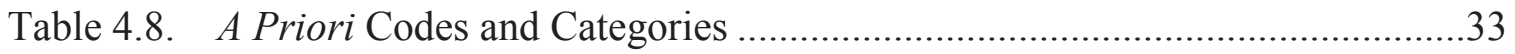

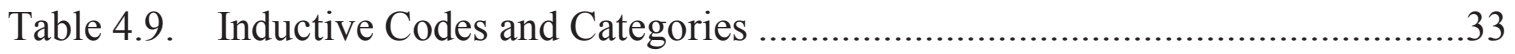

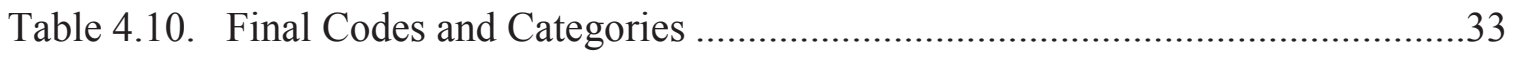

Table 4.11. Qualitative Coding Frequencies of 9 Primary Care Providers

Participating in the Interview Portion of the Study. 


\section{LIST OF FIGURES}

Figure 1.1. Simplified Theory of Planned Behavior ..................................................

Figure 1.2. Modified Theory of Planned Behavior for ACRFM....................................9

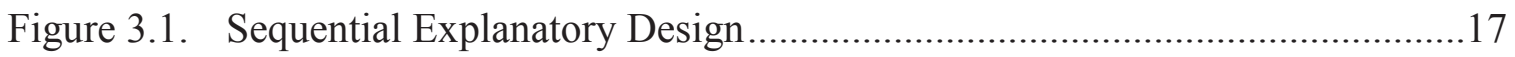




\section{LIST OF ABBREVIATIONS}

ACRFM

AIN

ART

HCP

HIV

HPV

KCA

LGBTQ

LRF

MSM

PCP

PLWHA
Anal Cancer Risk Factor Management

Anal Intraepithelial Neoplasia

Antiretroviral therapy

Health Care Provider

Human Immunodeficiency Virus

Human Papillomavirus

Knowledge, Confidence, and Attitude

Lesbian, Gay, Bisexual, Transgender, Queer

Lifestyle risk factor

Men Who Have Sex With Men

Primary Care Provider

People living with HIV and AIDS 


\section{CHAPTER 1. INTRODUCTION}

\section{Anal Cancer and Anal Cancer Risk Factor Management}

Anal cancer is on a dramatic rise in high-risk groups. There is a crucial need to increase knowledge among patients and providers about what it is, who it affects, and how it can be prevented. Anal cancer is a rare malignancy of the anus that develops from precancerous changes in the anal mucosa. These precancerous changes are termed dysplasia, and are commonly referred to as anal intraepithelial neoplasia (AIN). AIN is categorized as low grade (AIN I) and high grade (AIN II and AIN III). Low-grade dysplasia resembles normal cells, while high-grade dysplasia has more abnormal cells and a higher likelihood of progressing into anal cancer (American Cancer Society, 2014). Anal cancer is more commonly seen in persons who have receptive anal intercourse, multiple lifetime sexual partners, a smoking history (Daling et al., 2004) and in women with a history of cervical dysplasia (Daling et al., 2004; Melbye \& Sprogel, 1991; Palefsky, Holly, Ralston, Da Costa, \& Greenblatt, 2001). Human papillomavirus (HPV), the most common sexually transmitted infection, causing 6 million new infections each year (Centers for Disease Control and Prevention, 2012), is strongly associated with anal cancer (Daling et al., 2004; Frisch et al., 1997; Tilston, 1997). It has also been linked to a number of other genital cancers such as cervical, vulva, vaginal and penile cancer (CDC, 2012 ).

In immune competent persons, HPV is normally cleared from the system, and many may not realize they were ever infected (American Cancer Society, 2014). Most studies have reported a short duration of HPV infection (i.e. 8-24 months) (Franco et al., 1999; Ho, Bierman, Beardsley, Chang, \& Burk, 1998; Moscicki et al., 1998), but in immunocompromised persons, such as people living with HIV/AIDS (PLWHA), the virus has been found to have a higher risk of persistence, and this persistence may lead to anal cancer (Moscicki, Ellenberg, Farhat, \& Xu, 2004). There is a strikingly increased risk of anal cancer in PLWHA (Melbye, Cote, Kessler, Gail, \& Biggar, 1994). Healthcare providers should be cognizant of the increased risk of anal cancer in PLWHA and also the risk factors for anal cancer. Understanding risk factors helps to direct efforts towards disease prevention. Modifiable lifestyle risk factors for anal cancer may be mitigated through the implementation of anal cancer risk factor management (ACRFM).

Risk factor management is "the identification, assessment, and prioritization of risks followed by a coordinated application of resources to minimize, monitor, and control the probability of unfortunate events" (Hubbard, 2009, p. 10). The HIV primary care provider (HIV PCP) plays a major role in identifying, assessing, and prioritizing risk factors for anal cancer and then providing the patient with education and resources to properly manage those risk factors. ACRFM therefore becomes a type of lifestyle risk factor management in high-risk populations. 


\section{Background and Significance}

From 1973-2000, a rise in anal cancer was noted for both men and women: In men, anal cancer increased from 0.09 cases to 0.45 cases per 100,000 persons. In women, cases increased from 0.12 to 0.22 cases per 100,000 persons (Johnson, Madeleine, Newcomer, Schwartz, \& Daling, 2004). Although anal cancer is very rare in the general population at only 1.8 new cases per 100,000 people in the United States (National Cancer Institute, n.d. ), the incidence is disproportionately elevated in higher risk populations such as PLWHA because "HPV is more frequent, persistent, and more difficult to treat in HIV-infected individuals than in HIV-negative individuals" (RosaCunha, Cardenas, Dickinson, \& Metsch, 2010, p. 533). There is nearly an 8-fold increased risk of anal cancer in HIV positive women when compared to HIV negative women (Frisch, Biggar, \& Goedert, 2000), and in HIV positive men who have sex with men (MSM), the rate of anal cancer is up to 80 times higher than the general population (Silverberg et al., 2012).

In PLWHA, there are poorer treatment outcomes related to anal cancer than in HIV negative patients such as poorer treatment tolerances, poorer response rates, and even a shorter time to death (Kim et al., 2001). Some patients have reported acceptable quality of life scores after treatment, but others have reported poor sexual function scores (Das et al., 2010), a significant reduction in global quality of life, and symptoms such as impaired of bowel function and pain (Bentzen et al., 2013). Due to the sequela of the disease and the high risk of anal cancer in PLWHA, healthcare providers (HCPs) should address anal health particularly in the highest risk groups. However, it appears there is a gap in the care provided as it was found that only $36 \%$ of PLWHA reported discussing anal health with their HIV PCP in the past year (Rosa-Cunha et al., 2010). As more PLWHA live longer due to advancements in anti-retroviral therapy, it can be hypothesized that anal cancer may continue to increase. It is therefore imperative for HCPs to consider addressing anal cancer by making ACRFM a part of routine HIV primary care.

Screening is a key component for cancer prevention. Cervical cancer, once the most common cause of cancer in women in the United States (U.S.) and a major cause of death, now has incidence and death rates that have been markedly reduced because of the ability to screen for cancer and detect abnormal lesions (National Institute of Health, 2013 ) The rate of anal cancer in high-risk groups such as HIV positive MSM is 70-80 per 100,000 persons, and this rate is much higher than the incidence of cervical cancer before implementation of the cervical Pap smear (AIDS Education and Training Centers, 2006 ). There are improvements needed with the use of the anal Pap smear as a screening tool, treatment modality studies are ongoing, and there are no studies that indicate the effectiveness of anal cancer screening, treatment, or management program (Darragh \& Winkler, 2011). This lack of data has contributed to the argument against screening for anal cancer, but there are still other ways to address anal cancer such as through risk factor management. 
Some modifiable risk factors for anal cancer have been identified as smoking and risky sexual behaviors (i.e. number of lifetime partners that exceed fifteen and anal intercourse) (Daling et al., 2004). Lifestyle risk factor modification is the first step in a number of different types of cancer prevention, and should be considered as a first step in the prevention of anal cancer. In ACRFM, HCPs would first identify PLWHA and subgroups such as MSM and women with other lower genital tract dysplasias as high-risk for anal cancer. Next, HCPs would prioritize modifiable anal cancer risk factors and then use resources to intervene and reduce the probability of cancer based on risk factor management. This is the expected course of ACRFM, but the reality is that ACRFM is a newly coined term, and it is assumed to not routinely exist in the HIV primary care setting. Research about risk factor management is significant to this area of healthcare as there is no data that addresses this topic as a method of disease prevention. In PLWHA, the HIV PCP is a key player in assessing for and managing anal cancer risk factors. It was therefore imperative to understand how HCPs are currently managing anal cancer risk factors and to understand some of the factors that may promote or impede their ability to address anal health.

\section{Purpose of the Study}

Understand how HIV PCPs are currently practicing ACRFM and to understand some of the factors that may promote or impede their ability to address anal health with their patients in HIV primary care settings

\section{Specific Aims}

\section{Specific Aim 1 and Research Questions}

To determine demographic characteristics of research participants and to determine current HIV PCPs practices related to ACRFM

1.1 What are the demographic characteristics of this sample?

1.2 What are the average screening scores for anal cancer risk factors?

1.3 What are the average intervention scores for anal cancer risk factors?

1.4 What are the average practice scores (screening and intervention) for anal cancer risk factors? 


\section{Specific Aim 2 and Research Questions}

To determine the levels of self-reported knowledge, confidence, and attitudes related to managing modifiable anal cancer risk factors

2.1 What is the self-reported level of knowledge towards managing each modifiable anal cancer risk factor?

2.2 What is the self-reported level of confidence towards managing each modifiable anal cancer risk factor?

2.3 What is the self-reported attitude level towards managing each modifiable anal cancer risk factor?

\section{Specific Aim 3 and Research Questions}

To determine relationships among knowledge, confidence, and attitudes of HIV PCPs and their current practices

3.1 What relationship exists between knowledge towards managing each modifiable anal cancer risk factor and current practices related to each modifiable anal cancer risk factor?

3.2 What relationship exists between confidence towards managing each modifiable anal cancer risk factor and current practices related to each modifiable anal cancer risk factor?

3.3 What relationship exists between attitude towards managing each modifiable anal cancer risk factor and current practices related to each modifiable anal cancer risk factor?

\section{Specific Aim 4 and Research Questions}

To differentiate between high and low implementers of ACRFM

4.1 What demographic differences exist between high implementers versus low implementers of ACRFM?

4.2 What differences in self-reported levels of knowledge, confidence, and attitudes towards managing modifiable anal cancer risk factors exist between high and low implementers of ACRFM?

4.3 Do the relationships estimated in aim 3 (3.1-3.3) differ between high and low implementers of ACRFM? 


\section{Specific Aim 5 and Research Question}

To explore the barriers and facilitators to discussing anal health from the HIV PCP's perspective

5.1 What are the barriers and facilitators to discussing anal health within the HIV primary care setting?

\section{Operational Definitions}

- Anal health: The discussion of anal practices, management of anal symptoms, and examination of the anus (Rosa-Cunha et al., 2010)

- Sexual health: "Sexual health is a state of physical, mental, and social well-being in relation to sexuality. It requires a positive and respectful approach to sexuality and sexual relationships, as well as the possibility of having pleasurable and safe sexual experiences, free of coercion, discrimination and violence" (World Health Organization, 2006 , para. 4)

- Risk factor management: "Risk management is the identification, assessment, and prioritization of risks followed by a coordinated application of resources to minimize, monitor, and control the probability of unfortunate events" (Hubbard, 2009, p. 10)

- Anal cancer risk factor management: The identification, assessment, and prioritization of anal cancer risk factors followed by a coordinated application of resources to minimize, monitor, and control the probability of anal cancer

- ACRFM practices: ACRFM practices include screening for each modifiable risk factor and intervening to manage each modifiable risk factor

- Screening: Assessing for the presence of modifiable anal cancer risk factors

- Intervening: Taking action to decrease the presence of modifiable anal cancer risk factors

- Total ACRFM Practice: The combination of screening and intervention practices

- Knowledge of ACRFM: Awareness related to assessing for anal cancer risk factors and making recommendations to reduce or eliminate anal cancer risk factors (Harris, Davies, Williams, Eames-Brown, \& Amoroso, n.d.) 
- Confidence towards ACRFM: Self-assurance towards assessing for anal cancer risk factors and making recommendations to reduce or eliminate anal cancer risk factors (Harris et al., n.d.)

- Attitude towards ACRFM: Perspective on effectiveness, importance, and priority towards managing each anal cancer risk factor (Harris et al., n.d.)

\section{Assumptions}

- ACRFM is not part of routine HIV primary care.

- Knowledge, confidence, attitude, and perceived control towards ACRFM influence healthcare providers' practices towards managing anal cancer risk factors.

- HIV PCPs do not openly discuss anal health with PLWHA.

\section{Limitations}

- The ACRFM survey tool was modified from a lifestyle risk factor survey in primary healthcare and a survey to assess general practitioners risk factor management practice. Reliability and validity of the ACRFM survey was a limiting factor to the study.

- The sample size and characteristics (i.e. HIV PCPs in the Southern region of the United States: Arkansas, Mississippi, and Tennessee) of both quantitative and qualitative parts limited the generalizability of the study.

- Social desirability bias was a possible limiting factor to the study as survey responses were self-reported.

- Quantitative results required methodological modifications, thus limiting the use of the sequential explanatory design. Qualitative research questions were not modified to understand quantitative results. As a result, barriers to addressing anal health were hypothesized to explain why providers were less likely to address risky sexual behaviors.

\section{Conceptual Model}

To date, there is only one study that has examined anal health in the HIV primary care setting (Rosa-Cunha et al., 2010), and it did not apply any theoretical underpinnings to understand providers' practices related to anal health. The theory of planned behavior was used in this study to explain how behavior is best predicted by attitude and perceived 
control towards a behavior (Ajzen, 1991). Initially, the theory of reasoned action suggested that behavior is determined by intent to perform the behavior, and intent is a function of attitude and subjective norm (Ajzen, 1991). The concept of perceived control was added to the theory of reasoned action to consider the fact that uncontrollable factors might contribute to behavior (Glanz, Rimer, \& Viswanath, 2008). The addition of perceived control to the theory of reasoned action is how the theory of planned behavior was formed. Figure 1.1 is a simplified version of the theory of planned behavior (Ajzen, 2006). The constructs and assumptions of the theory of planned behavior are defined as the following:

Attitude is an individual's beliefs about outcomes or attributes of performing the behavior, and it is assumed that a person who holds strong beliefs about positively valued outcomes resulting from performing a behavior will have a positive attitude towards that behavior, and vice versa. Subjective norm is determined by a person's belief about how other important individuals approve or disapprove of performing a behavior, and it is assumed that if those important individuals think that a behavior should be performed and if it is motivational to meet the expectations of those individuals, a positive subjective norm will be held and vice versa. Perceived control is determined by control beliefs concerning the presence or absence of facilitators and barriers toward behavioral performance (Glanz et al., 2008, p. 71).

This study did not explore subjective norm or intention, so these constructs were struck through in Figure 1.2 to indicate that they were not assessed. The simplified theory of planned behavior was also modified to include knowledge and confidence as these constructs are quite commonly combined with attitude in assessing behavioral changes. Therefore, knowledge, confidence, and attitude in addition to perceived control were assessed in predicting the current behaviors/practices of HIV PCPs related to ACRFM. This was referred to as the modified theory of planned behavior for ACRFM (Figure 1.2).

"The theories of reasoned action and planned behavior have been applied to explain a variety of health behaviors including exercise, smoking and drug use, HIV/STD prevention behaviors, mammography use, clinicians' recommendation of and provision of preventive services, and oral hygiene behaviors," and the theories have been used to develop behavioral change interventions (Glanz et al., 2008, p. 76). An aim of this study was to assess HIV PCPs' current practices related to ACRFM, but to also understand how their self reported levels of knowledge, confidence, and attitudes towards ACRFM impact how they practice ACRFM. The modified theory of planned behavior for ACRFM (Figure 1.2) assumed that ACRFM practices (screening and intervening for each anal cancer risk factor) could be predicted by the knowledge, confidence, attitudes, and perceived control towards ACRFM. Based on the modified theory of planned behavior for ACRFM, implications for future research would include developing effective behavioral change interventions that impact knowledge, confidence, attitudes, and perceived control towards the practice of ACRFM. 


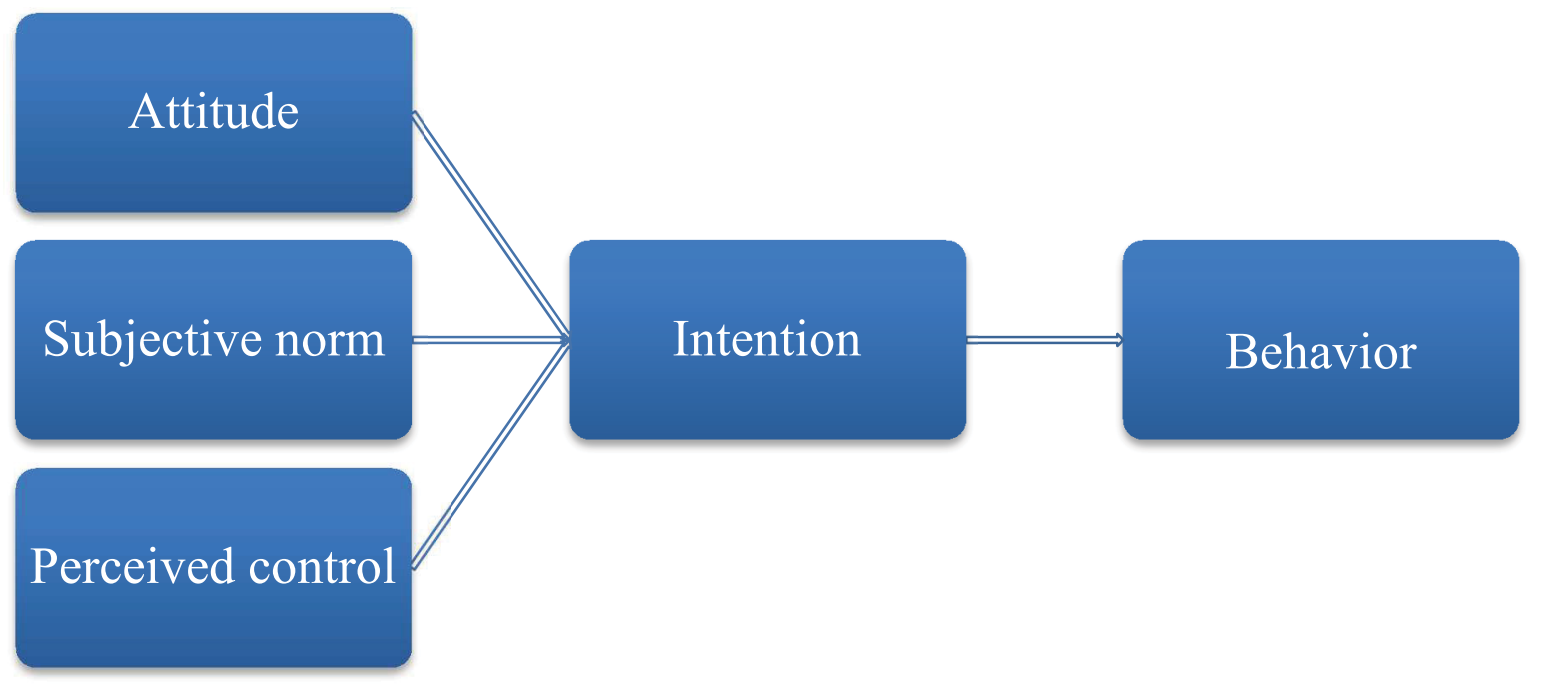

Figure 1.1. Simplified Theory of Planned Behavior

Modified with permission from Icek Ajzen, creator; copyright 2006. In Ajzen, I. (2006).

TPB diagram from $h$ ttp://people.umass.edu/aizen/tpb.diag.html 


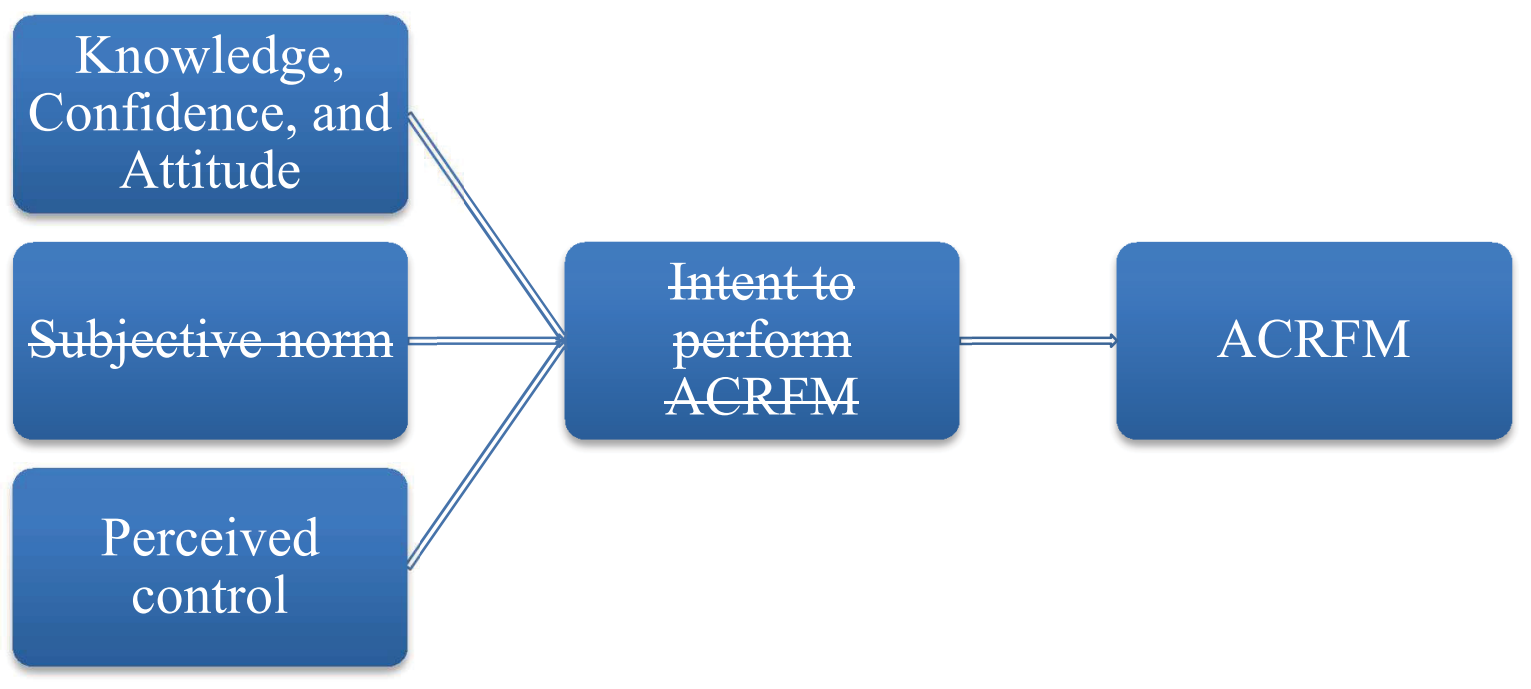

Figure 1.2. Modified Theory of Planned Behavior for ACRFM

Modified with permission from Icek Ajzen, creator; copyright 2006. In Ajzen, I. (2006). TPB diagram from http://people.umass.edu/aizen/tpb.diag.html

Note: This study did not explore subjective norm or intention, so these constructs were struck through in the figure to indicate that they were not assessed. 


\section{CHAPTER 2. REVIEW OF LITERATURE}

\section{Introduction}

The rate of anal cancer is higher in PLWHA (Holly et al., 2001; Melbye, Rabkin, Frisch, \& Biggar, 1994; Melbye et al., 1996; Williams et al., 1994) as there is nearly an 8-fold increased risk of anal cancer in HIV positive women when compared to HIV negative women (Frisch et al., 2000), and in HIV positive MSM, the rate of anal cancer is 80 times higher than HIV negative individuals (Silverberg et al., 2012). This disproportionate risk should encourage screening for anal disease in PLWHA to identify early stage disease before the progression to more advanced disease, but this is not a routine practice in the United States. There are no randomized control trials to indicate the effectiveness of a screening program; improvements are needed with the use of the anal Pap smear as a screening tool (Darragh \& Winkler, 2011), and there are more experienced providers needed to perform more advanced anal exams (Berry \& Palefsky, 2009). These issues contribute to the lack of widespread implementation of anal cancer screening and treatment programs, but in a population in which the rate of disease is disproportionately higher than the general population, there is still a need to make the anal health of PLWHA a priority.

In the only study that has examined anal health in HIV primary care settings, only $36 \%$ of 518 adult PLWHA reported discussing anal health with their HIV PCP in the past year (Rosa-Cunha et al., 2010). The researchers considered the results to be "a disappointing reality" in a population so greatly impacted by anal cancer (Rosa-Cunha et al., 2010, p. 533). The researchers recommended that HIV PCPs be encouraged to address anal health with patients on a periodic basis (Rosa-Cunha et al., 2010), and it was hypothesized that one of the ways this could be done is through anal cancer risk factor management. Risk factor management has been defined as "the identification, assessment, and prioritization of risks followed by a coordinated application of resources to minimize, monitor, and control the probability of unfortunate events" (Hubbard, 2009, p. 10). ACRFM would involve assessing for and managing specific anal cancer risk factors such as smoking and risky sexual behaviors (Daling et al., 2004). Since lifestyle risk factor management is one of the first steps in disease prevention for a number of different healthcare conditions, ACRFM could be considered a first step in the prevention of anal disease. In ACRFM, the HIV PCP has an important role to screen and counsel with regard to anal health and anal cancer risk factors.

Rosa-Cunha and colleagues' (2010) study on anal health in HIV primary care is the only one of its kind which highlighted two points (Rosa-Cunha et al., 2010): There is a paucity of information about anal health and role of the HIV PCP, and there is a need to address ACRFM on a periodic basis as a form of lifestyle modification management. In order to address the need, this would first necessitate understanding some of the reasons that anal health is not currently being addressed, so a review of literature was conducted to provide some rationales. There are several studies related to the barriers of discussing sexual health in the primary care setting, and those elucidations were hypothesized by 
Rosa-Cunha and colleagues (2010) to be related to why anal health, a component of sexual health, is poorly discussed in the HIV primary care setting (Rosa-Cunha et al., 2010). Anal health is considered a component of sexual health because of the link between a sexually transmitted disease (i.e. HPV) and anal disease (i.e. anal cancer). Since it is well documented that HPV is strongly linked to anal cancer, and may be necessary in the development of anal cancer (Daling et al., 2004; Frisch et al., 1997; Tilston, 1997), it is believed that improving a patient's sexual health and sexual health behaviors is one of the ways in which healthcare providers can improve anal health. Therefore, the review of literature focused on the barriers of managing sexual health in primary care to understand possible barriers of managing anal health in primary care. It also focused on other factors that were identified to have a possible impact on anal health management: determinants of health and the process of screening, diagnosing and managing anal cancer.

\section{Barriers to Managing Sexual Health in Primary Care Settings}

The World Health Organization has contributed to the definition of sexual health by defining it as "a state of physical, mental, and social well-being in relation to sexuality that requires a positive and respectful approach to sexuality and sexual relationships, as well as the possibility of having pleasurable and safe sexual experiences, free of coercion, discrimination and violence" (World Health Organization, 2006 , para. 4). According to the World Health Organization (2010), "good-quality sexual health services are fundamental to achieving a sexually healthy society, and healthcare providers should be trained to screen and detect sexual health problems and provide appropriate educational information about prevention, counseling, treatment, care and referral" (World Health Organization, 2010, p. vi). The problem is that sexual health is rarely initiated and managed in primary care settings due to a number of reasons including the provider's lack of knowledge and expertise, lack of time, and overall discomfort with the topic (Gott, Galena, Hinchliff, \& Elford, 2004; Hinchliff, Gott, \& Galena, 2005; Humphery \& Nazareth, 2001; Stokes \& Mears, 2000). Patients want to talk about sexual health with their providers, but the stigma associated with the topic creates a barrier for patients and providers (Ford, Barnes, Rompalo, \& Hook, 2013): Patients want the provider to raise the subject first (Berman et al., 2003; Martinez, n.d. ), and HCPs have common issues like fear of being offensive or embarrassing (Association of Reproductive Health Professionals, 2010 ). HCPs have expressed that the lack of sexual health training and education (Gott, Galena, et al., 2004; Hinchliff et al., 2005; Humphery \& Nazareth, 2001; Stokes \& Mears, 2000), the sensitivity and complexity of sexual health (Gott, Galena, et al., 2004), and language barriers with diverse patient populations (Gott, Galena, et al., 2004; Gott, Hinchliff, \& Galena, 2004; Hinchliff et al., 2005) contribute to their reluctance to discuss sexual health and serve as barriers to managing sexual heath in primary care settings. These barriers make it difficult to achieve a sexually healthy society, and even more difficult to address more specific components of sexual health such as anal health. 
One major barrier to sexual health in primary care is the lack of training and education. According to Coleman and colleagues (2013), there is an urgent need to address sexual health education in medical training programs (Coleman et al., 2013). Providers may be taught in their medical training programs to initiate routine sexual health discussions by asking questions such as "do you have sex with men, women, or both", but they may not be comfortable with maintaining an effective conversation on the topic (Bull et al., 1999; Guthrie, 1999; Obedin-Maliver et al., 2011; Solursh et al., 2003). Medical students have even expressed dissatisfaction with their sexual health education (Wittenberg \& Gerber, 2009). It has been found that only 3-10 hours of sexual health related education have been dedicated to the medical school curricula over the course of 4 years (Galletly, Lechuga, Layde, \& Pinkerton, 2010; Solursh et al., 2003). Time is also limited to discuss healthcare related concerns of the lesbian, gay, bisexual, transgender, and queer community (LGBTQ) (Obedin-Maliver et al., 2011), and there is a limited number of sexual health courses offered in medical school training programs across the U.S. (Coleman et al., 2013). The lack of time spent on sexual health education and the limited number of resources related to sexual health education may contribute to the overall discomfort that providers have in addressing the topic of sexual health.

Another barrier is the overall sensitivity and complexity of the topic that contributes to time and resource limitations in primary care. Most times HCPs feel that other priorities are more demanding and that discussing sexual health opens a "can of worms, could "take up a long time, and therefore are best avoided" (Gott, Galena, et al., 2004, p. 531). As stated by one HCP, “once you open that can of worms, you have to follow through. You can't then say oh, I haven't had time for this, you need to make another appointment', you can't do that when sexual health is involved" (Gott, Galena, et al., 2004, p. 531). "The term "can of worms" summarized the beliefs that sexually related issues are highly problematic within primary care because of their sensitivity, complexity, and constraints of time and expertise" (Gott, Galena, et al., 2004, p. 528). Time constraints are a major barrier to addressing sexual health in primary care because there is not enough time to build rapport, there are tight limits on clinic visit times, and priorities are usually related to diagnosing health conditions and prescribing medications (Gott, Galena, et al., 2004). Providers have also reported not feeling prepared to discuss all of the content related to sexual health (Gott, Galena, et al., 2004). One provider mentioned that "maybe you're outside the ability to do anything about it anyway and then what good does it do you or them" (Gott, Galena, et al., 2004, p. 531). The lack of time and content expertise has created a reluctance to discuss sexual health in primary care.

In addition to issues related to sensitivity and complexity of the topic, HCPs have expressed more specific fears related to addressing sexual health such as sexual history taking and using appropriate language. Some HCPs have a fear of inadequacy in sexual history taking, and are uncomfortable with using the appropriate language (TempleSmith, Hammond, Pyett, \& Presswell, 1996). According to Dr. Ng, clinical director of LGBT health services at the MetroHealth Medical Center in Cleveland, OH, "Language can cause labeling, and labeling can turn patients away", so knowing how to communicate is an important aspect of "creating a supportive and affirmative environment" (Raymond, 2014, para. 28). Knowing how to communicate with patients 
from diverse cultural or ethnic backgrounds has been identified as an issue in addressing sexual health (Gott, Galena, et al., 2004; Gott, Hinchliff, et al., 2004; Hinchliff et al., 2005). HCPs avoid talking about same-sex orientation because they are uncomfortable with what to say and when to say it (Stein \& Bonuck, 2001a), and some have even found it difficult to discuss sexual health with patients who have a different gender or sexual orientation than themselves (Stokes \& Mears, 2000).

Barriers to addressing sexual health in primary care contribute to HCPs' reluctance to discuss it. Because anal health is a component of sexual health, it is hypothesized that these same barriers exist for the lack of anal health management in HIV primary care. Barriers to addressing anal health in primary care may include lack of training and education on the topic of anal health management, the sensitivity and complexity of the topic as it is related to sexual health, and language barriers associated with discussing anal health with patients from diverse cultural, sexual, and ethnic backgrounds.

\section{Determinants of Health}

"Determinants of health are factors that contribute to a person's current state of health and generally fall into five categories: Genes and biology, health behaviors (i.e. smoking and unprotected sex), social characteristics (i.e. discrimination, gender, stigma), physical environment (i.e. place of residence), and health services (i.e. access to care)" (CDC, 2014e, para. 2). The determinants of health that may be more likely to contribute to poor management of anal health in high-risk populations such as PLWHA and MSM include discrimination, stigma, and access to care. PLWHA and people from diverse sexual backgrounds (i.e. LGBTQ) have often been discriminated against in healthcare because of stigma and insensitivity to healthcare needs, which have led to poor healthcare access and compromised care (Trust for America's Health, 2014).

According to the minority stress model, people from the LGBTQ community suffer from stress related to stigma, and this could lead to adverse health outcomes (Trust for America's Health, 2014). People from the LGBTQ community may cope by concealing information about sexual orientation, and this could have a negative impact on their healthcare outcomes (Trust for America's Health, 2014). For example, the risk of anal cancer is greatest in HIV positive MSM (Palefsky et al., 1998; Silverberg et al., 2012), so states like New York have implemented screening protocols for this population (Office of the Medical Director and New York State Department of Health AIDS Institute in collaboration with the Johns Hopkins University Division of Infectious Diseases, 2007 ). If a patient conceals his sexual orientation, this would limit the potential to be categorized as high-risk and screened periodically for anal cancer in the State of New York. Laws, policies, and regulations (i.e. denial to marry, religious rejections, workplace discriminations) also create barriers related to access and also contribute to stress (Trust for America's Health, 2014). For example, there may be issues related to health insurance access for unmarried domestic partners, especially same sex partners, 
and this may have an impact on healthcare access and healthcare outcomes (Trust for America's Health, 2014).

Stigma and discrimination have also created a sense of mistrust in the LGBTQ community and in the African American community. For example, homosexuality was reclassified by the American Psychiatric Association as a sexual orientation disturbance instead of a mental disorder, but historical understandings of homosexuality caused several people to go through treatments such as electric shock and castration (Institute of Medicine, 2011). This history has created a sense of distrust in the healthcare system, and patients may have poor healthcare outcomes because of their poor comfort level in revealing their sexual orientation (Eliason \& Schope, 2001). The most studied of these poor outcomes are sexually transmitted diseases such as HIV, and this disease has been known to disproportionately affect members of the LGBTQ community such as MSM more severely than any other group in the United States (CDC, 2014c). In the lesbian community, women are at a higher risk for different types of cancers because they are less likely to have full-term pregnancies, less likely to get screenings for cervical disease that can be caused by sexually transmitted diseases such as HPV, and less likely to get routine mammograms (U.S. Department of Health \& Human Services, 2012). This makes the LGBTQ community a targeted group for risk factor management. In a study with 575 lesbian and gay men, nearly half did not disclose information related to sexual orientation because they were concerned about bad treatment, and some even delayed seeking healthcare (Stein \& Bonuck, 2001b). In another study on lesbian and bisexual women, participants avoided healthcare due to past issues of stigma, discrimination, and fear (White \& Dull, 1997). Other people in the LGBTQ community have avoided or delayed seeking healthcare because they desire to have LGBT-positive healthcare providers who have been difficult to find (Hiestand, Horne, \& Levitt, 2007).

African Americans have also developed mistrust in the healthcare system due to stigma and discrimination. The Tuskegee syphilis experiment was a negative past experience that made African Americans less likely to trust the healthcare system, and this history has created a barrier in obtaining healthcare access and preventive care (King, 2003). In a study of 118 individuals, Black participants were statistically less likely to trust their providers when compared to White participants, and they also had greater concerns about personal privacy and potential for harmful experiments (King, 2003). Many patients have reported mistrust in the healthcare system, but African Americans are significantly more likely to report mistrust (LaVeist, Nickerson, \& Bowie, 2000).

In general, individuals in the LGBTQ community report negative healthcare experiences related to their sexuality and may avoid or delay care because of their experiences. The same is true in PLWHA and African Americans, as stigma and discrimination have caused negative health experiences that have created disparities in healthcare access. It is therefore important to understand the determinants of health that may reduce the likelihood of anal health management in these populations. Determinants of health such as discrimination, stigma, and access to care have an impact on healthcare outcomes, and may negatively impact how anal health is addressed and managed in primary care. 


\section{Anal Cancer Screening, Diagnosis, and Management}

Since the implementation of the cervical Pap smear in the 1950s, the incidence of cervical cancer and mortality rates have declined by almost $60 \%$ (National Cancer Institute, 2010 ). There are many cytological similarities that exist between the cervix and the anal canal, so the anal Pap smear, a test similar to the cervical Pap smear, has been proposed as a screening tool for anal disease (Palefsky et al., 1997). The problem is that there are several issues associated with anal cancer screening methods, diagnostic methods, and management of the disease (Darragh \& Winkler, 2011). These issues may have an impact on how anal health is addressed and managed in healthcare settings.

There are many similarities that exist between anal disease and cervical disease, but there are also "significant differences in epidemiology, natural history, and treatment of anal disease that have prevented the adoption of national screening guidelines" (Darragh \& Winkler, 2011, p. 6). In addition to significant differences between cervical and anal disease, the sensitivity and specificity of a single anal-rectal cytology test is 42$98 \%$ and 16-96\%, respectively (Bean \& Chhieng, 2010), which are wide variations.

There are also no randomized control trials related to anal cancer screening methods, the number of clinicians trained in diagnosing anal disease is limited, and treatment studies are ongoing (Darragh \& Winkler, 2011). In the diagnosis of anal disease, high resolution anoscopy was adopted from the cervical model (Darragh \& Winkler, 2011). Although high resolution anoscopy has been indicated as a sensitive, specific, and cost-effective strategy for the detection of anal disease in HIV positive MSM, (Lam et al., 2011; Salit et al., 2010), there is still a need for more trained providers to perform the anal exams (Berry \& Palefsky, 2009). With regard to treatment for anal disease, there are only a few studies that evaluate treatment modalities such as the use of infrared coagulation for highgrade anal disease (Cranston, Hirschowitz, Cortina, \& Moe, 2008; Goldstone, Hundert, \& Huyett, 2007; Goldstone, Kawalek, \& Huyett, 2005; Stier et al., 2008). These studies showed some promise in the use of infrared coagulation, but larger studies are needed. Other studies related to treatment modalities are ongoing, and thus treatment options and effectiveness of treatment are limited.

The issues related to anal cancer screening have contributed to several differences in opinions about the initiation of a formal screening program (Chiao, Giordano, Palefsky, Tyring, \& El Serag, 2006; Mathews, Caperna, Cachay, \& Cosman, 2007). Screening benefits have not been clearly identified (Sigel et al., 2011), and as a result, providers may be less likely to manage anal health in primary care settings. There is still a need to conduct more research related to anal cancer screening, diagnosis, and management in order to move in the direction of a formal anal cancer screening program.

\section{Conclusion}

In the only study that has examined anal health in HIV primary care, less than $50 \%$ of patients reported discussing the topic with their providers, and the researchers contributed this to issues related to sexual health in primary care (Rosa-Cunha et al., 
2010). Issues such as lack of training and education, discomfort, and language barriers were examined in greater detail to understand why sexual health is still an issue in primary care. To date, there are only a few medical training programs with sexual health courses, and there is no general idea of what should be covered in these courses (Coleman et al., 2013). There are a limited number of studies that have examined sexual health education in training programs other than medical schools, so it is possible that other clinicians such as advanced practice nurses and physician assistants have challenges with discussing sexual health in primary care as well. There are a number of gaps in sexual health education, and this may be contributing to the overall discomfort that providers have with the topic of sexual health.

Other barriers to addressing anal health were considered and included stigma, discrimination, and healthcare access as determinants of health. Stigma and discrimination have an impact on healthcare behaviors of high-risk populations, which subsequently have an impact on access to quality health services. Healthy People 2020 have identified unmet health needs, delays in receiving appropriate care, inability to get preventive services, and preventable hospitalizations as issues related to poor healthcare access (U.S. Department of Health and Human Services. Office of Disease Prevention and Health Promotion. Healthy People 2020, n.d. ), so determinants of health are important to consider in the management of anal health. When stigma and discrimination towards PLWHA and individuals from the LGBTQ community are reduced, this may improve healthcare behaviors and healthcare access. Another barrier identified to possibly have an impact on anal health management was associated with anal cancer screening, diagnosis, and management. There are improvements needed with the use of the anal Pap smear as a screening tool, treatment modality studies are ongoing, and there are no studies that indicate the effectiveness of anal cancer screening, diagnostic, or management program (Darragh \& Winkler, 2011). There are also no national guidelines suggesting screening and treatment in high-risk populations, so these issues may contribute to providers making anal health less of a priority in primary care.

There are currently no reviews of literature to that examine possible reasons that anal health is poorly managed in primary care, so this review is the first of its kind to give insight into topics that may have an impact on anal health. An implication for future research may include exploring these barriers in greater detail from the HIV PCP's perspective in order to confirm them as barriers to addressing anal health in HIV primary care settings. 


\section{CHAPTER 3. METHODOLOGY}

\section{Introduction}

This exploratory study consisted of a mixed methods approach modeled after a study by Laws and colleagues (Laws et al., 2008). It followed a sequential explanatory design: The initial phase consisted of quantitative data collection and analysis followed by a second phase of qualitative data collection and analysis (Figure 3.1). The purpose of this design was to use the qualitative results to explain and interpret the findings of the quantitative data (Tashakkori \& Teddlie, 2003). The plan was to use an ACRFM survey to differentiate HIV PCPs into high and low implementers based on current practices. Qualitative data collection was then based on conducting one-on-one interviews with high and low implementers to examine if barriers and facilitators of discussing anal health in the HIV primary care setting would differ between the two groups (Figure 3.1).

\section{Research Design}

\section{Quantitative Design}

In the quantitative design, a 20-question ACRFM survey was developed as modified from a lifestyle risk factor survey (LRF) in community health (Harris et al., n.d.). The LRF survey was adapted from a survey to assess general practitioners' risk factor management practices (Amoroso, Hobbs, \& Harris, 2005). Permission was granted to reprint and modify the LRF survey (Appendix A) into an ACRFM survey (Appendix B). A panel of HIV primary care specialists and a lower genital tract specialist helped to develop the ACRFM survey. The panel included one medical doctor and four advanced practice nurses. The medical doctor and three of the advanced practice nurses have practiced HIV primary care in adults and/or adolescents for approximately fifteen years. The lower genital tract specialist has practiced for approximately twenty years in performing cervical, vulvar, and anal exams for the presence of cancer in both PLWHA and people without HIV/AIDS.

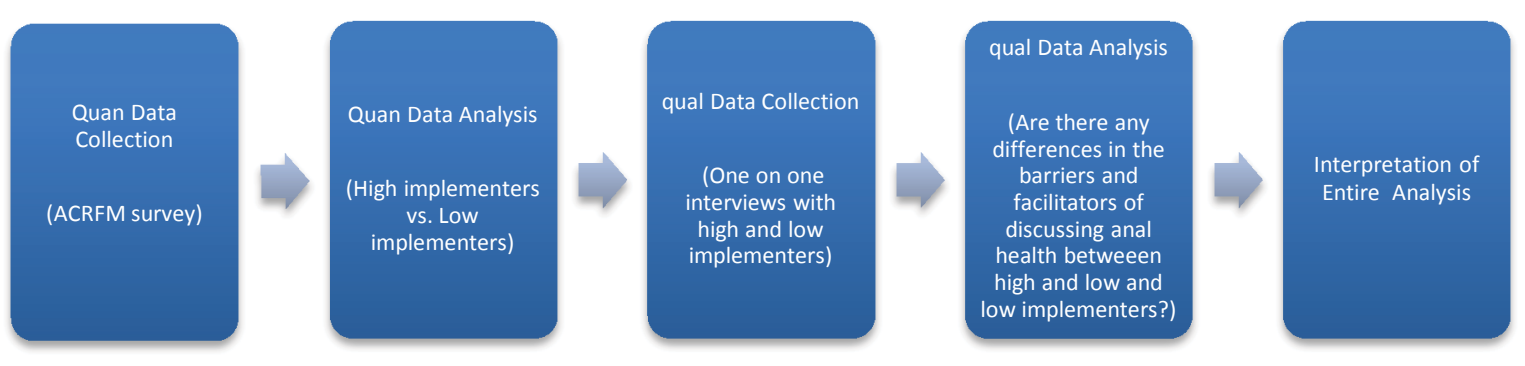

Figure 3.1. Sequential Explanatory Design 


\section{Instrument Development}

The LRF survey assessed current lifestyle risk factor practices by examining how often healthcare providers ask about risk factors, ask about readiness to change, and provide advice and resources to help their patients take steps to decrease lifestyle modifiable risk factors (Appendix A: survey numbers 1-6). The modifiable risk factors in the LRF survey included: smoking, nutrition, alcohol, and physical activity. In modifying the LRF survey to focus on ACRFM, modifiable anal cancer risk factors were substituted for the lifestyle risk factors and included smoking (Daling et al., 2004), number of lifetime partners exceeding fifteen (Daling et al., 2004), unprotected anal sex (American Society of Colon \& Rectal Surgeons, 2012), and non-adherence to anti-retroviral therapy (Duncan et al., 2015). Immunosuppression was considered a risk factor for anal cancer, so the ACRFM survey development panel agreed that anti-retroviral therapy (ART) adherence in PLWHA aided in decreasing immunosuppression. A recent study also explained that early use of ART may delay progression to anal cancer (Duncan et al., 2015). Therefore, non-adherence to ART was considered a modifiable risk factor for anal cancer, and it was included in the survey. The panel also agreed to combine unprotected anal sex and number of lifetime sexual partners into one category, risky sexual behaviors, for the survey analysis. There were a number of other anal cancer risk factors, but in order to keep the ACRFM survey aligned with the LRF survey, only modifiable risk factors as defined by the review of literature and the panel were included: smoking, nonadherence to ART, and risky sexual behaviors.

The LRF survey also assessed perceived knowledge and confidence in screening and managing each risk factor to elucidate what healthcare providers knew about each managing each risk factor and their comfort levels in making recommendations to decrease a patient's exposure to each risk factor (Appendix A: survey numbers 10 and 11). Providers were asked to rate their knowledge and confidence level in managing each risk factor. Providers were also asked to rate their attitudes towards managing each risk factor. Measures for attitude slightly differed from Laws and colleagues (2008), and included perceived effectiveness of interventions, perceived importance for improving a client's health, and perceived work priority (Laws et al., 2008) (Appendix A: survey numbers 12, 14-16). The combination of these measures was defined as perceived attitudes. The demographic section of the LRF survey was modified to include the HIV primary care provider's name for identification purposes in the event that he or she was selected to participate in the one-on-one interviews and practice location information. In the closing of the survey, the same format was used to inquire about education or training opportunities.

The ACRFM survey development panel was formed and led by the principle investigator. The principle investigator conducted the review of literature for anal cancer risk factors and for risk factor surveys. This information was shared by e-mail correspondence with the survey development panel, and the panel members were given an opportunity to prepare questions and input for the face-to-face survey development meeting. The survey development meeting lasted for approximately two hours at The University of Tennessee Health Science Center's College of Nursing, and at completion 
of the meeting, an ACRFM survey was developed as modified from a lifestyle risk factor survey (Appendix B). It was reviewed by the panel members and the dissertation committee statistician for face validity. The ACRFM survey instrument and dissertation proposal in its entirety were then reviewed and approved by the Institutional Review Board (IRB) at The University of Tennessee Health Science Center (Appendix C).

\section{Qualitative Design}

In the qualitative portion of this study, HIV PCPs were randomly selected from the pool of survey participants to participate in brief semi-structured one-on-one (individual) interviews. Interviews were conducted to understand the barriers and facilitators of discussing anal health in the HIV primary care setting. There were five interview questions. The first two questions were developed to introduce the concept of anal health to the participants and to transition into specific questions related to facilitators and barriers: What is the meaning of anal health within the HIV primary care setting, and how do healthcare providers approach the topic of anal health with PLWHA? The more specific questions involved asking: What are the facilitators to discussing anal health/what are some things that help you practice anal health? What are the barriers to discussing anal health/what are some things that prevent you from practicing anal health? A final question was asked: What aspects of the patient-provider relationship need improvement in discussing anal health? This portion of the study offered a brief description of the factors that participants saw as facilitating or impeding their approach to discuss anal health in HIV primary care.

\section{Sample and Setting}

This study was conducted in Memphis, TN, an urban city that was ranked in 2012 among cities in the United States as having the fifth highest proportion of its residents with newly diagnosed HIV and as being the second worst city with respect to addressing the HIV-related needs of Black MSM (Black AIDS Institute, 2012 ). Purposive sampling was used to select the HIV PCPs located in Memphis, TN. The sample also included HIV PCPs located in other cities in Tennessee as well as HIV PCPs from Arkansas and Mississippi. Initially, HIV PCPs were recruited through the Memphis Ryan White HIV/AIDs program and the HIV Treaters' Group of Memphis, TN, because these two groups served as gatekeepers to the healthcare providers needed for this study.

The Ryan-White HIV/AIDS program is administered by the U.S. Department of Health and Human Services, Health Resources and Services Administration, HIV/AIDS Bureau as a payer of last resort for people who are uninsured or underinsured. The program consists of Ryan-White funded medical care providers who provide comprehensive primary health care in outpatient settings (Memphis Ryan White Program, 2013). National funds are allocated to states, and the states determine how Ryan-White monies are allocated. Ryan-White program coordinators for Tennessee, Mississippi, and Arkansas were contacted and asked to forward information about this 
study to the HIV PCPs in their jurisdictions. The HIV Treaters' Group of Memphis, TN is comprised of HIV medical care providers (i.e. physicians, advanced practice nurse practitioners, registered nurses, case managers, and pharmacists), who meet monthly in Memphis, TN with guest speakers to discuss current topics in HIV/AIDS. The advantage of drawing participants from the HIV Treaters' Group was the ability to enroll providers outside of the Ryan-White program and to include providers offering HIV primary care to a more diverse patient population. HIV PCPs recruited from the Ryan White programs of TN, MS, and AR as well as from the HIV Treaters' Group of Memphis, TN were then asked to refer other HIV PCPs in the states of TN, MS, and AR based on colleague acquaintance. This snowball sampling technique was used to recruit a variety of HCPs from different centers and clinics who practice with a variety of PLWHA. The following inclusion criteria were used for this study:

- HIV primary care provider (i.e., medical doctor, including post-graduate trainee, advanced practice nurse, or physician assistant)

- Having $\geq 1$ year of experience as an HIV primary care provider

- Licensed to practice healthcare in at least one of the following states: Tennessee, Arkansas, or Mississippi

Having greater than or equal to one year of experience as an HIV primary care provider was incorporated into the inclusion criteria because of a known learning curve associated with being a new healthcare provider. New providers may be less likely to address any type of management outside of routine HIV primary care, especially anal cancer risk factor management.

The ACRFM survey was delivered through an online survey software program, so the setting for survey completion depended on location of the HIV primary care provider (i.e. homes, offices, etc.). The ACRFM was also delivered as a hard copy in pdf format for participants who wanted to complete the survey on paper, so completion of hard copies occurred in the participant's HIV primary care setting. After completion of the surveys, participants were randomly selected to participate in one-on-one interviews. One-on-one interviews were conducted at The University of Tennessee Health Science Center's College of Nursing by telephone or face to face in the HIV primary care provider's work setting at a mutually convenient time.

\section{Study Procedures}

HIV PCPs were directly recruited from Ryan White programs in Tennessee, Mississippi, and Arkansas as well as the HIV Provider's Group of Memphis, TN. A short recruitment statement and web link to the electronic survey were sent by e-mail to the program coordinators of the three Ryan White state programs and to the organizing provider of the HIV Treaters' Group of Memphis, TN. The e-mail included introductory information regarding purpose of the study, research design, and information about an 
incentive for participation. Recipients were then asked to forward the e-mail and survey web link to HIV primary care colleagues who may not have participated in either of the access groups listed above. This snowball technique was designed to capture a variety of HIV PCPs caring for diverse patient populations, and it involved the indirect recruitment of other HIV PCPs.

The web link directed participants to a web-based survey tool. The first page of the survey tool included a survey consent form (Appendix D) in which participants were given detailed information about the survey portion of the study. The consent form included purpose, procedural details, risks associated with participation, payment for participation, estimated time of survey completion, contact information for questions, and an option to accept or decline participation. Participants were informed in the survey consent form that placement of his or her first and last name on the survey would be required in the event of being randomly chosen to participate in one-on-one interviews. Participants were also informed that responses would remain confidential by deidentifying names with ID numbers and that the PI would be the only person with access to the master code sheet including participants' names. Participants were informed that the code sheet would be stored in a locked room at The University of Tennessee Health Science Center's College of Nursing and destroyed upon completion of the study. The IRB at the University of Tennessee Health Science Center approved the survey consent form, study procedures, and recruitment statement for this portion of the study. After a revision to the IRB application, an approval was granted to contact HIV primary care clinics about face-to-face recruitment of potential participants for hard copy survey completion. This process allowed participants to complete the survey on site. Therefore, surveys for this study were completed online and in face-to-face settings.

There were 20 HIV PCPs who participated in the quantitative portion of the study. Those who were randomly chosen for interviews were contacted by e-mail about interview participation, and this e-mail included a second consent form, the main consent form (Appendix E) in a pdf-format. This main consent form included purpose, procedural details, risks associated with participation, payment for participation, contact information for questions, and an option to decline participation. Participations were informed that the main consent form could be signed and returned by e-mail, fax, or mail, or it could be submitted face to face prior to the interview. As with the survey consent process, participants were also informed that responses would remain confidential by deidentifying names with ID numbers and that the principal investigator would be the only person with access to the master code sheet including participants' names. Participants were informed that the code sheet was stored in a locked room at The University of Tennessee Health Science Center's College of Nursing and destroyed upon completion of the study. Out of the ten HIV PCPs randomly selected to participate in the qualitative interviews, only nine agreed to participate. The PI conducted one-on-one interviews by phone or face-to-face, whichever was more convenient for the participant. All phone interviews were conducted at The University of Tennessee Health Science Center, and all face-to-face interviews were conducted in a secluded area of the provider's work setting. All interviews were voice-audio recorded. The IRB at the University of Tennessee Health 
Science Center approved the main consent form and study procedures for this portion of the study.

\section{Data Analysis}

\section{Quantitative Analysis}

The ACRFM survey was modified from a LRF survey by Harris and colleagues (n.d.) that assessed: a) current practices (survey numbers \#1-6) and b) perceived knowledge (\#10), perceived confidence (\#11), and perceived attitudes (\#12, 14-16) towards ACRFM (Harris et al., n.d.). Survey numbers 1-16 included a Likert-scale format in which numerical values were assigned to calculate scores. The Likert-scale values were coded in the analysis to range from 1 (extremely unlikely or very low) to 5 (extremely likely or very high). The dependent variable, practices related to risk factor management, included scores for screening (\#1-2) and intervening (\#3-8). The dependent variable was arranged into domains related to specific risk factor practices: $Y_{a}$ was the score for practices related to smoking, $Y_{b}$ was the score for practices related to risky sexual behaviors, $\mathrm{Y}_{\mathrm{c}}$ was the score for practices related to non-adherence to antiretroviral therapy. The independent variables included $\mathrm{X}_{1}$, the score measuring knowledge; $\mathrm{X}_{2}$, the score measuring confidence; and $\mathrm{X}_{3}$, the score measuring attitudes. Each variable related to personal intentions was arranged into separate domains, and similarly, each variable

related to practices was arranged into domains, which corresponded to each practice type:

\section{Variables Related to Personal Intentions}

- Knowledge

$\mathrm{X}_{1 \mathrm{a}}=$ measure of knowledge towards smoking as a risk factor;

$\mathrm{X}_{1 \mathrm{~b}}=$ measure of knowledge towards risky sexual behaviors as a risk factor; and

$\mathrm{X}_{1 \mathrm{c}}=$ measure of knowledge towards non-adherence to antiretroviral medications as a risk factor

- $\quad$ Confidence

$\mathrm{X}_{2 \mathrm{a}}=$ measure of confidence towards smoking as a risk factor;

$\mathrm{X}_{2 \mathrm{~b}}=$ measure of confidence towards risky sexual behaviors as a risk factor; and

$\mathrm{X}_{2 \mathrm{c}}=$ measure of confidence towards non-adherence to antiretroviral medications

as a risk factor

- $\quad$ Attitudes

$\mathrm{X}_{3 \mathrm{a}}=$ measure of attitude towards smoking as a risk factor;

$\mathrm{X}_{3 \mathrm{~b}}=$ measure of attitude towards risky sexual behaviors as a risk factor; and

$\mathrm{X}_{3 \mathrm{c}}=$ measure of attitude towards non-adherence to antiretroviral medications as a risk factor 


\section{Variables Related to Practices}

\section{- Screening Score}

$\mathrm{Y}_{1 \mathrm{a}}=$ screening score towards smoking as a risk factor;

$\mathrm{Y}_{1 \mathrm{~b}}=$ screening score towards risky sexual behaviors as a risk factor; and

$\mathrm{Y}_{1 \mathrm{c}}=$ screening score towards non-adherence to antiretroviral medications as a risk factor

- $\underline{\text { Intervention Score }}$

$\mathrm{Y}_{2 \mathrm{a}}=$ intervention score towards smoking as a risk factor;

$\mathrm{Y}_{2 \mathrm{~b}}=$ intervention score towards risky sexual behaviors as a risk factor; and

$\mathrm{Y}_{2 \mathrm{c}}=$ intervention score towards non-adherence to antiretroviral medications as a

risk factor

- Total Practice Score

$\mathrm{Y}_{3 \mathrm{a}}=$ total practice score towards smoking as a risk factor;

$\mathrm{Y}_{3 \mathrm{~b}}=$ total practice score towards risky sexual behaviors as a risk factor; and

$\mathrm{Y}_{3 \mathrm{c}}=$ total practice score towards non-adherence to antiretroviral medications as a risk factor

\section{Specific Aim 1: To Determine Demographic Data of Research Participants and to Determine HIV PCPs Current Practices Related to ACRFM}

1.1: In order to describe the demographic characteristics of the research participants, descriptive statistic analyses were performed on each demographic variable on the survey: gender, age, total number of years in profession, number of years working with PLWHA, practice location by state, and clinician type. These analyses were performed in order to understand the characteristics of the sample, and to ensure that all inclusion criteria were met for study participation.

1.2-1.4: In order to estimate the mean and standard deviation for each anal cancer risk factor, Likert scale responses for questions 1-6 were assigned numerical values from 1-5, and the PROC UNIVARIATE procedure in the SAS software was used to determine the descriptive statistics for each risk factor. This analysis was performed to get the mean screening, intervention, and practice scores with standard deviation for each risk factor. The following questions were posed: What is the average screening score for a) smoking, b) risky sexual behaviors, and c) medication non-adherence? The same questions were posed for intervention scores: What is the average intervention score for a) smoking, b) risky sexual behaviors, and c) medication non-adherence? Screening and intervention scores were combined as total practice scores for each risk factor, and the following research questions were addressed: What are the average practice scores for smoking, risky sexual behaviors, and medication non-adherence?

The numerical values (1-5) that were assigned to questions 1-6 were coded as extremely unlikely to extremely likely in order to explain the range of practice scores (i.e. $1=$ extremely unlikely, $2=$ unlikely, $3=$ neutral, $4=$ likely, and 5=extremely likely). 
Midpoint cutoff values were also included to facilitate interpretation of the means. A value less than each midpoint cutoff value corresponded to the preceding score or lower coded response. For example, a value of 1.3 would be interpreted as extremely unlikely to screen, intervene, or practice towards a particular anal cancer risk factor. Greater than or equal to each decimal point value corresponded to the higher coded response. For example, a value of 4.5 would be interpreted as extremely likely to screen, intervene, or practice towards a particular anal cancer risk factor.

In order to determine statistical significance of each screening, intervention, and practice score for each risk factor, confidence limits were computed using the CIBASIC function in the SAS statistical software, and $95 \%$ confidence intervals were obtained. If the mean score of a particular risk factor was contained within the confidence interval of another risk factor, the means were not considered different. If the mean score of a particular risk factor did not lie within the confidence interval of another risk factor, the means were considered different at an alpha of 0.05 .

\section{Specific Aim 2: To Determine Self-reported Knowledge, Confidence, and Attitudes Related to ACRFM}

Survey questions 10 and 11 asked participants to rate their knowledge and confidence related to specific anal cancer risk factors. A Likert scale was used to quantify knowledge and confidence towards ACRFM as very poor to excellent, and maintained the assigned numerical values of 1-5 as presented on the survey. The very poor to excellent Likert scale survey responses were re-coded as very low to very high in order to explain the range of knowledge and confidence scores (i.e. $1=$ very low, $2=1$ low, $3=$ moderate, $4=$ high, $5=$ very high). Midpoint cutoff values were also included to facilitate interpretation of the means. A value less than each midpoint cutoff value corresponded to the preceding score or lower coded response. For example, a value of 1.3 was interpreted as a score of 1 or a very low coded response. Greater than or equal to each midpoint cutoff value corresponded to the higher score or coded responses. For example, a value of 4.5 was interpreted as a score of 5 and a very high coded response. The following questions were posed: What is the average knowledge score towards a) smoking, b) risky sexual behaviors, c) medication non-adherence? The same questions were posed for average confidence score for each risk factor. The UNIVARIATE procedure of the SAS was used to estimate the mean and standard deviation for the knowledge and confidence scores with regards to each anal cancer risk factor. Results were interpreted as described above.

Survey questions 12, 14-16 asked participants about effectiveness, importance, and priority of ACRFM. A Likert scale was used to quantify effectiveness, importance, and priority as not at all effective to very effective or not at all important to very important. The Likert scale maintained the assigned numerical values of 1-5 as presented on the survey, and the scales were recoded for analysis as very low to very high in order to explain the range attitudes scores. The effectiveness, importance, and priority scores were combined and averaged as an attitude score for each risk factor. Midpoint cutoff values were also included to facilitate interpretation of the means. The following 
questions were posed: What is the average attitude score for a) smoking b) risky sexual behaviors and c) medication non-adherence? The UNIVARIATE procedure was used to compute the mean and standard deviation for the attitude score for each risk factor and results were interpreted as described above.

\section{Specific Aim 3: To Determine Relationships Among Knowledge, Confidence, and Attitudes of Providers and their Current Practices}

The following questions were posed: What relationship exists between average knowledge score for smoking and average practice score related to smoking? What relationship exists between average knowledge score for risky sexual behaviors and average practice score related to risky sexual behaviors? What relationship exists between average knowledge score for medication nonadherence and average practice score related to medication nonadherence? The same questions were posed for the relationships between average confidence scores and practices for each risk factor as well as the relationships between average attitudes scores and practices for each risk factor. In order to estimate the relationship between ACRFM practices and knowledge, confidence, and attitudes towards ACRFM, a correlation analysis was performed using the PROCEDURE of the SAS. Variables related to practices include average practice scores for each risk factor. Variables related to personal intentions included average knowledge, confidence, and attitude scores for each risk factor. The Spearman correlation coefficient was estimated for each relationship. An alpha $(\alpha)$ of .05 was set, and data was highly significant at the 0.01 level.

\section{Specific Aim 4: To Differentiate Between High and Low Implementers of ACRFM}

The dependent variable, total practice score (a combination of screening and intervention score) for all modifiable risk factors, was analyzed using the UNIVARIATE procedure of the SAS. To differentiate between high and low implementers of anal cancer risk factor management, the dependent variable was converted into a dichotomous variable by a median split of the practice scores to classify HIV PCPs as high implementers and low implementers of ACRFM.

\section{Qualitative Analysis}

\section{Specific Aim 5: To Explore the Differences in the Barriers and Facilitators of Addressing Anal Health Between High and Low Implementers of ACRFM}

HIV PCPs were randomly chosen from the sample of survey participants to participate in individual interviews. After collecting the qualitative data, interviews were transcribed into a word processing document. These transcripts were read individually, and preliminary notes were made regarding inferred categories: barriers and facilitators 
of addressing anal health. Transcripts were then uploaded into QDA Miner ${ }^{\circledR}$, a qualitative data analysis software program, and the data were coded to fall in into categories that were considered inductive codes as they were developed while examining the qualitative data. Prior to examining the data, a priori codes were developed. These codes were developed from the review of literature on the barriers and facilitators of addressing sexual health in the primary care setting since anal health was considered a component of sexual health. These served as the a priori codes for the study, so the transcripts were also explored for the presence of these codes. A coding frequency was performed in the QDA Miner software program to get the count of code frequencies and the count of case frequencies. All codes were expounded upon to provide a more in depth understanding of the barriers and facilitators of discussing anal health in the HIV primary care setting.

\section{Protection of Human Subjects}

The study was approved by the University of Tennessee Health Science Center's IRB. The survey informed consent (Appendix D) and main informed consent (Appendix E) forms for the study explained that every effort would be made to keep all survey and interview responses confidential; however, this could not be guaranteed. Participants were informed that all study responses would be handed as confidentially as possible, but were also informed of the risk in breach of confidentiality with all research studies. They were informed that names were required on the ACRFM survey in the event that participants were randomly selected to participate in the one-on-one interviews. They were also informed that names were de-identified with a code number, and the master list, linking name and code number was only accessed by the PI and stored in a locked room at the University of Tennessee Health Science Center's College of Nursing.

The informed consent for the quantitative portion of the study explained that participants were not obligated to participate in the study. They were also informed that at anytime during completing the survey, they had the right to withdraw from the study. For the qualitative interviews, a second informed consent was used, and participants were informed again that they were not obligated to participate and had the right to withdraw from the study at any point during the interview. The risks associated with this study, though minimal, included social harm related to loss of confidentiality and psychological harm related to the interview process, and participants were given examples of those risks. Participants were also informed that no individual identifying information would be used with conclusions or results. 


\title{
CHAPTER 4. ANALYSIS
}

\author{
Quantitative Analysis
}

\section{Specific Aim 1}

\section{Aim 1.1: Demographic Data}

There were 20 HIV PCPs who participated in the quantitative portion of the research study. Demographic data were summarized for these 20 participants from the characteristic variables listed on the survey (Table 4.1). There were 14 participants in the age range of 35-54 years old. The average number of years working with PLHWA was 10.25 years. The minimum was 1 year, and the maximum was 20 years. The majority of the participants practiced in the state of Tennessee, and various cities were represented in that state: Memphis, Millington, Nashville, and Crossville. The city represented in Arkansas was West Memphis, AR, and those represented in Mississippi included Jackson and Meridian. The majority of participants were advanced practice nurses $(60 \%)$ followed by medical doctors $(40 \%)$.

\section{Aims 1.2-1.4: Practice Scores}

Mean screening, intervention, and practice scores with standard deviations for each risk factor were analyzed (Table 4.2). Confidence intervals were also constructed for each mean score in order to determine statistical significance (Table 4.3). Mean practice scores were a combination of screening and intervention scores, and they indicated the likelihood of the providers incorporating practices towards managing each anal cancer risk factor. The mean practice score for risky sexual behaviors $(2.57 \pm 1.2)$ was significantly lower than the mean practice scores towards managing smoking and non-adherence to ART. HIV PCPs had a lesser likelihood of managing risky sexual behaviors when compared to smoking and ART non-adherence.

\section{Specific Aim 2}

The variables related to personal intention — knowledge, confidence, and attitudes towards ACRFM - were evaluated to estimate the means and standard deviations of the respective scores related to the three anal cancer risk factors (Table 4.4). After scales were recoded for analysis, the interpretations were made about average knowledge, confidence, and attitude scores, and all scores were high-very high (Table 4.5). All mean knowledge, confidence, and attitude scores for each risk factor exceeded 4.0 on a Likert scale of 1-5 for each risk factor (The attitude score towards smoking, 3.94, corresponded to the higher score of 4.0), thus making them all high scores. However, the very high scores were observed for the knowledge, confidence, and attitude towards managing non- 
Table 4.1. Demographic Information for 20 Participating Primary Care Providers

\begin{tabular}{lc}
\hline Characteristics & Count $(\%)$ or Mean \pm SD \\
\hline Gender & $5(25)$ \\
Male & $15(75)$ \\
Female & \\
Age range & $0(0)$ \\
$18-24$ & $2(10)$ \\
$25-34$ & $7(35)$ \\
$35-44$ & $7(35)$ \\
$45-54$ & $3(15)$ \\
$55-64$ & $1(5)$ \\
$65+$ & $13.35 \pm 1.72$ \\
Total number of years in profession & $10.25 \pm 1.49$ \\
Number of years working with PLWHA & \\
Practice location by state & $1(5)$ \\
Arkansas & $2(10)$ \\
Mississippi & $17(85)$ \\
Tennessee & \\
Clinician type & $12(60)$ \\
Advanced Practice Nurse & $6(30)$ \\
Medical Doctor & $2(10)$ \\
Medical Doctor/Fellow & $0(0)$ \\
Physician Assistant & \\
\hline
\end{tabular}

Table 4.2. Average Practice Scores by Anal Cancer Risk Factor of 20 HIV Primary Care Providers

\begin{tabular}{lccc}
\hline \multirow{2}{*}{ Anal Cancer Risk } & \multicolumn{3}{c}{ Average Practice Scores (Mean \pm SD) } \\
\cline { 2 - 4 } Factor & Screening & Intervention & Practice \\
\hline Smoking & $4.10 \pm 1.1$ & $2.70 \pm 1.2$ & $3.40 \pm 1.1$ \\
Risky sexual behaviors & $2.88 \pm 1.3$ & $2.26 \pm 1.2$ & $2.57 \pm 1.2$ \\
Non-adherence to ART & $4.50 \pm .81$ & $3.24 \pm 1.1$ & $3.87 \pm .74$ \\
\hline
\end{tabular}


Table 4.3. Average Practice Scores and 95\% Confidence Intervals of 20 HIV Primary Care Providers

\begin{tabular}{lccc}
\hline \multirow{2}{*}{$\begin{array}{l}\text { Anal Cancer Risk } \\
\text { Factor }\end{array}$} & \multicolumn{3}{c}{ Average Practice Scores (95\% Confidence Intervals) } \\
\cline { 2 - 4 } & Screening & Intervention & Practice \\
\hline Smoking & $4.10(3.58,4.62)$ & $2.70(2.13,3.27)$ & $3.40(2.90,3.90)$ \\
Risky sexual behaviors & $2.88(2.25,3.50)$ & $2.26(1.70,2.83)$ & $2.57(2.01,3.13)$ \\
Non-adherence to ART & $4.50(4.12,4.88)$ & $3.24(2.74,3.73)$ & $3.87(3.52,4.21)$ \\
\hline
\end{tabular}

Table 4.4. Average Knowledge, Confidence, and Attitude Scores of 20 HIV Primary Care Providers

\begin{tabular}{|c|c|c|c|}
\hline \multirow{2}{*}{$\begin{array}{l}\text { Anal Cancer Risk } \\
\text { Factor }\end{array}$} & \multicolumn{3}{|c|}{$\begin{array}{l}\text { Average Knowledge, Confidence, and Attitude Scores } \\
(\text { (Mean } \pm \text { SD) }\end{array}$} \\
\hline & Knowledge & Confidence & Attitude \\
\hline Smoking & $4.13 \pm 1.0$ & $4.22 \pm 1.0$ & $3.94 \pm .56$ \\
\hline Risky sexual behaviors & $4.10 \pm .93$ & $4.23 \pm .92$ & $4.02 \pm .66$ \\
\hline Non-adherence to ART & $4.75 \pm .70$ & $4.70 \pm .68$ & $4.59 \pm .24$ \\
\hline
\end{tabular}

Table 4.5. Interpretations of Average Knowledge, Confidence, and Attitude Scores of 20 HIV Primary Care Providers

\begin{tabular}{llll}
\hline \multirow{2}{*}{ Anal Cancer Risk } & \multicolumn{3}{c}{ Score Interpretation } \\
\cline { 2 - 4 } Factor & Knowledge & Confidence & Attitude \\
\hline Smoking & High score & High score & High score \\
Risky sexual behaviors & High score & High score & High score \\
Non-adherence to ART & Very high score & Very high score & Very high score \\
\hline
\end{tabular}


adherence to ART. In order to determine if these mean scores for non-adherence to ART were statistically higher than those respective means for the other two risk factors, 95\% confidence intervals were estimated (Table 4.6). None of the mean knowledge, confidence, and attitude scores for smoking and risky sexual behaviors fell into the respective confidence intervals for non-adherence to ART, which indicated that by selfreport HIV PCPs had higher knowledge, confidence, and attitude scores towards managing non-adherence to ART when compared to managing smoking or risky sexual behaviors.

\section{Specific Aim 3}

In order to determine the relationship between the dependent variables (ACRFM practices) and independent variables (knowledge, confidence, and attitudes towards ACRFM) for each risk factor, a correlation analysis was performed (Table 4.7). Only one statistically significant relationship was observed $(p<.05)$ between the total score for ACRFM practices and knowledge of risky sexual practices. The estimated correlation, quantifying the relationship between what HIV PCPs know about managing risky sexual behaviors and how they practice in regards to managing risky sexual behaviors was moderate in size $(r=.56699, \mathrm{p}=.0091)$.

\section{Specific Aim 4}

Once data were obtained for the combinations of mean practice scores (nonadherence to ART, smoking, and risky sexual behaviors), the distribution of scores was such that splitting the sample into high and low implementers was not feasible. There were no providers who met the criteria for low implementers (practice score $<2.5$ ). Therefore, the study procedure was modified. Providers were randomly sampled from the sample of survey participants to participate in individual interviews. Specific aim 4 was not examined any further.

\section{Qualitative Analysis}

\section{Specific Aim 5}

An exploratory approach was used to understand the factors that impede or facilitate anal health discussions in the HIV primary care setting. Of the 20 HIV PCPs who participated in the quantitative portion of the study, ten were randomly chosen to participate in brief one-on-one interviews, with nine agreeing to participate in the qualitative portion of the study. On average, the length of the interviews was approximately 15 minutes. Out of the nine participants, there were two males and seven females with an average range in age of 45-54 years old. The average number of years 
Table 4.6. Average Knowledge, Confidence, and Attitude Scores and 95\% Confidence Intervals of 20 HIV Primary Care Providers

\begin{tabular}{lccc}
\hline \multirow{2}{*}{$\begin{array}{l}\text { Anal Cancer Risk } \\
\text { Factor }\end{array}$} & \multicolumn{3}{c}{$\begin{array}{c}\text { Average Knowledge, Confidence, and Attitude Scores } \\
\text { (95\% Confidence Intervals) }\end{array}$} \\
\cline { 2 - 4 } & Knowledge & Confidence & Attitude \\
\hline Smoking & $4.13(3.63,4.62)$ & $4.22(3.74,4.71)$ & $3.94(3.68,4.21)$ \\
Risky sexual behaviors & $4.10(3.67,4.53)$ & $4.23(3.79,4.66)$ & $4.02(3.71,4.33)$ \\
Non-adherence to ART & $4.75(4.40,5.00)$ & $4.70(4.38,5.00)$ & $4.59(4.48,4.71)$ \\
\hline
\end{tabular}

Table 4.7. Estimated Spearman Correlation Coefficients between Total Score for ACRFM Practices and Scores for Knowledge, Confidence, and Attitudes towards ACRFM based on 20 HIV Primary Care Providers

\begin{tabular}{llcc}
\hline $\begin{array}{l}\text { Anal Cancer Risk } \\
\text { Factor }\end{array}$ & $\begin{array}{c}\text { Independent } \\
\text { Variable }\end{array}$ & $\begin{array}{c}\text { Estimated } \\
\text { Correlation } \\
\text { Coefficient }\left(\mathbf{r}_{\text {s }}\right)\end{array}$ & p-Value \\
\hline Smoking & Knowledge & .33250 & .1520 \\
& Confidence & .40754 & .0745 \\
& Attitude & .37083 & .1075 \\
Risky sexual behaviors & Knowledge & .56699 & .0091 \\
& Confidence & .43072 & .0580 \\
& Attitude & .19604 & .4705 \\
Non-adherence to ART & Knowledge & .21456 & .3637 \\
& Confidence & .29451 & .2075 \\
& Attitude & -.09494 & .6905 \\
\hline
\end{tabular}


working with people living with HIV and AIDs was $10.7 \pm 6.2$ with a range of 1-19 years. The subsample was composed of five medical doctors and four advanced practice nurses, with one individual practicing in Arkansas and the remaining eight in Tennessee at one of four different HIV/AIDs primary care clinics.

\section{A Priori Codes}

Facilitators and barriers were the primary organizing categories for the qualitative data. Barriers of addressing sexual health in the primary care setting from the review of literature included the following: time constraints, the demand of other priorities, provider embarrassment, provider comfort level and provider lack of content knowledge. The one major facilitator of addressing sexual health from the review of literature was the patient provider relationship. These specific barriers and facilitators served as the a priori codes for the data analysis (Table 4.8).

\section{Inductive Codes}

After searching the cases for the a priori codes, additional barriers and facilitators were included in the data analysis as inductive codes. The additional barriers included external issues, perception of patient embarrassment, lack of resources, gender discordance, and lack of anal complaints. Additional facilitators included awareness and advantageous circumstances. Inductive categories and codes are listed in Table 4.9.

\section{Final Codes and Categories}

After the a priori and inductive codes were established, codes were combined based on resemblance. For the barriers, time constraints were merged into external issues as limited amounts of time with patients is commonly related to a fixed visit schedule. Other barriers related to the healthcare provider such as provider embarrassment, provider comfort level and provider lack of content knowledge were all merged into a code that was more representative of the text segments: provider embarrassment. Final codes are in Table 4.10.

The a priori codes and inductive codes were combined for a total of 10 codes. In analyzing the data, a coding frequency was obtained across the 9 cases (Table 4.11). 
Table 4.8. A Priori Codes and Categories

\begin{tabular}{ll}
\hline Categories & \multicolumn{1}{c}{ A Priori Codes } \\
\hline Barriers & Time constraint \\
& The demand of other priorities \\
& $\begin{array}{l}\text { Provider embarrassment } \\
\text { Provider comfort level } \\
\text { Provider lack of content knowledge } \\
\end{array}$ \\
& Good patient provider relationship \\
\hline
\end{tabular}

Table 4.9. Inductive Codes and Categories

\begin{tabular}{ll}
\hline Categories & \multicolumn{1}{c}{ Inductive Codes } \\
\hline Barriers & External issues \\
& Perception of patient embarrassment \\
& Lack of resources \\
& Gender discordance \\
& Lack of anal complaints \\
& Awareness \\
Facilitators & Advantageous circumstances \\
& \\
\hline
\end{tabular}

Table 4.10. Final Codes and Categories

\begin{tabular}{ll}
\hline Final Categories & \multicolumn{1}{c}{ Final Codes } \\
\hline Barriers & External issues \\
& Demand of other priorities \\
& Perception of patient embarrassment \\
& Lack of resources \\
& Gender discordance \\
& Provider embarrassment \\
& Lack of anal complaints \\
& Awareness \\
& Advantageous circumstances \\
& Good patient-provider relationship \\
\hline
\end{tabular}


Table 4.11. Qualitative Coding Frequencies of 9 Primary Care Providers Participating in the Interview Portion of the Study

\begin{tabular}{llcc}
\hline Category & \multicolumn{1}{c}{ Code } & Cases & \% Cases \\
\hline Barriers & External issues & 6 & $66.70 \%$ \\
Barriers & Demand of other priorities & 6 & $66.70 \%$ \\
Barriers & Perception of patient embarrassment & 7 & $77.80 \%$ \\
Barriers & Lack of resources & 2 & $22.20 \%$ \\
Barriers & Gender discordance & 2 & $22.20 \%$ \\
Barriers & Provider embarrassment & 6 & $66.70 \%$ \\
Barriers & Lack of anal complaints & 3 & $33.30 \%$ \\
Facilitators & Awareness & 4 & $44.40 \%$ \\
Facilitators & Advantageous circumstances & 9 & $100.00 \%$ \\
Facilitators & The patient-provider relationship & 5 & $55.60 \%$ \\
\hline
\end{tabular}




\section{Facilitators}

\section{Advantageous Circumstances}

HIV PCPs expressed that it was the co-location of the anal health discussion with another relevant portion of the physical exam or with a specific topic that aided in the discussion of anal health. Therefore, those text statements were coded as advantageous circumstances. It was easier to discuss anal health when providers were already discussing sexual health, and it was easier to discuss anal health with women who were already scheduled for a cervical exam.

When providers were asked how they initiate the discussion of anal health with their patients, several of them mentioned using the topic of sexual health to segue into the discussion of anal health.

I usually start with the discussion of just sexual behaviors in general, and then I move to how many partners, do you use protection, what kind of intercourse do you have? Again it's always tied to sexual activity or any diagnosis of STDs (Participant 1)

The participants quoted below thought broadly about anal health as a component of sexual health and used this as a way to transition into anal health.

The condoms that we give away for free, I use that as a segue sometimes. Do you need any condoms? Then, we start talking about what they're doing. (Participant 2)

If patients identify themselves as homosexual, especially as a homosexual male, we then talk about intercourse or sexual practices. I will explain to them the risk for HPV and this segues into an anal Pap (Participant 4)

So, whenever I get to the social history aspect of new patients or whenever I'm doing the preventive health maintenance portion with my established patients, I first go over sexual health and ask if there have been any changes. Those who are new I just ask them directly if their intercourse is vaginally, anally, both, none... things like that. Then, if they screen positive for high-risk behaviors, we talk about the long-term effects of HPV and the chance for carcinoma. It's like a stepwise process (Participant 3)

It was also advantageous to discuss anal health when they were performing a cervical Pap smear. Because women were already prepared for the exam, and most have some familiarity with the Pap smear process, the PCPs reported greater ease in this situation for discussing the importance of anal health and anal Pap smears.

With women, I include it in their cervical screening and so it's just another thing that we do (Participant 2) 
For my female patients, I think it's a little bit easier because I'm doing a Pap smear on them, and it's easier for them to understand. When I do their cervical vaginal Pap, I will also let them know that I will be doing an anal Pap at the same time and I explain the reasons why. I explain that's why I'm papping your anal area because HPV can get there too. It has helped them understand that HPV can be a precursor for cancer (Participant 4)

My women, I will bring them back for a cervical only visit and then I can address the anus, but I haven't done that with the men-to bring them back.

For women, it's a part of their vaginal and pelvic exams annually when we pap them. For men, anal health is a little different. I'm interested in his prostate most of the time (Participant 4)

\section{The Patient-Provider Relationship}

There were several barriers in the literature as to why sexual health is not addressed in the primary care setting, but there was only one major facilitator: the patient-provider relationship. The patient-provider relationship was defined as connectedness between patient and provider that helped to ease into discussion of anal health. When asked about factors that may facilitate addressing anal health, participants provided the following responses about the impact of the patient-provider relationship:

I find it much easier in a patient that I have seen several times who I have known over a few years. I have a lot of trouble asking on the first visit. I try not to get too detailed until somebody is comfortable with me. It is hard on the first visit to say nice to meet you, why don't you take your clothes off and tell me everything you do and who you do it with (Participant 1)

What I found was if I move anal health to one of the very last things that I talk about in the visit, and I've gotten to know them, and they've become friendly with me, it really helps to be the last thing we talk about. I stress to them how important it is and they really feel my sincerity (Participant 3)

I start off with a relationship. For example, yesterday I had a young man: A brand new inmate, 19 years old and bitter. I began to ask the intake questions and he threw out some information that I took advantage of. I got next to him and got friendly with him and let him know that I understood his dilemma and we talked. He went on to tell me that he was same gender loving, had been itching around his anus and thought he had hemorrhoids. I said let me check back there. He had early HPV back there, and I was able to explain it to him and make a referral on his first visit. He let me see his whole body because of the relationship that I initiated. I think that's so important to do because if you have a relationship with the patient, and the patient feels cared about, he will be more likely to let you do things that you need to do that may be uncomfortable at times (Participant 4) 


\section{Awareness}

Awareness was defined as the state of being more aware or being more knowledgeable about facts or information related to anal health that aided in the discussion of anal health. One provider mentioned a referral center that has aided in the discussion of anal health:

I can discuss anal health now because of the fact that we can do something about it. We have someone who can do anoscopes, so the patients have good follow ups. Our referral center has made all the difference in the world. We have gone from nothing to something, and I'm happy with that something right now (Participant 2)

Another provider mentioned seminars and talks as a source of knowledge that aided in the discussion of anal health

I go to talks from content experts because I always pick up something that I didn't hear before. I take that back with me, and that kind of gives me the tools and the confidence to discuss anal health, especially with men (Participant 7)

\section{Barriers}

\section{Perception of Patient Embarrassment}

If HIV PCPs perceived a feeling of shame, discomfort, or awkwardness from their patient as a barrier to discussing anal health or sexual practices, this was defined as perception of patient embarrassment.

It is hard to get somebody that is shy to be very open about his or her sexual practices. They won't even tell you that they had anal sex even though they do because they think that it is a bad thing (Participant 6)

They get embarrassed when you ask very private questions about a part of their body they don't often want to talk about (Participant 1)

I have to be the one to bring it up because like I said earlier, some patients are embarrassed or fear judgment that they won't discuss it (Participant 7)

\section{Provider Embarrassment}

Provider embarrassment was defined as a personal feeling of shame, discomfort, or awkwardness that served as a barrier to discussing anal health with patients. 
One barrier to anal health is embarrassment on my part. I don't like to talk about it with someone I don't know or someone I don't feel that comfortable with. I'm still not that comfortable with what all conditions I need to be worried about or looking for or even screening recommendations (Participant 1)

Well, I think I probably need to get rid of some of my feelings about anal health because I get shy with some of my male patients when I ask about anal health (Participant 6)

If your preceptor or supervisor doesn't teach you to ask about anal health or talk about anal health, then you're not going to remember and you're not going to feel comfortable (Participant 1)

Sometimes when they are newer and they haven't really built their rapport with me, it is a little bit hard to approach the subject of anal health (Participant 5)

\section{External Issues and the Demand of Other Issues}

External issues were any issues outside of the healthcare provider's control in addressing anal health, and this code was present in over half of the interviews. These external issues consisted of time as patients are commonly scheduled during fixed visit slots (i.e. 10:30-11:00) and system issues such as the complexity of electronic charting. When asked about the barriers of discussing anal health, providers expressed the following:

I would say time. The time I have to see my patients. Do all the charting with the EHR (electronic health record). You know I'm supposed to get these people in and out in 15 minutes. (Participant 2)

Sometimes we're in a rush that it's just a time issue. I might say that I will do it next time they come in (Participant 4)

I want to improve anal health by educating my patients, but we don't have a lot of time for that. (Participant 6)

Time. I have patients scheduled every 20 minutes, and I'm trying to do everything I can in 20 minutes (Participant 5)

I do think that time is limited with each patient, so you do what is the most important which is take care of the HIV (Participant 6)

Participants also gave similar examples of how the demand of other issues may limit their time and serve as a barrier to addressing anal health. One provider labeled it is fire-fighting: 
There is a lot of fire fighting, and this is a big barrier. Someone comes in with a CD4 count of 50 and a fever. Well you're not going to address anal health that visit. I have several, many patients that there is always something going on, and it sort of takes priority: uncontrolled diabetes, hypertension, oh I just had a heart attack. That kind of stuff (Participant 1)

Other providers agreed as follows:

They may have depression issues, spousal abuse, or partner abuse. There are so many potential issues, and this becomes a barrier (Participant 2)

They may be stressed out due to family matters, relationship problems. Sometimes they are just so high strung when they come in here, its hard to get them to settle down and say your T-cell is 10 and you need to take your medicine Like one of my patient's today, her diastolic blood pressure was 114. So, you've got to take care of that because that's the most pressing issue today. (Participant 6)

\section{Lack of Anal Complaints}

Participants stated that if patients did not present with an anal complaint, anal health was not addressed. This barrier was coded as the lack of anal complaints.

If they don't complain, I don't check it. I look at anal health like I look at other disease processes. It's just like if you come in and told me that you had a sore throat, I would do a head and neck assessment, I would listen to your lungs. I probably wouldn't check your toes. If they don't complain, I don't fool with it. (Participant 5)

As far as talking about safe sex practices with all patients, I won't always ask about it unless there is generally a complaint (Participant 4)

When we talk about anal health its usually problem related. They notice warts or have pain or bleeding. We don't talk about anal health unless they have a problem (Participant 1)

\section{Lack of Resources}

Resources were defined as any external source of information or expertise that enhanced anal health in the primary care setting, but providers defined the lack of resources as the absence of those external sources. One provider explained that there were limited resources to make referrals.

I don't do it routinely because we don't have resources for referral for abnormal disease. We have limited resources to refer abnormal, therefore anal Paps are limited (Participant 7) 
Another provider stated that the lack of guidelines about screening programs is a barrier to care.

There is no real consensus in terms of guidelines. In order for something to really be accepted as a screening program, you've got to have firm data that shows reduction of morbidity and mortality as a result of that screening. That's the part that I don't think is solely there yet (Participant 8)

\section{Gender Discordance}

Gender discordance was defined as gender differences between the provider and patient that were perceived by the HIV PCP as a barrier to discussing anal health. There were two providers who mentioned gender differences as a barrier:

A female participant stated, I need to get rid of some of my feelings about me being shy with some of the male patients about asking about anal health (Participant 6)

A male participant stated, I find with my female patients it's harder for them to discuss anal health with me because I'm a man, whereas my male patients will tell me just about anything (Participant 3) 


\title{
CHAPTER 5. DISCUSSION
}

\author{
Quantitative Discussion
}

\section{ACRFM Practices}

HIV PCPs were less likely to manage risky sexual behaviors when compared to smoking and non-adherence to ART. This finding was congruent to information from the literature as sexual health in primary care has been best avoided due to topic complexity and lack of resources related to sexual health management (Gott, Galena, et al., 2004). There are limited resources related to the management of sexual health in primary care when compared to resources for smoking and non-adherence to ART management. The process of ACRFM includes a coordinated application of resources to minimize, monitor, and control the probability of anal cancer, so resources are important to have to fully practice ACRFM. Limited sexual health resources, especially resources more specific to anal health, may be one reason that HIV PCPs were less likely to address risky sexual behaviors.

There is a plethora of information on ART adherence and smoking cessation for healthcare providers when compared to managing risky sexual behaviors. For example, the World Health Organization has developed a consolidated handbook for ART management, and it serves as a resource to help with screening for medication adherence and providing innovative ways to intervene (World Health Organization, 2013). One of the main ways that providers screen for ART adherence is through viral load monitoring. This monitoring has been recommended by the World Health Organization as a way to identify treatment failures (World Health Organization, 2013). The management of ART is a standard of care in HIV care as viral load is usually monitored at every clinic visit (34 times per year). In the event of poor ART adherence, the handbook also provides a list of interventions to improve medication adherence. There are program level interventions such as avoiding out of pocket payments, using fixed-dose combination regimens, and using drug supply management systems (World Health Organization, 2013).

Recommendations for individual level interventions include peer support, mental health interventions, nutritional support, financial support, and even more innovative recommendations like mobile text messaging as a reminder tool (World Health Organization, 2013). There are resources to screen for ART adherence and a number of options to aid in improving medication adherence. The priority of ART management in HIV care and the abundance of resources may have contributed to a higher likelihood of practicing towards the management non-adherence to ART when compared to risky sexual behaviors.

There are also a number of resources to aid the healthcare provider in facilitating smoking cessation. The 5A's model/tool of asking, advising, assessing, assisting, and arranging has been used to aid in smoking cessation, and the model has been identified as effective (Fiore, Jaen, Baker, \& al., 2008). There are also a number of tools such as how 
to guides, documentation forms, booklets, videos, handbooks, posters, toolkits, information on reimbursement for smoking cessation therapy, and even population specific guides (i.e. youth and pregnancy) recommended by the National Tobacco Cessation Collaborative and the Centers for Disease Control to aid in smoking cessation for providers (CDC, 2014a; National Tobacco Cessation Collaborative, 2011). There are also a number of therapies that that aid in smoking cessation such as cognitive behavioral therapy, nicotine replacement therapy (i.e. nicotine gum, patch, lozenge, and nasal spray), and non-nicotine replacement therapy (i.e. antidepressants and anxiolytics). The United States Preventive Services Task Force is also heavily involved in developing guidelines related to smoking cessation, as smoking cessation in all populations is a grade A recommendation. Providers are encouraged to ask all patients about smoking status and provide interventions for smoking cessation (U.S. Preventive Services Task Force, 2009). In addition to the number of resources to screen for smoking and intervene, there are screening prompts for smoking in most electronic charts that may also urge the provider to screen and intervene. Smoking is a major risk factor for a number of healthcare conditions, and in PLWHA, prevalence of smoking is two to three times higher, and there are poorer HIV treatment outcomes than in non-smokers who are HIV positive (Reynolds, 2009). Factors that contribute to poorer HIV treatment outcomes may also be considered a priority in HIV care. This, along with the resources that aid in smoking cessation, may explain why HIV PCPs were more likely to practice towards managing this risk factor when compared to risky sexual behaviors.

In comparison to ART non-adherence and smoking, resources for addressing risky sexual behaviors are limited and may have contributed to the poor management of sexual health in primary care settings. Most resources for addressing and managing risky sexual behaviors are geared towards teens and young adults since they are at a higher risk for risky sexual behaviors than adults (National Cancer Institute, 2014). Most funding for sexual health education is provided by the Centers for Disease Control to help state and local agencies deliver education about HIV and STD in schools (CDC, 2013). Most screening tools and resources that address sexual health are tailored more for assessing patients for sexual violence (National Sexual Violence Resource Center, 2011 ), measuring sexual interests, and assessing overall behavioral risk factors to identify patients who may be at risk for HIV such as the B.R.A.T (behavioral risk assessment tool) (Wisconsin HIV Prevention Evaluation Work Group, 2000). A subscale of the HIV Risk-Taking Behavior Scale has been used to measure risky sexual behaviors (Lejuez, Simmons, Aklin, Daughters, \& Dvir, 2004), but this screening tool is not part of routine primary care to measure risky sexual behaviors. Providers have even acknowledged that because of the lack of resources related to addressing sexual health, it is not a top priority in policy or clinical practice (Gott, Galena, et al., 2004).

HIV PCPs in this study were less likely to practice towards managing risky sexual behaviors, and this was an unfortunate finding, as risky sexual behaviors may be the most important risk factor to address in the prevention of anal cancer. HPV is strongly linked to anal cancer, and may be necessary in the development of anal cancer (Daling et al., 2004; Frisch et al., 1997; Tilston, 1997). Because of how the virus can be transmitted, this requires risky sexual behaviors to be managed more than it currently is. There were 
no descriptions in the literature about addressing smoking and ART non-adherence as opening a can of worms or opening a floodgate possibly because of the number and quality of resources available to manage these risk factors. Providers may be aware that there is a safety net with addressing these risk factors, and as a result, may be more likely to address them when compared to the complex issues related risky sexual behaviors. ART management is a standard of HIV primary care, and smoking may also be a priority of HIV primary care as PLWHA who smoke have been found to have poorer treatment outcomes and greater disease progression (Reynolds, 2009). This, along with resources to manage smoking and non-adherence to ART, may have contributed to providers being more likely to practice towards managing these risk factors when compared to risky sexual behaviors. It is therefore hypothesized that HIV PCPs would be more likely to address risky sexual behaviors if they have the proper resources to screen, intervene, and manage the behaviors. Implications for future practice include the implementation of screening tools for anal cancer risk factors and resource guides specific to ACRFM for providers and patients. The American Cancer Society's resource guide for anal cancer provides a detailed list of anal cancer risk factors (American Cancer Society, 2014), but does not provide information on how risk factors should be managed. Further implications for future practice include strengthening the anal cancer resource guide to include evidence based practices related to screening for each risk factor and intervening to reduce the risk factors so that all information related to ACRFM is in one consolidated guide for providers.

\section{Knowledge, Confidence, and Attitudes}

HIV PCPs had very high knowledge, confidence, and attitude (KCA) scores towards managing non-adherence to ART, which may have been due to the numerous advancements of ART in managing HIV. The success of ART has advanced HIV/AIDS from a fatal disease to a manageable chronic disease (Deeks, Lewin, \& Havlir, 2013), and the World Health Organization believes that medication adherence is key to continuing to improve clinical outcomes related to HIV/AIDS (World Health Organization, 2013). Healthcare providers understand the importance of ART in helping patients to live longer and in reducing viral transmission, so ART has not only become a primary focus in HIV primary care, but also a standard in HIV care (U.S. Department of Health \& Human Services, 2009). Interestingly, all KCA scores for each anal cancer risk factor exceeded 4.0 on a 5.0 Likert scale. Even though KCA scores towards managing risky sexual behaviors were significantly lower than the KCA scores for non-adherence to ART, all KCA scores were still high. All scores ranged from high to very high indicating that in this sample of $20 \mathrm{HIV}$ PCPs, variables related to personal intention (KCA), may not have contributed to the lesser likelihood of addressing risky sexual behaviors in the HIV primary care setting.

One rationale that may explain high KCA scores in this population may be related to a nationwide initiative to focus more on preventing HIV transmission from those who are already positive. The 'prevention with positives' initiative started in 2003 with recommendations from the Centers for Disease Control: Focus on screening for HIV 
transmission risk behaviors such as sex-related behaviors and incorporate behavioral interventions such as general messages about HIV prevention and ART adherence (CDC, 2003). Behavioral risk reduction interventions have been found to increase condom use and increase use of ART (U.S. Department of Veterans Affairs, 2011). The Health Resources and Services Administration recently promoted 'prevention with positives' by designing initiatives with 15 multisite clinics to implement and evaluate different prevention strategies in PLWHA (Health Resources and Services Administration, n.d.). Their preliminary findings have indicated that HIV providers have a key role in HIV prevention and will be more likely to implement 'prevention with positive' interventions if they feel a sense of responsibility (Center for AIDS Prevention Studies (CAPS), n.d.). Providers may be knowledgeable, confident, and have positive attitudes towards addressing risky sexual behaviors and non-adherence to ART because of the priorities of the 'prevention with positives' initiative.

Variables related to personal intentions were also high for smoking. Although smoking cessation is not part of routine 'prevention with positives' management, it is a routine part of primary care as it is the leading cause of preventable illness and death in the U.S. (CDC, 2014b). It is a major risk factor for several different types of cancer, heart disease, and lung disease (CDC, 2010; Warren, Alberg, Kraft, \& Cummings, 2014). In PLWHA, the smoking rate is two to three times higher, and there are poorer HIV treatment outcomes than non-smokers who are HIV positive (Reynolds, 2009). With the number of evidence based practices related to smoking cessation and electronic charting prompts to identify tobacco users, this may have contributed to high KCA scores towards managing smoking as a risk factor for anal cancer.

An important finding in this study was the high-very high KCA scores for all anal cancer risk factors. This indicated that factors other than knowledge, confidence, and attitudes might play a role in why providers were less likely to practice towards managing risky sexual behaviors when compared to other risk factors. These findings challenged the modified theory of planned behavior for ACRFM and the original theory of planned behavior, as KCA scores were not found to predict practice scores with regard to risky sexual behaviors. Perceived behavioral control, another component of the theory of planned behavior, was explored to understand the quantitative findings in more detail. "Behaviors pose difficulties of execution that may limit volitional control, so it is useful to consider perceived behavioral control as it can serve as a proxy for actual control and contribute to the prediction of the behavior in question" (Ajzen, n.d., p. 1). Therefore, impeding and promoting factors towards addressing anal health were explored in greater detail to understand the impact of perceived behavioral control on addressing risky sexual behaviors. This was the only risk factor that HIV PCPs were less likely to practice even with high KCA scores. 


\section{Correlation Analysis}

There was only one significant relationship observed between variables related to personal intention and those related to practices: What providers know about risky sexual behaviors as a risk factor for anal cancer may impact how they practice with regard to addressing risky sexual behaviors. Interestingly, this finding did not correlate with findings related to personal intentions and practices: Providers reported to know about managing risky sexual behaviors, but this was not reflected in their practices. This indicated that other factors may have contributed to a lesser likelihood of managing risky sexual behaviors when compared to other risk factors. However, the correlation still indicated that knowledge is an important variable related to personal intention with regard to addressing risky sexual behaviors and should be considered in improving ACRFM.

The statistical relationship in this study simply indicated an association between the two variables. If knowledge is associated with practice, this continues to highlight the need for improved sexual health and anal health training and education as a source of knowledge. One major barrier to the management of sexual health in the primary care setting is related to the lack of knowledge, training, and education (Gott, Galena, et al., 2004; Hinchliff et al., 2005; Humphery \& Nazareth, 2001; Stokes \& Mears, 2000).

Studies have shown that time spent on sexual health in training programs such as medical school has been very limited (Galletly et al., 2010; Obedin-Maliver et al., 2011; Solursh

et al., 2003). Knowing what to say to patients from diverse cultural or ethnic backgrounds is problematic for providers and discussing sexual health with patients of a different gender or sexual orientation has also been identified as difficult (Gott, Galena, et al., 2004; Gott, Hinchliff, et al., 2004; Hinchliff et al., 2005; Stokes \& Mears, 2000). Even though providers reported high knowledge scores towards managing risky sexual behaviors, findings from the literature have indicated a crisis related to the lack of sexual health education (Coleman et al., 2013).

As there was a correlation between knowledge and practice with regard to addressing risky sexual behaviors, efforts are needed to improve sexual health education in healthcare training programs across the country. There are a limited number of medical training programs with sexual health courses (Coleman et al., 2013), which further indicates a need to improve sexual health education. Although high knowledge scores did not correspond to a higher likelihood of managing risky sexual behaviors in this population, there is still a broader need to improve sexual health education and knowledge across the healthcare system.

\section{Qualitative Discussion}

In order to understand the impact of perceived behavioral control on addressing risky sexual behaviors, a component of ACRFM, HIV PCPs were asked about barriers to addressing anal health in HIV primary care settings. They identified the perception of patient embarrassment, provider embarrassment, external issues, demand of other 
priorities, lack of anal complaints, lack of resources, and gender discordance as barriers. According to the theory of planned behavior, these were considered factors that limited the providers' volitional control in addressing anal health in their HIV primary care settings (Ajzen, 1991). Since anal health is a component of sexual health, and the management of sexual health includes addressing risky sexual behaviors, barriers to addressing anal health were hypothesized to explain why providers were less likely to manage risky sexual behaviors in HIV primary care.

\section{Perception of Patient Embarrassment and Provider Embarrassment}

HIV PCPs frequently mentioned a feeling of shame, discomfort, or awkwardness from the patient as a barrier to discussing anal health. Since there were no patients included in this study and no way to identify if patient embarrassment was indeed a barrier, this code was labeled as the perception of patient embarrassment. Interestingly, patients want to talk about sexual concerns, they just want the provider to initiate the discussion (Berman et al., 2003; Martinez, n.d. ). One provider recognized this as she stated, "you have to be the one to bring it up because some patients are embarrassed" (Participant 7). The provider's embarrassment is therefore an important barrier to consider. If patients do not initiate the discussion on anal health, and providers are too embarrassed to initiate the discussion, anal health may never be a topic in routine HIV primary care and risk factors for anal cancer may never be managed.

Patient discomfort has been identified as a barrier to discussing sexual problems (Sarkadi \& Rosenqvist, 2001), but a greater focus in the literature has been on the provider's level of embarrassment and discomfort in talking with patients about sexuality and sexual health (Association of Reproductive Health Professionals, 2010 ; Gott, Galena, et al., 2004; Stein \& Bonuck, 2001a; Temple-Smith et al., 1996). In this study, patient embarrassment was identified as a barrier, but it may have been a deflection of feelings, as providers may not have wanted to express their personal embarrassment and discomfort as a barrier to care. Participants 1 and 6 both identified patient embarrassment as a barrier, but also identified their own personal embarrassment as barrier to addressing anal health: Participant 1 stated "they get embarrassed when you ask private questions about a part of their body they don't often want to talk about," but also stated "one barrier to anal health is embarrassment on my part. I don't like to talk about it with someone I don't know or someone I don't feel that comfortable with." Personal embarrassment was more prevalent in the responses by participant 1 and 6 than the perception of patient embarrassment indicating that personal embarrassment may have contributed more as a barrier to addressing anal health. It is well known that providers have a difficult time discussing sexual health due to lack of training and the personal embarrassment of talking about sex.

Comfort level and modesty were identified as sources of personal embarrassment: Participant 6 said she needs to get rid of her feelings about anal health because she gets shy with her patients, and Participant 1 explained that because she was not taught by her preceptor to ask about anal health, she does not feel comfortable talking about it. 
Providers in primary care have stated that lack of training and education has contributed to the discomfort they have in addressing sexual health with patients (Gott, Galena, et al., 2004; Hinchliff et al., 2005; Humphery \& Nazareth, 2001; Stokes \& Mears, 2000), but providers in this study indicated that knowledge, confidence, and attitudes towards addressing risky sexual behaviors were not issues related to why they were less likely to manage this risk factor when compared to other risk factors. There are currently no studies that examine barriers to addressing anal health in HIV primary care settings, so this is the first of its kinds to offer an explanation. HIV PCPs have some personal embarrassment related to addressing anal health, and this may be related to some of the other barriers identified in this study such as external issues like the lack of time to address anal health in primary care and issues related to gender discordance.

\section{External Issues and the Demand of Other Priorities}

Time constraints have always been an issue with addressing sexual health in the primary care setting (World Health Organization, 2010). Providers feel as if other priorities are more demanding and that discussing sexual health "opens a can of worms", could "take up a long time, and therefore are best avoided" (Gott, Galena, et al., 2004, p. 531). "Sexual health is an area in which primary care could be effectively involved, but pressures of time as well as the complex and difficult nature of issues have been acknowledged to result in sexual health being afforded low priority within day to day clinical practice" (Gott, Galena, et al., 2004, p. 530). Time constraints have been identified as key barriers to discussing sexual health, building good patient-provider relationships, and getting beyond a patient's chief complaints (Gott, Galena, et al., 2004).

Several providers mentioned time as a barrier to addressing anal health in this study: "You know I'm supposed to get these people in and out in 15 minutes" (Participant 2), and "I have patients scheduled every 20 minutes, and I'm trying to do everything I can in 20 minutes" (Participant 5). Since patients are usually scheduled during short fixed appointment slots (i.e. 10:30-10:45), this makes it difficult for the provider to address complex issues such as sexual health and anal health. One provider stated that she wants to improve anal health by educating her patients, but she also explained "we don't have a lot of time for that, so we do what is most important which is take care of the HIV" (Participant 6). This correlated to information from Gott and colleagues (2004) about primary care priorities: "Time pressures that healthcare providers work within means that priorities deal with diagnosing health conditions and prescribing medication, meaning little, if any, time is available to discuss a patient's sex life" (Gott, Galena, et al., 2004, p. 531). In 2001, a study showed that time spent with patients in primary care had increased (Mechanic, McAlpine, \& Rosenthal, 2001), which is a contrary belief. Campion (2001) believes that because of fragmented healthcare system issues and added pressures, providers still feel as if their time is limited (Campion, 2001). Even preventive care services recommended by the United States Preventive Services Task Force require large amounts of time (Yarnall, Pollak, Ostbye, Krause, \& Michener, 2003). Although Yarnell and colleagues (2003) found that grade A recommendations are delivered most often by providers, patient concerns are prioritized in primary care and providers have to choose 
between the two (Yarnall et al., 2003). Time is a common barrier to care, as it is not unusual for a typical clinic visit to be 15 minutes or less (The Henry J. Kaiser Family Foundation, 2014). Patients do not get enough time with providers, and providers have reported feeling rushed to see more patients (Mechanic et al., 2001). Participant 6 stated that HIV care is the priority, and it leaves little to no time discuss more complex and sensitive issues like sexual health and anal health. Time is a major part of the perceived control that HIV PCPs see as impeding their ability to address anal health and may contribute to their discomfort and embarrassment with addressing the topic. There appeared to be an uneasiness and increased level of discomfort with addressing a sensitive topic within a limited time frame.

Providers also mentioned issues that limited their time, such as "fire-fighting" (Participant 1). The "fire-fighting" analogy characterized their feelings about addressing anal health at a time in which they were busy repairing other problems. According to participants 6 and 1, "anal health is just not a priority when a patient's diastolic blood pressure is 114 or the CD4 count is 50 and the patient has a fever." Those fires must be fixed before addressing anal health, and when a patient presents with more pressing issues, "Well you're not going to address anal health that visit" (Participant 1). This correlated to findings from Gott and colleagues (2004) that the demand of other priorities makes it difficult to address sexual health (Gott, Galena, et al., 2004).

\section{Lack of Anal Complaints}

If patients presented with complaints unrelated to anal health, anal health was not addressed: "If they don't complain, I don't check it" (Participant 5). In a study by OscosSanchez and colleagues (2008), barriers to adolescent preventive care included competing demands such as focusing on the chief complaints or acute issues (OscosSanchez et al., 2008). Pollak and colleagues (2008) also mentioned that preventive services compete with acute care issues (Pollak et al., 2008), so if anal health issues are not the chief complaint or an acute finding, it is not a priority for the clinic visit. Participant 5 explained this process best: I look at anal health like I look at other disease processes. It's just like if you come in and told me that you had a sore throat, I would do a head and neck assessment, I would listen to your lungs. I probably wouldn't check your toes. If they don't complain, I don't fool with it. In an average clinic visit of 15-30 minutes, it may be difficult for the provider to address acute issue like uncontrolled diabetes and hypertension, and still have time to address a complex topic like anal health, especially if it is not a priority. Participant 1 stated, "We don't talk about anal health unless they have a problem." The issue is that if providers wait until patients present with symptoms related to anal cancer such as rectal bleeding, itching, a lump at the anal opening, a change in bowel movements, abnormal discharge, or swollen lymph nodes in the groin area (American Cancer Society, 2014), the disease process might be more advanced, more difficult to treat, and have poorer outcomes. ACRFM should be a form of preventive health, which would lessen the provider's reliance on symptoms and direct the focus to prevention. 


\section{Gender Discordance}

Gender discordance was perceived to be a barrier to addressing anal health by two of the participants in this study. Providers in another study also found it difficult to discuss sexual health issues with patients from different genders or sexual orientations (Stokes \& Mears, 2000). With anal cancer being most prevalent in men who have sex with men, patient and provider gender differences are important to consider in the discussion of anal health.

Providers have reported the greatest discomfort when collecting a sexual history from a patient of the opposite sex (Burd, Nevadunsky, \& Bachmann, 2006). A female participant in this study mentioned that she was shy about discussing anal health with her male patients (Participant 6). This indicated she might have less discomfort discussing the topic with patients of the same gender. Interestingly, male patients of female providers are the most satisfied with their primary care providers when compared to the other dyads (female patients of female doctors; female patients of male doctors; and male patients of male doctors) (Schmittdiel, Grumbach, Selby, \& Quesenberry, 2000). This indicates that HIV positive MSM, a population greatly affected by anal cancer, may be more satisfied with females as primary care providers. It has also been observed that regardless of the patient-provider dyad, patients who chose their providers are equally satisfied with their providers (Schmittdiel et al., 2000).

If providers are uncomfortable with gender discordance, this may have an impact on healthcare outcomes for those patients who prefer opposite-sex providers to discuss topics like anal health. The variation in patient-provider dyad preferences indicates a need to address the discomfort that providers have with gender discordant relationships and anal health. Bertakis (2009) has recommended that medical training programs improve content related to gender preferences as it will have an impact on improving high quality education and practice (Bertakis, 2009).

\section{Lack of Resources}

The lack of resources like a referral center was a barrier to addressing anal health: "I don't do it routinely because we don't have resources for referral for abnormal disease" (Participant 7). This participant specifically referred to anal Pap smears and not the general idea of anal health in primary care. She associated anal health with anal Pap smears unlike the majority of other providers who associated anal health with sexual health. This indicated different perceptions of "anal health" in HIV primary care. Some providers used sexual health as a way to segue into anal health while others believed that anal health involved screening for disease and treating disease.

Data is limited on anal Pap smears as a screening tool as there are wide variations in the sensitivity and specificity of the tool (Bean \& Chhieng, 2010) and no randomized anal cancer screening trials (Darragh \& Winkler, 2011). These shortcomings indicated why the participant considered the lack of resources as a barrier. There are no national 
guidelines suggesting screening and treatment in high-risk populations, so this may have also contributed to providers making anal health less of a priority in their practice settings. Anal health had different meanings among the providers. The lack of resources was identified as a barrier to those providers who associated anal health with anal Pap smears. Therefore, future research should be directed at understanding the barriers and facilitators specific to addressing anal cancer risk factors instead of broadly understanding those factors related to addressing anal health.

Barriers to addressing anal health in the HIV primary care setting were important to understand. They indicated possible reasons that providers were less likely to address risky sexual behaviors with their patients when compared to other risk factors for anal cancer. Facilitators were also explored in order to give insight into the factors that promote anal health in HIV primary care. Both barriers and facilitators were helpful to explore for implications of future practice and research.

\section{Advantageous Circumstances}

Providers were more likely to address anal health in the context of sexual health. This supported an important hypothesis that anal health is a component of sexual health. Sexual health is inevitably related to anal health because risky sexual behaviors such as number of lifetime partners that exceed fifteen and unprotected anal sex are risk factors for anal cancer in both men and women (American Society of Colon \& Rectal Surgeons, 2012; Daling et al., 2004). It was easier for providers to introduce the specifics of anal health when broadly discussing sexual health. One participant stated that she starts with a general discussion of sexual health by asking about "number of partners, type of protection, and type of intercourse, and this helps to lead into the discussion of anal health" (Participant 1). Another participant stated "if patients identify themselves as homosexual, especially as a homosexual male, we talk about intercourse or sexual practices, and I will explain to them the risk for HPV and this segues into an anal Pap" (Participant 4). His discussion of sexual health led to questions that he could use in screening for anal cancer risk factors. In a study by Rosa-Cunha and colleagues (2010), anal health was rarely addressed in the HIV primary care setting, and reasons for this rarity were hypothesized as the same reasons that sexual health is rarely addressing in primary care (Rosa-Cunha et al., 2010). That was the first and only study that assumed a relationship between anal health and sexual health. The relationship was confirmed in this study as providers used sexual health as a way to segue into anal health. Participant 3 referred to it as a "stepwise process". If providers start with understanding a patient's sexual history and sexual health such as number of lifetime partners, gender preferences, intercourse preferences, types of protection, and etc. this may lead them to the next step in identifying them as high risk for anal cancer. If it is indeed a "stepwise process," providers would need to start with addressing sexual health, and it is already understood, that addressing sexual is not an easy task in the primary care setting. This indicated that in order for anal health to become a priority in HIV primary care, sexual health should also be a priority in HIV primary care. 
Providers also stated that it was easier to discuss anal health with women during their cervical Pap smear exams. Participant 4 stated that doing cervical Pap smears creates an opportunity to discuss anal health: "I explain that's why I'm papping your anal area because HPV can get there too." The provider discussed the role of HPV in causing cervical cancer and then used that information to explain how HPV can also cause anal cancer. It was convenient for the provider to transition into anal health. During a cervical Pap smear, the patient is already in the lithotomy position, an ideal position for an anal Pap smear, and the provider may already be discussing cervical screening for cervical cancer. This may help to facilitate the discussion on anal health and anal cancer. Although the United States Preventive Services Task Force recommends that women get cervical Pap smears every 3 years instead of annually, the recommendation statement does not apply to women living with HIV/AIDS (U.S. Preventive Services Task Force, 2012). Women living with HIV and AIDs may still be seen on a yearly basis, and this may create an annual opportunity for healthcare providers to address their anal health.

Although it may be easier to discuss anal health with women because of the advantageous circumstance of discussing cervical cancer and doing cervical Pap smears, the greatest risk of anal cancer is not present in this gender. The greatest risk of anal cancer is seen in men who have sex with men (Palefsky et al., 1998; Silverberg et al., 2012), but it is not as convenient to discuss anal health with this population. Participant 4 expressed that "For my female patients, I think it's a little bit easier because I'm doing a Pap smear on them, and it's easier for them to understand." Participant 4 also stated that female patients could be brought back to the clinic for a cervical Pap only visit, which is when the anus could be addressed, but she also stated "I haven't done that with the mento bring them back." This showed the difference in the anal health of men and women, and how it is initiated in the primary care setting. This becomes a missed opportunity for men because they do not have cervixes and therefore, no need to have annual gynecological exams. They still however make up the majority of anal cancer cases, and thus should have greater opportunities for providers to address their anal health.

\section{Patient-Provider Relationship}

"The doctor-patient relationship has been and remains a keystone of care" (Goold \& Lipkin, 1999, p. 20). In the one study that examined anal health in the HIV primary care setting, patient-provider engagement was a factor related to the frequency of anal health discussions (Rosa-Cunha et al., 2010). That indicated the importance of the relationship in addressing sensitive topics such as sexual health and anal health.

Participant 1 stated, "I have a lot of trouble asking on the first visit, and I try not to get too detailed until somebody is comfortable with me. It is hard on the first visit to say nice to meet you, why don't you take your clothes off and tell me everything you do and who you do it with." This statement showed how sensitive the discussion of anal health can be because it is a difficult topic to discuss with a patient on their first visit. It highlighted the importance of rapport and relationship. The patient-provider relationship has been found to have a positive impact on discussing sexual health (American Social 
Health Association, 1994; Hughes, 2013), and there are other studies that have shown how collaboration and communication between providers and patients is effective with other healthcare topics such as quality HIV/AIDS care (Davis-Michaud, Yurk, Lansky, Asch, \& Wu, 2004) and the discussion of alcohol use in PLWHA (Metsch et al., 2008). Most importantly, the patient-provider relationship has been shown to be effective in discussing sexual health, implying that it may be just as effective in anal health. A good patient-provider relationship plays a major part in the development and maintenance of ACRFM in the HIV primary care setting.

\section{Awareness}

Providers mentioned a referral center and seminars as sources of knowledge that aided in the discussion of anal health. The awareness of a referral center "made all the difference in the world" and participant 2 also added that because of the referral center "We have gone from nothing to something, and I'm happy with that something right now." Participant 7 mentioned that information from seminars and talks from content experts gave her the "tools and confidence to discuss anal health," so it was through awareness of anal health resources that providers became more knowledgeable and confident in addressing anal health. Referral centers such as the Center for HPV and Dysplasia in Memphis, TN is a resource for providers because it is a specialty clinic designed to assess and treat anal disease. "Physician knowledge gaps due to specialization creates a natural demand for referrals (Song, Sequist, \& Barnett, 2014, p. 597)," so if HIV PCPs have a resource to refer a patient for anal disease, they may be more inclined to assess for anal cancer risk factors and anal disease.

\section{Conclusions and Recommendations}

HIV PCPs were found to have high knowledge, confidence, and attitude scores towards managing all anal cancer risk factors. However, the practice score for managing risky sexual behaviors was not consistent with the high KCA scores for managing this risk factor. This finding indicated that factors other than knowledge, confidence, and attitudes might have contributed to a lesser likelihood of managing risky sexual behaviors. The lack of resources related to screening for risky sexual behaviors and intervening to reduce risky sexual behaviors was hypothesized as one reason to explain this finding. Using the theory of planned behavior, the barriers to addressing anal health were also hypothesized to have a major impact on why risky sexual behaviors were less likely to be addressed. The barriers that might have contributed to this finding included issues like the lack of time, the demand of other issues, the lack of anal health complaints, personal embarrassment, and issues related to gender discordance.

When a population is at an increased risk for a health problem, efforts are usually directed at screening and intervening to prevent that health problem. For example, The United States Preventive Services Task Force recommends screening for colorectal cancer beginning at age 50 and continuing to age 75 because there is an increased risk for 
colorectal cancer at age 50 (U.S. Preventive Services Task Force, 2008). Lung cancer screening is recommended for patients at increased risk: adults ages 55-80 with 30 pack year history and currently smoke or have quit within past 15 years (U.S. Preventive Services Task Force, 2013). There is even a grade A recommendation to ask all adults and adolescents about tobacco use and provide cessation interventions as tobacco is a risk factor for a number of healthcare conditions (U.S. Preventive Services Task Force, 2014). Just as evidence has shown that people greater than or equal to 50 years old are at an increased risk for colorectal cancer and that smoking is a major risk factor for a number of healthcare conditions, evidence has also showed that PLWHA are at an increased risk for anal cancer. Even though there are no randomized trials to indicate the effectiveness of anal cancer screening and treatment (Darragh \& Winkler, 2011), and there are wide variations in the sensitivity and specificity of the anal Pap smear tool (Bean \& Chhieng, 2010), the risk for anal cancer is still disproportionately higher in specific patient populations indicating that this disease should not be overlooked. Risk factors for anal cancer should be assessed and managed as a way to address anal health in HIV primary care until further studies related to anal cancer screening and treatment are conducted. National, state, and local efforts should be directed at aiding providers to screen for anal cancer risk factors and intervene to reduce those risk factors.

A greater focus should be on the management of risky sexual behaviors as providers were less likely to practice towards managing this risk factor when compared to smoking and non-adherence to ART. Limited resources related to the management of sexual health and anal health may contribute to poor ACRFM. Therefore, an improvement in the quantity and quality of resources related to anal health is required. Resource guides for patients and providers specific to anal cancer and risk factors for anal cancer may aid in improving how this disease is addressed in HIV primary care. Resources guides for providers may be helpful if they include ways to screen for each anal cancer risk factor and ways to intervene with special emphasis on risky sexual behaviors. Implications for future practice include the development of resource guides related to ACRFM or modifications to current resource guides related to anal cancer. Future research should also be directed at making evidence based recommendations towards screening and intervening for all anal cancer risk factors with special emphasis on screening and intervening for risky sexual behaviors.

Barriers to addressing anal health were also identified as possible reasons that providers were less likely to practice towards managing risky sexual behaviors. Since participants identified external issues like time constraints and the demand of other issues as a limiting factor to discussing anal health with patients, one recommendation to consider is implementation of a preventive health visit as a component of HIV primary care. The lack of anal health complaints as a barrier to addressing anal health also identified the need to address anal health as part of preventive health rather than waiting on a patient to present with symptoms. The purpose of preventive health is "the promotion of health that fosters wellness in general and thus reduces the likelihood of disease, disability, and premature death in a nonspecific manner, as well as specific protection against the inception of disease" (Katz \& Ali, 2009, p. 3). In the HIV primary care setting, the HIV PCP plays a major role in promoting healthy behaviors related to 
anal cancer. Rosa-Cunha and colleagues (2010) stated that meeting with PLWHA six times per year is a great opportunity to address issues related to anal health (Rosa-Cunha et al., 2010), and it is recommended that at least one of those six visits be dedicated to preventive health. HIV primary care clinics should be encouraged to consider implementing a separate preventive health visit in order to address anal health in this population. This would also create an equal opportunity for both men and women to have their anal health addressed, as providers in this study indicated that anal health was easier to discuss with women during their cervical Pap exams.

When providers address anal health and risk factors for anal disease, this is a form of preventive health. The issue is that time is a common barrier to care. The United States Preventive Services Task Force has already recommended a number of recommendations for providers that require very large amounts of time (Yarnall et al., 2003), so it may be difficult to implement another task into a routine primary care visit such as addressing sexual health especially when this topic is not an A graded recommendation. Preventive health visits should be separate from complaint-based visits and routine HIV primary care in that they are prevention focused, not problem focused. These separate visits would allow the HIV PCP or even other members of the healthcare team such as nurses, behavioral specialists, dieticians, and etc. to address a number of risk factors for a number of different diseases, including anal cancer. HIV clinics should consider the impact of a separate preventive health visit and should be creative in their methods of preventive health such as using risk reduction strategies in focus group type settings. Focus groups may be a more cost-effective method to introduce preventive health visits. A separate preventive health visit may also help to alleviate personal embarrassment related to addressing anal health. It is believed that providers may not be comfortable discussing a topic as sensitive and as complex as anal health within a 15 minute visit when more acute issues are taking precedence or if the patient has not presented with anal complaints. Implementation of preventive health visits may have an impact on embarrassment level as providers would have more time, a more informal setting, and the absence of competing demands to focus on the sensitivity and complexity of anal health.

In America's plan for better health and wellness, increasing the focus of prevention is a top priority (CDC, 2014d). Two of the seven priority areas include tobacco free living and an improvement in sexual health (CDC, 2014d). These two recommendations are pertinent to the prevention of anal cancer as smoking and risky sexual behaviors have been identified as risk factors for anal cancer. It therefore becomes important for future researchers to collaborate with the National Prevention Council to support and achieve the goals of the National Prevention Strategy with regard to a specific disease process and specific patient population: anal cancer in PLWHA. This can be accomplished with a goal to make preventive health a standard in HIV primary care in order to address specific risk factors for anal cancer.

Personal issues of perceived control like embarrassment, comfort level, and issues related to gender discordance could be addressed through an improvement in sexual health education. Coleman and colleagues (2013) have considered sexual health education to be a crisis in medical school (Coleman et al., 2013), and other providers 
have identified the lack of training and education as a barrier to addressing sexual health (Gott, Galena, et al., 2004; Hinchliff et al., 2005; Humphery \& Nazareth, 2001; Stokes \& Mears, 2000). This indicates that an improvement in sexual health education is still needed in order to improve sexual health and anal health in HIV primary care, especially with regard to some of the personal embarrassment issues that providers may have. The moderately positive relationship that existed between providers' knowledge about managing risky sexual behaviors and their practices toward risky sexual behaviors also indicated the importance of sexual health and anal health education for HIV primary care providers.

Ford (2013) believes that sexual health should become a priority on three levels: undergraduate clinical education, postgraduate residency training, and continuing education (Ford et al., 2013). Ways to make sexual health a priority on these levels include having faculty interested in implementing sexual health courses, including sexual health check-offs as part of residency programs, and creating continuing education opportunities for providers through courses and workshops (Ford et al., 2013). Other recommendations include increasing the presence of sexual health and LGBT issues in the curricula of undergraduate and graduate healthcare training programs and requiring state and national licensing programs to assess for sexual health competencies during examinations. Programs and agencies such as the National Network of STD/HIV Prevention Training Centers, AIDS Education and Training Centers, Centers for Disease Control, and Health Resources and Services Administration should be encouraged to develop sexual health training programs, develop conferences specifically related to sexual health education and training for students and healthcare providers, and offer continuing education credits. There must be an increased effort across the nation to improve the sexual health training of healthcare providers in order to improve how sexual health, risky sexual behaviors, and anal health are addressed in HIV primary care. As providers become more exposed to sexual health and anal health in their training programs, this may have an impact on reducing their embarrassment with the topics.

Courses similar to the online Sexual Health Leadership course provided by the American Medical Student Association (American Medical Student Association, n.d. ) would be a good start in implementing sexual health into the curricula of healthcare training programs. The course begins with exploring sexual attitudes and comfort with discussing sexuality, and other topics include communication about sexuality, taking a sexual history, components of sexual health, cross-cultural aspects of sexuality, safer sex guidelines, sexual health promotion, and etc. (Coleman, 2014). Course content similar to the Sexual Health Leadership course has only been implemented at four medical training programs in the U.S. (Coleman et al., 2013). Future research should be directed at understanding the percentage of healthcare training programs that have sexual health courses similar to the Sexual Health Leadership course, understanding the impact of the courses in enhancing knowledge, confidence, and attitudes towards managing sexual health, and then moving towards an increase in the proportion of healthcare training programs that offer sexual health courses to their students. It would also be important to know if anal health is part of the sexual health training programs. If training fails to include anal health, programs should be encouraged to include it in order to promote 
comprehensive sexual health education. Other recommendations to increase students' exposure to anal health include the discussion of sexual health and anal health in simulated environments, language modules on the appropriate language to use with patients from diverse backgrounds in regards to sexual health and anal health, and handson experience such as crucial conversations between students and volunteers from diverse patient backgrounds in the discussion of anal health. Improved exposure to sexual health and anal health is expected to have an impact on reducing some of the personal barriers associated with managing anal health in HIV primary care. Efforts should be aimed at improving sexual health and anal health in healthcare training programs for students and as continuing education opportunities for healthcare providers. 


\section{LIST OF REFERENCES}

AIDS Education and Training Centers. (2006 ). Clinical manual for the management of the HIV-infected adult from http://media.mycme.com/documents/15/aetc clinical_management 3629.pdf

Ajzen, I. (1991). The theory of planned behavior Organizational Behavior and Human Decision Processes 50, 179-211.

Ajzen, I. (2006). TPB diagram from http://people.umass.edu/aizen/tpb.diag.html

Ajzen, I. (n.d.). Interventions based on the theory of planned behavior from http://people.umass.edu/aizen/pdf/tpb.intervention.pdf

American Cancer Society. (2014). Anal cancer from http://www.cancer.org/acs/groups/cid/documents/webcontent/003083-pdf.pdf

American Medical Student Association. (n.d. ). Sexual health leadership course from http://www.amsa.org/AMSA/Homepage/EducationCareerDevelopment/AMSAAc ademy/SHLC.aspx

American Social Health Association. (1994). Finding the words: How to communicate about sexual health Triangle Park, NC American Social Health Association

American Society of Colon \& Rectal Surgeons. (2012). Anal cancer from http://www.fascrs.org/patients/conditions/anal cancer/

Amoroso, C., Hobbs, C., \& Harris, M. F. (2005). General practice capacity for behavioural risk factor managment: A SNAP-shot of a needs assessment in Australia. Australian Journal of Primary Health 11(2), 120-126

Association of Reproductive Health Professionals. (2010). Talking with patients about sexuality and sexual health from https://http://www.arhp.org/publications-andresources/clinical-fact-sheets/shf-talking

Bean, S. M., \& Chhieng, D. C. (2010). Anal-rectal cytology: The other pap test LABMEDICINE 41, 168-171. doi: 10.1309/LMHYS464MYWZOXFW

Bentzen, A. G., Balteskard, L., Wanderas, E. H., Frykholm, G., Wilsgaard, T., Dahl, O., \& Guren, M. G. (2013). Impaired health-related quality of life after chemoradiotherapy for anal cancer: Late effects in a national cohort of 128 survivors. Acta Oncol, 52(4), 736-744. doi: 10.3109/0284186X.2013.770599

Berman, L., Berman, J., Felder, S., Pollets, D., Chhabra, S., Miles, M., \& Powell, J. A. (2003). Seeking help for sexual function complaints: What gynecologists need to know about the female patient's experience. [Review]. Fertil Steril, 79(3), 572576.

Berry, J. M., \& Palefsky, J. M. (2009). Invited commentary. [Comment]. Dis Colon Rectum, 52(11), 1860-1863. doi: 10.1097/01.dcr.0000361970.30352.e0

Bertakis, K. D. (2009). The influence of gender on the doctor-patient interaction. [Review]. Patient Educ Couns, 76(3), 356-360. doi: 10.1016/j.pec.2009.07.022

Black AIDS Institute. (2012). Back of the line: The state of AIDS among black gay men in america, from http://www.blackaids.org/docs/back.pdf 
Bull, S. S., Rietmeijer, C., Fortenberry, J. D., Stoner, B., Malotte, K., VanDevanter, N., . . . Hook, E. W., 3rd. (1999). Practice patterns for the elicitation of sexual history, education, and counseling among providers of STD services: Results from the gonorrhea community action project (GCAP). [Research Support, U.S. Gov't, P.H.S.]. Sex Transm Dis, 26(10), 584-589.

Burd, I. D., Nevadunsky, N., \& Bachmann, G. (2006). Impact of physician gender on sexual history taking in a multispecialty practice. [Comparative Study]. J Sex Med, 3(2), 194-200. doi: 10.1111/j.1743-6109.2005.00168.x

Campion, E. W. (2001). A symptom of discontent. [Comment Editorial]. N Engl J Med, 344(3), 223-225. doi: 10.1056/NEJM200101183440311

CDC. (2003). Incorporating HIV prevention into the medical care of persons living with HIV. Recommendations of CDC, the Health Resources and Services Administration, the National Institutes of Health, and the HIV Medicine Association of the Infectious Diseases Society of America. [Guideline Practice Guideline]. MMWR Recomm Rep, 52(RR-12), 1-24.

CDC. (2010). A report of the surgeon general: How tobacco smoke causes disease from http://www.cdc.gov/tobacco/data_statistics/sgr/2010/consumer_booklet/pdfs/cons umer.pdf

CDC. (2012). Number of HPV-associated cancer cases per year from http://www.cdc.gov/cancer/hpv/statistics/cases.htm

CDC. (2013). HIV, STD, and unintended pregnancy prevention Adolescent and school health from http:/www.cdc.gov/healthyyouth/partners/funded/hiv.htm

CDC. (2014a). Health care professionals: Help your patients quit smoking from http://www.cdc.gov/tobacco/campaign/tips/partners/health/hcp/

CDC. (2014b). Health effects of cigarette smoking from http://www.cdc.gov/tobacco/data_statistics/fact_sheets/health_effects/effects_cig smoking/

CDC. (2014c). HIV among gay and bisexual men from http://www.cdc.gov/hiv/risk/gender/msm/facts/index.html

CDC. (2014d). National prevention strategy: American's plan for better health and wellness from http://www.cdc.gov/features/preventionstrategy/

CDC. (2014e). Social determinants of health from http://www.cdc.gov/socialdeterminants/FAQ.html

Center for AIDS Prevention Studies (CAPS). (n.d.). Enhancing prevention with positives evaluation center (EPPEC) from http://caps.ucsf.edu/enhancing-prevention-withpositives-evaluation-center-eppec

Centers for Disease Control and Prevention. (2012). Genital HPV infection fact sheet from http://www.cdc.gov/std/hpv/stdfact-hpv.htm

Chiao, E. Y., Giordano, T. P., Palefsky, J. M., Tyring, S., \& El Serag, H. (2006). Screening HIV-infected individuals for anal cancer precursor lesions: A systematic review. [Research Support, N.I.H., Extramural Review]. Clin Infect Dis, 43(2), 223-233. doi: 10.1086/505219

Coleman, E. (2014). Sexual health education in medical school: A comprehensive curriculum. Virtual Mentor, 16(11), 903-908. doi: 10.1001/virtualmentor.2014.16.11.medu1-1411 
Coleman, E., Elders, J., Satcher, D., Shindel, A., Parish, S., Kenagy, G., . . . Light, A. (2013). Summit on medical school education in sexual health: Report of an expert consultation. [Research Support, Non-U.S. Gov't]. J Sex Med, 10(4), 924-938. doi: $10.1111 /$ jsm.12142

Cranston, R. D., Hirschowitz, S. L., Cortina, G., \& Moe, A. A. (2008). A retrospective clinical study of the treatment of high-grade anal dysplasia by infrared coagulation in a population of HIV-positive men who have sex with men. [Evaluation Studies]. Int J STD AIDS, 19(2), 118-120. doi: 10.1258/ijsa.2007.005665

Daling, J. R., Madeleine, M. M., Johnson, L. G., Schwartz, S. M., Shera, K. A., Wurscher, M. A., . . . McDougall, J. K. (2004). Human papillomavirus, smoking, and sexual practices in the etiology of anal cancer. [Research Support, Non-U.S. Gov't Research Support, U.S. Gov't, P.H.S.]. Cancer, 101(2), 270-280. doi: 10.1002/cncr.20365

Darragh, T. M., \& Winkler, B. (2011). Anal cancer and cervical cancer screening: Key differences. [Review]. Cancer Cytopathol, 119(1), 5-19. doi: 10.1002/cncy.20126

Das, P., Cantor, S. B., Parker, C. L., Zampieri, J. B., Baschnagel, A., Eng, C., . . C Crane, C. H. (2010). Long-term quality of life after radiotherapy for the treatment of anal cancer. [Research Support, N.I.H., Extramural]. Cancer, 116(4), 822-829. doi: 10.1002/cncr.24906

Davis-Michaud, M., Yurk, R., Lansky, D., Asch, S., \& Wu, A. W. (2004). Quality care for people with HIV/AIDS: Patients' perspectives. [Research Support, Non-U.S. Gov't Research Support, U.S. Gov't, P.H.S.]. HIV Clin Trials, 5(6), 406-415.

Deeks, S. G., Lewin, S. R., \& Havlir, D. V. (2013). The end of AIDS: HIV infection as a chronic disease. [Research Support, N.I.H., Extramural Research Support, NonU.S. Gov't Review]. Lancet, 382(9903), 1525-1533. doi: 10.1016/S01406736(13)61809-7

Duncan, K. C., Chan, K. J., Chiu, C. G., Montaner, J. S., Coldman, A. J., Cescon, A., . . Press, N. M. (2015). HAART slows progression to anal cancer in HIV-infected MSM. AIDS, 29(3), 305-311. doi: 10.1097/QAD.0000000000000537

Eliason, M. J., \& Schope, R. (2001). Does "don't ask don't tell" apply to health care? Lesbian, Gay, and Bisexual people's disclosure to health care providers. . Journal of the Gay and Lesbian Medical Association, 5(4), 19-34.

Fiore, M. C., Jaen, C. R., Baker, T. B., \& al., e. (2008). Treating tobacco use and dependence: 2008 Update. Clincial practice guideline. Rockville, MD: U.S. Department of Health \& Human Services.

Ford, J. V., Barnes, R., Rompalo, A., \& Hook, E. W., 3rd. (2013). Sexual health training and education in the U.S. [Research Support, U.S. Gov't, Non-P.H.S. Research Support, U.S. Gov't, P.H.S.]. Public Health Rep, 128 Suppl 1, 96-101.

Franco, E. L., Villa, L. L., Sobrinho, J. P., Prado, J. M., Rousseau, M. C., Desy, M., \& Rohan, T. E. (1999). Epidemiology of acquisition and clearance of cervical human papillomavirus infection in women from a high-risk area for cervical cancer. [Research Support, U.S. Gov't, P.H.S.]. J Infect Dis, 180(5), 1415-1423. doi: $10.1086 / 315086$ 
Frisch, M., Biggar, R. J., \& Goedert, J. J. (2000). Human papillomavirus-associated cancers in patients with human immunodeficiency virus infection and acquired immunodeficiency syndrome. [Multicenter Study Research Support, Non-U.S. Gov't Research Support, U.S. Gov't, Non-P.H.S. Research Support, U.S. Gov't, P.H.S.]. J Natl Cancer Inst, 92(18), 1500-1510.

Frisch, M., Glimelius, B., van den Brule, A. J., Wohlfahrt, J., Meijer, C. J., Walboomers, J. M., . . Melbye, M. (1997). Sexually transmitted infection as a cause of anal cancer. [Research Support, Non-U.S. Gov't]. N Engl J Med, 337(19), 1350-1358. doi: 10.1056/NEJM199711063371904

Galletly, C., Lechuga, J., Layde, J. B., \& Pinkerton, S. (2010). Sexual health curricula in U.S. medical schools: Current educational objectives. Acad Psychiatry, 34(5), 333-338. doi: 10.1176/appi.ap.34.5.333

Glanz, K., Rimer, B. K., \& Viswanath, K. (2008). Health behavior and health education: Theory, reserach, and practice (4 ed.). San Francisco: CA Jossey-Bass Publishers

Goldstone, S. E., Hundert, J. S., \& Huyett, J. W. (2007). Infrared coagulator ablation of high-grade anal squamous intraepithelial lesions in HIV-negative males who have sex with males. [Research Support, Non-U.S. Gov't]. Dis Colon Rectum, 50(5), 565-575. doi: 10.1007/s10350-006-0874-x

Goldstone, S. E., Kawalek, A. Z., \& Huyett, J. W. (2005). Infrared coagulator: A useful tool for treating anal squamous intraepithelial lesions. [Research Support, NonU.S. Gov't]. Dis Colon Rectum, 48(5), 1042-1054. doi: 10.1007/s10350-0040889-0

Goold, S. D., \& Lipkin, M. (1999). The doctor-patient relationship. J Gen Intern Med, 14(Suppl 1 ), S26-S33. doi: 10.1046/j.1525-1497.1999.00267.x

Gott, M., Galena, E., Hinchliff, S., \& Elford, H. (2004). "Opening a can of worms": GP and practice nurse barriers to talking about sexual health in primary care. [Research Support, Non-U.S. Gov't]. Fam Pract, 21(5), 528-536. doi: 10.1093/fampra/cmh509

Gott, M., Hinchliff, S., \& Galena, E. (2004). General practitioner attitudes to discussing sexual health issues with older people. [Research Support, Non-U.S. Gov't]. Soc Sci Med, 58(11), 2093-2103. doi: 10.1016/j.socscimed.2003.08.025

Guthrie, C. (1999). Nurses' perceptions of sexuality relating to patient care. J Clin Nurs, $8(3), 313-321$.

Harris, M., Davies, G. P., Williams, A., Eames-Brown, R., \& Amoroso, C. (n.d.). Lifestyle risk factor survey: Community health from http://cphce.unsw.edu.au/sites/default/files/uploads/Baseline_survey_pdf

Health Resources and Services Administration. (n.d.). Prevention with HIV-infected persons seen in primary care settings from http://hab.hrsa.gov/abouthab/special/primarycaresettings.html

Hiestand, K. R., Horne, S. G., \& Levitt, H. M. (2007). Effects of gender identity on experiences of healthcare for sexual minority women. $J$ LGBT Health Res, 3(4), $15-27$.

Hinchliff, S., Gott, M., \& Galena, E. (2005). 'I daresay I might find it embarrassing': General practitioners' perspectives on discussing sexual health issues with lesbian and gay patients. [Research Support, Non-U.S. Gov't]. Health Soc Care Community, 13(4), 345-353. doi: 10.1111/j.1365-2524.2005.00566.x 
Ho, G. Y., Bierman, R., Beardsley, L., Chang, C. J., \& Burk, R. D. (1998). Natural history of cervicovaginal papillomavirus infection in young women. [Research Support, Non-U.S. Gov't Research Support, U.S. Gov't, P.H.S.]. N Engl J Med, 338(7), 423-428. doi: 10.1056/NEJM199802123380703

Holly, E. A., Ralston, M. L., Darragh, T. M., Greenblatt, R. M., Jay, N., \& Palefsky, J. M. (2001). Prevalence and risk factors for anal squamous intraepithelial lesions in women. [Research Support, U.S. Gov't, P.H.S.]. J Natl Cancer Inst, 93(11), 843 849.

Hubbard, D. (2009). The failure of risk management: Why it's broken and how to fix it. Hoboken, NJ: John Wiley \& Sons

Hughes, A. K. (2013). Mid-to-late-life women and sexual health: Communication with health care providers. [Research Support, N.I.H., Extramural Research Support, Non-U.S. Gov't]. Fam Med, 45(4), 252-256.

Humphery, S., \& Nazareth, I. (2001). GPs' views on their management of sexual dysfunction. [Research Support, Non-U.S. Gov't]. Fam Pract, 18(5), 516-518.

Institute of Medicine. (2011). The health of lesbian, gay, bisexual, and transgender people: Building a foundation for better understanding Washington, DC: The National Academies Press

Johnson, L. G., Madeleine, M. M., Newcomer, L. M., Schwartz, S. M., \& Daling, J. R. (2004). Anal cancer incidence and survival: The surveillance, epidemiology, and end results experience, 1973-2000. Cancer, 101(2), 281-288. doi:

10.1002/cncr.20364

Katz, D. L., \& Ali, A. (2009). Preventive medicine, integrative medicine, and the health of the public from http://www.iom.edu/ /media/Files/Activity

Files/Quality/IntegrativeMed/Preventive Medicine Integrative Medicine and the Health of the Public.pdf

Kim, J. H., Sarani, B., Orkin, B. A., Young, H. A., White, J., Tannebaum, I., . . . Bennett, B. (2001). HIV-positive patients with anal carcinoma have poorer treatment tolerance and outcome than HIV-negative patients. [Comparative Study]. Dis Colon Rectum, 44(10), 1496-1502.

King, W. D. (2003). Examining African Americans' mistrust of the health care system: Expanding the research question. Commentary on "Race and trust in the health care system". [Comment]. Public Health Rep, 118(4), 366-367.

Lam, J. M., Hoch, J. S., Tinmouth, J., Sano, M., Raboud, J., \& Salit, I. E. (2011). Costeffectiveness of screening for anal precancers in HIV-positive men. [Research Support, Non-U.S. Gov't]. AIDS, 25(5), 635-642. doi: 10.1097/QAD.0b013e3283434594

LaVeist, T. A., Nickerson, K. J., \& Bowie, J. V. (2000). Attitudes about racism, medical mistrust, and satisfaction with care among African American and white cardiac patients. [Comparative Study Research Support, Non-U.S. Gov't Research Support, U.S. Gov't, P.H.S.]. Med Care Res Rev, 57 Suppl 1, 146-161.

Laws, R. A., Kirby, S. E., Davies, G. P., Williams, A. M., Jayasinghe, U. W., Amoroso, C. L., \& Harris, M. F. (2008). "Should I and can I?" A mixed methods study of clinician beliefs and attitudes in the management of lifestyle risk factors in primary health care. [Comparative Study]. BMC Health Serv Res, 8, 44. doi: $10.1186 / 1472-6963-8-44$ 
Lejuez, C. W., Simmons, B. L., Aklin, W. M., Daughters, S. B., \& Dvir, S. (2004). Risktaking propensity and risky sexual behavior of individuals in residential substance use treatment. [Research Support, U.S. Gov't, P.H.S.]. Addict Behav, 29(8), 16431647. doi: 10.1016/j.addbeh.2004.02.035

Martinez, L. (n.d. ). The women's sexual health foundation from http://www.womenshealthresearch.org/site/DocServer/DC briefing_HSDD and FSD 10- 2009 st.pdf?docID $=2944$

Mathews, C., Caperna, J., Cachay, E. R., \& Cosman, B. (2007). Early impact and performance characteristics of an established anal dysplasia screening program: Program evaluation considerations. Open AIDS J, 1, 11-20. doi: $10.2174 / 1874613600701010011$

Mechanic, D., McAlpine, D. D., \& Rosenthal, M. (2001). Are patients' office visits with physicians getting shorter? [Research Support, Non-U.S. Gov't]. N Engl J Med, 344(3), 198-204. doi: 10.1056/NEJM200101183440307

Melbye, M., Cote, T. R., Kessler, L., Gail, M., \& Biggar, R. J. (1994). High incidence of anal cancer among AIDS patients. The AIDS/Cancer Working Group. [Research Support, Non-U.S. Gov't Research Support, U.S. Gov't, P.H.S.]. Lancet, 343(8898), 636-639.

Melbye, M., Rabkin, C., Frisch, M., \& Biggar, R. J. (1994). Changing patterns of anal cancer incidence in the United States, 1940-1989. [Research Support, Non-U.S. Gov't]. Am J Epidemiol, 139(8), 772-780.

Melbye, M., Smith, E., Wohlfahrt, J., Osterlind, A., Orholm, M., Bergmann, O. J., . . . Palefsky, J. M. (1996). Anal and cervical abnormality in women--prediction by human papillomavirus tests. [Research Support, Non-U.S. Gov't Research Support, U.S. Gov't, P.H.S.]. Int J Cancer, 68(5), 559-564. doi: 10.1002/(SICI)1097-0215(19961127)68:5<559::AID-IJC1>3.0.CO;2-Y

Melbye, M., \& Sprogel, P. (1991). Aetiological parallel between anal cancer and cervical cancer. [Comparative Study Research Support, Non-U.S. Gov't]. Lancet, 338(8768), 657-659.

Memphis Ryan White Program. (2013). Ryan White legislation from http://www.hivmemphis.org/about/legislation

Metsch, L. R., Pereyra, M., Colfax, G., Dawson-Rose, C., Cardenas, G., McKirnan, D., \& Eroglu, D. (2008). HIV-positive patients' discussion of alcohol use with their HIV primary care providers. [Research Support, U.S. Gov't, P.H.S.]. Drug Alcohol Depend, 95(1-2), 37-44. doi: 10.1016/j.drugalcdep.2007.12.006

Moscicki, A. B., Ellenberg, J. H., Farhat, S., \& Xu, J. (2004). Persistence of human papillomavirus infection in HIV-infected and -uninfected adolescent girls: Risk factors and differences, by phylogenetic type. [Research Support, U.S. Gov't, P.H.S.]. J Infect Dis, 190(1), 37-45. doi: 10.1086/421467

Moscicki, A. B., Shiboski, S., Broering, J., Powell, K., Clayton, L., Jay, N., . . Palefsky, J. (1998). The natural history of human papillomavirus infection as measured by repeated DNA testing in adolescent and young women. [Research Support, NonU.S. Gov't Research Support, U.S. Gov't, P.H.S.]. J Pediatr, 132(2), 277-284.

National Cancer Institute. (2010). Cervical Cancer from http://www.cancer.gov/cancertopics/factsheet/cancer-advances-in-focus/cervical 
National Cancer Institute. (2014). High-risk sexual behavior topic overview, from http://www.webmd.com/sex/tc/high-risk-sexual-behavior-topic-overview

National Cancer Institute. (n.d. ). SEER stat fact sheets: Anal cancer from http://seer.cancer.gov/statfacts/html/anus.html

National Institute of Health. (2013 ). Cervical cancer from http://report.nih.gov/nihfactsheets/viewfactsheet.aspx?csid=76

National Sexual Violence Resource Center. (2011). Assessing patients for sexual violence: A guide for healthcare providers from http://www.nsvrc.org/sites/default/files/Publications NSVRC Guides Assessingpatients-for-sexual-violence.pdf

National Tobacco Cessation Collaborative. (2011). Tools you can use from http://www.tobacco-cessation.org/resources/tools.html - clinicians

Obedin-Maliver, J., Goldsmith, E. S., Stewart, L., White, W., Tran, E., Brenman, S., . . . Lunn, M. R. (2011). Lesbian, gay, bisexual, and transgender-related content in undergraduate medical education. [Research Support, Non-U.S. Gov't]. JAMA, 306(9), 971-977. doi: 10.1001/jama.2011.1255

Office of the Medical Director and New York State Department of Health AIDS Institute in collaboration with the Johns Hopkins University Division of Infectious Diseases. (2007). Anal dysplasia and cancer from http://www.hivguidelines.org/clinical-guidelines/adults/anal-dysplasia-andcancer/

Oscos-Sanchez, M. A., White, D., Bajorek, E., Dahlman, M., Albright, T., Trevino, J., \& Burge, S. K. (2008). SAFE TEENS: facilitators of and barriers to adolescent preventive care discussions. Fam Med, 40(2), 125-131.

Palefsky, J. M., Holly, E. A., Hogeboom, C. J., Berry, J. M., Jay, N., \& Darragh, T. M. (1997). Anal cytology as a screening tool for anal squamous intraepithelial lesions. [Research Support, Non-U.S. Gov't Research Support, U.S. Gov't, P.H.S.]. J Acquir Immune Defic Syndr Hum Retrovirol, 14(5), 415-422.

Palefsky, J. M., Holly, E. A., Ralston, M. L., Arthur, S. P., Jay, N., Berry, J. M., . . . Darragh, T. M. (1998). Anal squamous intraepithelial lesions in HIV-positive and HIV-negative homosexual and bisexual men: Prevalence and risk factors. [Research Support, U.S. Gov't, P.H.S.]. J Acquir Immune Defic Syndr Hum Retrovirol, 17(4), 320-326.

Palefsky, J. M., Holly, E. A., Ralston, M. L., Da Costa, M., \& Greenblatt, R. M. (2001). Prevalence and risk factors for anal human papillomavirus infection in human immunodeficiency virus (HIV)-positive and high-risk HIV-negative women. [Research Support, U.S. Gov't, P.H.S.]. J Infect Dis, 183(3), 383-391. doi: 10.1086/318071

Pollak, K. I., Krause, K. M., Yarnall, K. S., Gradison, M., Michener, J. L., \& Ostbye, T. (2008). Estimated time spent on preventive services by primary care physicians. [Research Support, N.I.H., Extramural]. BMC Health Serv Res, 8, 245. doi: $10.1186 / 1472-6963-8-245$

Raymond, R. (2014). Caring for LGBT patients: A primer from http://thedo.osteopathic.org/2014/05/caring-for-lgbt-patients-a-primer/ 
Reynolds, N. R. (2009). Cigarette smoking and HIV: More evidence for action. [Research Support, N.I.H., Extramural Review]. AIDS Educ Prev, 21(3 Suppl), 106-121. doi: 10.1521/aeap.2009.21.3 supp.106

Rosa-Cunha, I., Cardenas, G. A., Dickinson, G., \& Metsch, L. R. (2010). Addressing anal health in the HIV primary care setting: a disappointing reality. [Research Support, N.I.H., Extramural Research Support, U.S. Gov't, P.H.S.]. AIDS Patient Care STDS, 24(9), 533-538. doi: 10.1089/apc.2010.0032

Salit, I. E., Lytwyn, A., Raboud, J., Sano, M., Chong, S., Diong, C., . . . Tinmouth, J. (2010). The role of cytology (Pap tests) and human papillomavirus testing in anal cancer screening. [Research Support, Non-U.S. Gov't]. AIDS, 24(9), 1307-1313. doi: 10.1097/QAD.0b013e328339e592

Sarkadi, A., \& Rosenqvist, U. (2001). Contradictions in the medical encounter: Female sexual dysfunction in primary care contacts. Fam Pract, 18(2), 161-166.

Schmittdiel, J., Grumbach, K., Selby, J. V., \& Quesenberry, C. P., Jr. (2000). Effect of physician and patient gender concordance on patient satisfaction and preventive care practices. [Research Support, U.S. Gov't, P.H.S.]. J Gen Intern Med, 15(11), 761-769.

Sigel, K., Dubrow, R., Silverberg, M., Crothers, K., Braithwaite, S., \& Justice, A. (2011). Cancer screening in patients infected with HIV. [Research Support, N.I.H., Extramural Review]. Curr HIV/AIDS Rep, 8(3), 142-152. doi: 10.1007/s11904011-0085-5

Silverberg, M. J., Lau, B., Justice, A. C., Engels, E., Gill, M. J., Goedert, J. J., . . . Dubrow, R. (2012). Risk of anal cancer in HIV-infected and HIV-uninfected individuals in North America. [Research Support, N.I.H., Extramural Research Support, Non-U.S. Gov't Research Support, U.S. Gov't, P.H.S.]. Clin Infect Dis, 54(7), 1026-1034. doi: 10.1093/cid/cir1012

Solursh, D. S., Ernst, J. L., Lewis, R. W., Prisant, L. M., Mills, T. M., Solursh, L. P., . . . Salazar, W. H. (2003). The human sexuality education of physicians in North American medical schools. Int J Impot Res, 15 Suppl 5, S41-45. doi: 10.1038/sj.ijir.3901071

Song, Z., Sequist, T. D., \& Barnett, M. L. (2014). Patient referrals: A linchpin for increasing the value of care. [Research Support, N.I.H., Extramural]. JAMA, 312(6), 597-598. doi: 10.1001/jama.2014.7878

Stein, G. L., \& Bonuck, K. A. (2001a). Attitudes on end-of-life care and advance care planning in the lesbian and gay community. [Research Support, Non-U.S. Gov't]. $J$ Palliat Med, 4(2), 173-190.

Stein, G. L., \& Bonuck, K. A. (2001b). Physician-Patient relationships among the lesbian and gay community Journal of the Gay and Lesbian Medical Association 5(3), 87-93.

Stier, E. A., Goldstone, S. E., Berry, J. M., Panther, L. A., Jay, N., Krown, S. E., . . Palefsky, J. M. (2008). Infrared coagulator treatment of high-grade anal dysplasia in HIV-infected individuals: An AIDS malignancy consortium pilot study. [Multicenter Study Research Support, N.I.H., Extramural]. J Acquir Immune Defic Syndr, 47(1), 56-61. doi: 10.1097/QAI.0b013e3181582d93

Stokes, T., \& Mears, J. (2000). Sexual health and the practice nurse: A survey of reported practice and attitudes. Br J Fam Plann, 26(2), 89-92. 
Tashakkori, A., \& Teddlie, C. (2003). Handbook of mixed methods in social and behavioral research Thousand Oaks, CA: Sage.

Temple-Smith, M., Hammond, J., Pyett, P., \& Presswell, N. (1996). Barriers to sexual history taking in general practice. [Research Support, Non-U.S. Gov't]. Aust Fam Physician, 25(9 Suppl 2), S71-74.

The Henry J. Kaiser Family Foundation. (2014). 15-Minute visits take a toll on the doctor-patient relationship from http://kaiserhealthnews.org/news/15-minutedoctor-visits/

Tilston, P. (1997). Anal human papillomavirus and anal cancer. [Review]. J Clin Pathol, 50(8), 625-634.

Trust for America's Health. (2014). Addressing the social determinants of health inequities among gay men and other men who have sex with men in the United States, from http://healthyamericans.org/assets/files/TFAH-2014-MSM-Reportfinal.pdf

U.S. Department of Health \& Human Services. (2009). Overview of HIV treatments from https://http://www.aids.gov/hiv-aids-basics/just-diagnosed-with-hivaids/treatment-options/overview-of-hiv-treatments/

U.S. Department of Health \& Human Services. (2012). Lesbian and bisexual health fact sheet from http://womenshealth.gov/publications/our-publications/factsheet/lesbian-bisexual-health.html

U.S. Department of Health and Human Services. Office of Disease Prevention and Health Promotion. Healthy People 2020. (n.d. ). Determinants of health from https://http://www.healthypeople.gov/2020/about/foundation-healthmeasures/Determinants-of-Health

U.S. Department of Veterans Affairs. (2011). Prevention for positives from http://www.hiv.va.gov/provider/manual-primary-care/prevention-for-positives.asp

U.S. Preventive Services Task Force. (2008). Colorectal cancer: Screening from http://www.uspreventiveservicestaskforce.org/Page/Topic/recommendationsummary/colorectal-cancer-screening

U.S. Preventive Services Task Force. (2009). Tobacco use in adults and pregnant women: Counseling and interventions from http://www.uspreventiveservicestaskforce.org/Page/Topic/recommendationsummary/tobacco-use-in-adults-and-pregnant-women-counseling-andinterventions

U.S. Preventive Services Task Force. (2012). Cervical cancer: Screening from http://www.uspreventiveservicestaskforce.org/Page/Topic/recommendationsummary/cervical-cancer-screening

U.S. Preventive Services Task Force. (2013). Lung cancer: Screening from http://www.uspreventiveservicestaskforce.org/Page/Topic/recommendationsummary/lung-cancer-screening?ds $=1 \& s=$ lung cancer

U.S. Preventive Services Task Force. (2014). USPSTF A and B recommendations from http://www.uspreventiveservicestaskforce.org/Page/Name/uspstf-a-and-brecommendations/ 
Warren, G. W., Alberg, A. J., Kraft, A. S., \& Cummings, K. M. (2014). The 2014 Surgeon General's report: "The health consequences of smoking--50 years of progress": A paradigm shift in cancer care. [Editorial Research Support, Non-U.S. Gov't]. Cancer, 120(13), 1914-1916. doi: 10.1002/cncr.28695

White, J. C., \& Dull, V. T. (1997). Health risk factors and health-seeking behavior in lesbians. [Research Support, Non-U.S. Gov't]. J Womens Health, 6(1), 103-112.

Williams, A. B., Darragh, T. M., Vranizan, K., Ochia, C., Moss, A. R., \& Palefsky, J. M. (1994). Anal and cervical human papillomavirus infection and risk of anal and cervical epithelial abnormalities in human immunodeficiency virus-infected women. [Research Support, Non-U.S. Gov't Research Support, U.S. Gov't, P.H.S.]. Obstet Gynecol, 83(2), 205-211.

Wisconsin HIV Prevention Evaluation Work Group. (2000). Instructions for the behavioral risk assessment tool (BRAT) from http://www.cdc.gov/hiv/topics/evaluation/health_depts/guidance/strathandbook/pdf/Appendix 87.pdf

Wittenberg, A., \& Gerber, J. (2009). Recommendations for improving sexual health curricula in medical schools: Results from a two-arm study collecting data from patients and medical students. $J$ Sex Med, 6(2), 362-368. doi: 10.1111/j.17436109.2008.01046.x

World Health Organization. (2006 ). Sexual health from http://www.who.int/topics/sexual health/en/

World Health Organization. (2010). Developing sexual health programmes: A framework for action from http://whqlibdoc.who.int/hq/2010/WHO_RHR_HRP_10.22 eng.pdf?ua=1

World Health Organization. (2013). Consolidated guidelines on the use of antiretroviral drugs for treating and preventing HIV infection: Recommendations for a public health approach.

Yarnall, K. S., Pollak, K. I., Ostbye, T., Krause, K. M., \& Michener, J. L. (2003). Primary care: Is there enough time for prevention? [Research Support, U.S. Gov't, P.H.S.]. Am J Public Health, 93(4), 635-641. 


\section{APPENDIX A. LIFESTYLE RISK FACTOR SURVEY}

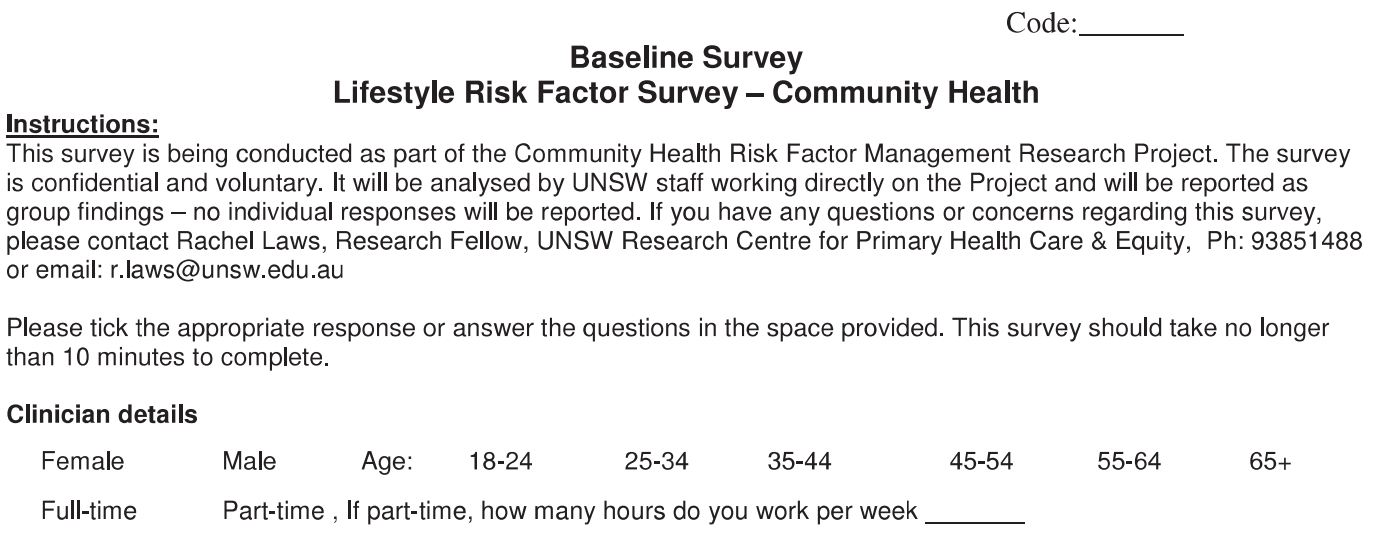

How many years have you worked in your profession?

How many years have you worked in community health?

How many years have you worked in this team/service?

Clinician type:

nurse

Allied health or other staff

Management of risk factors

1. Thinking of the new clients that you have seen over the past $\mathbf{2}$ weeks, what percentage of these clients did you ask about the following risk factors :

$\begin{array}{llllll}\text { Smoking } & \text { None } & 1-25 \% & 26-50 \% & 51-75 \% & >75 \% \\ \text { Nutrition } & \text { None } & 1-25 \% & 26-50 \% & 51-75 \% & >75 \% \\ \text { Alcohol } & \text { None } & 1-25 \% & 26-50 \% & 51-75 \% & >75 \% \\ \text { Physical Activity } & \text { None } & 1-25 \% & 26-50 \% & 51-75 \% & >75 \%\end{array}$

2. Thinking of the clients that you have seen for review appointments over the past $\mathbf{2}$ weeks, what percentage of these clients did you ask about the following risk factors :

$\begin{array}{llllll}\text { Smoking } & \text { None } & 1-25 \% & 26-50 \% & 51-75 \% & >75 \% \\ \text { Nutrition } & \text { None } & 1-25 \% & 26-50 \% & 51-75 \% & >75 \% \\ \text { Alcohol } & \text { None } & 1-25 \% & 26-50 \% & 51-75 \% & >75 \% \\ \text { Physical Activity } & \text { None } & 1-25 \% & 26-50 \% & 51-75 \% & >75 \%\end{array}$

3. Of the clients that you identified as having a lifestyle risk factor in the past 2 weeks, what percentage of these clients did you assess their readiness to change their behaviour (stage of change).

$\begin{array}{lcccccc}\text { Smokers } & \text { None } & 1-25 \% & 26-50 \% & 51-75 \% & >75 \% & \text { did not identify any smokers } \\ \text { Clients with poor nutrition } & \text { None } & 1-25 \% & 26-50 \% & 51-75 \% & >75 \% & \begin{array}{c}\text { did not identify any clients } \\ \text { with poor nutrition }\end{array} \\ \text { Clients with at risk drinking } & \text { None } & 1-25 \% & 26-50 \% & 51-75 \% & >75 \% & \begin{array}{c}\text { did not identify any clients } \\ \text { with at risk drinking }\end{array} \\ \text { Physically inactive clients } & \text { None } & 1-25 \% & 26-50 \% & 51-75 \% & >75 \% \quad \begin{array}{c}\text { did not identify any clients } \\ \text { who were physically inactive }\end{array}\end{array}$


4. Of the clients that you identified as having a lifestyle risk factor in the past 2 weeks, what percentage of these clients did you provide verbal advice to:

$\begin{array}{lllllll}\text { Smokers } & \text { None } & 1-25 \% & 26-50 \% & 51-75 \% & >75 \% & \text { did not identify any smokers } \\ \text { Clients with poor nutrition } & \text { None } & 1-25 \% & 26-50 \% & 51-75 \% & >75 \% & \begin{array}{c}\text { did not identify any clients } \\ \text { with poor nutrition }\end{array} \\ \text { Clients with at risk drinking } & \text { None } & 1-25 \% & 26-50 \% & 51-75 \% & >75 \% & \begin{array}{c}\text { did not identify any clients } \\ \text { with at risk drinking }\end{array} \\ \text { Physically inactive clients } & \text { None } & 1-25 \% & 26-50 \% & 51-75 \% & >75 \% \quad \begin{array}{c}\text { did not identify any clients } \\ \text { who were physically inactive }\end{array}\end{array}$

5. Of the clients that you identified as having a lifestyle risk factor in the past $\mathbf{2}$ weeks, what percentage of these clients did you provide written advice (eg pamphlet, summary sheet etc) to:

$\begin{array}{lcccccc}\text { Smokers } & \text { None } & 1-25 \% & 26-50 \% & 51-75 \% & >75 \% & \text { did not identify any smokers } \\ \text { Clients with poor nutrition } & \text { None } & 1-25 \% & 26-50 \% & 51-75 \% & >75 \% & \begin{array}{c}\text { did not identify any clients } \\ \text { with poor nutrition }\end{array} \\ \text { Clients with at risk drinking } & \text { None } & 1-25 \% & 26-50 \% & 51-75 \% & >75 \% & \begin{array}{c}\text { did not identify any clients } \\ \text { with at risk drinking }\end{array} \\ \text { Physically inactive clients } & \text { None } & 1-25 \% & 26-50 \% & 51-75 \% & >75 \% & \begin{array}{c}\text { did not identify any clients } \\ \text { who were physically inactive }\end{array}\end{array}$

6. Of the clients that you identified as having a lifestyle risk factor in the past 2 weeks, what percentage of these clients did you refer to other service providers/agencies or support groups (e.g. quitline) for help in managing their risk factor:

$\begin{array}{lllllll}\text { Smokers } & \text { None } & 1-25 \% & 26-50 \% & 51-75 \% & >75 \% & \text { did not identify any smokers } \\ \begin{array}{l}\text { Clients with poor nutrition } \\ \text { Clients with at risk drinking }\end{array} & \text { None } & 1-25 \% & 26-50 \% & 51-75 \% & >75 \% & \begin{array}{c}\text { did not identify any clients } \\ \text { with poor nutrition }\end{array} \\ \text { Physically inactive clients } & \text { None } & 1-25 \% & 26-50 \% & 51-75 \% & >75 \% & \begin{array}{c}\text { did not identify any clients } \\ \text { with at risk drinking }\end{array} \\ & \text { None } & 1-25 \% & 26-50 \% & 51-75 \% & >75 \% & \begin{array}{c}\text { did not identify any clients } \\ \text { who } \text { were physically inactive }\end{array}\end{array}$

7. When you provide advice about lifestyle risk factors, how much time do you estimate that you spend on average addressing each of the following:

$\begin{array}{lllllll}\text { Smoking } & 1-2 \text { mins } & 3-5 \text { mins } & 6-10 \text { mins } & 11-15 \text { mins } & \text { more than } 15 \text { mins } & \text { do not provide advice } \\ \text { Nutrition } & 1-2 \text { mins } & 3-5 \text { mins } & 6-10 \text { mins } & 11-15 \text { mins } & \text { more than } 15 \text { mins } & \text { do not provide advice } \\ \text { Alcohol } & 1-2 \text { mins } & 3-5 \text { mins } & 6-10 \text { mins } & 11-15 \text { mins } & \text { more than } 15 \text { mins } & \text { do not provide advice } \\ \text { Physical Activity } & 1-2 \text { mins } & 3-5 \text { mins } & 6-10 \text { mins } & 11-15 \text { mins } & \text { more than } 15 \text { mins } & \text { do not provide advice }\end{array}$

8. For clients that you have given advice to about their lifestyle, what percentage of these clients do you check their progress in subsequent visits (on average)?

$\begin{array}{llccccc}\text { Smokers } & \text { None } & 1-25 \% & 26-50 \% & 51-75 \% & >75 \% & \text { did not identify any smokers } \\ \text { Clients with poor nutrition } & \text { None } & 1-25 \% & 26-50 \% & 51-75 \% & >75 \% & \begin{array}{c}\text { did not identify any clients } \\ \text { with poor nutrition }\end{array} \\ \text { Clients with at risk drinking } & \text { None } & 1-25 \% & 26-50 \% & 51-75 \% & >75 \% & \begin{array}{c}\text { did not identify any clients } \\ \text { with at risk drinking }\end{array} \\ \text { Physically inactive clients } & \text { None } & 1-25 \% & 26-50 \% & 51-75 \% & >75 \% & \begin{array}{c}\text { did not identify any clients } \\ \text { who were physically inactive }\end{array}\end{array}$


9. How easy is it to find accessible services /agencies/ support programs to refer your clients to for the following? ( $1=$ very difficult, $5=$ very easy)

Very difficult

Smoking cessation

Nutrition counselling

Alcohol counselling

Physical Activity

$\begin{array}{lllll}1 & 2 & 3 & 4 & 5 \\ 1 & 2 & 3 & 4 & 5 \\ 1 & 2 & 3 & 4 & 5 \\ 1 & 2 & 3 & 4 & 5\end{array}$

\begin{abstract}
don't know
don't know

don't know

don't know
\end{abstract}

10. Please rate your knowledge in relation to each of the following ( $1=$ very poor, $5=$ excellent):

\begin{tabular}{lcccccc} 
& Very Poor & \multicolumn{3}{c}{ Excellent } \\
Assessing nicotine dependency & 1 & 2 & 3 & 4 & 5 \\
Smoking cessation recommendations & 1 & 2 & 3 & 4 & 5 \\
Assessing nutrition & 1 & 2 & 3 & 4 & 5 \\
Nutrition recommendations & 1 & 2 & 3 & 4 & 5 \\
Assessing for risk alcohol consumption & 1 & 2 & 3 & 4 & 5 \\
Recommendations for safe alcohol consumption & 1 & 2 & 3 & 4 & 5 \\
Assessing physical activity levels & 1 & 2 & 3 & 4 & 5 \\
Physical activity recommendations & 1 & 2 & 3 & 4 & 5 \\
Motivational interviewing & 1 & 2 & 3 & 4 & 5 \\
Assessing a client's readiness to change & 1 & 2 & 3 & 4 & 5 \\
Principles of adult education & 1 & 2 & 3 & 4 & 5
\end{tabular}

11. Please rate how confident you are in undertaking the following activities with clients: ( $1=$ not at all confident, 5 =very confident)

Assessing nicotine dependency
Smoking cessation recommendations
Assessing nutrition
Nutrition recommendations
Assessing for risk alcohol consumption
Recommendations for safe alcohol consumption
Assessing physical activity levels
Physical activity recommendations
Motivational interviewing
Assessing a client's readiness to change
Principles of adult education

Not at all confident

Very confident

12. Please rate how effective you think your advice is in helping clients to: ( $1=$ not at all effective, $5=$ very effective $)$

Not at all effective

$\begin{array}{lllll}\text { Give up smoking } & 1 & 2 & 3 & 4 \\ \text { Improve nutrition / eating habits } & 1 & 2 & 3 & 4 \\ \text { Reduce alcohol consumption } & 1 & 2 & 3 & 4\end{array}$

\section{Very effective}

5

do not provide advice

do not provide advice

do not provide advice 


\begin{tabular}{|c|c|c|c|c|c|c|}
\hline \multicolumn{2}{|c|}{ Become more physically active } & 1 & 2 & $\checkmark$ & 4 & do not provide advice \\
\hline \multicolumn{7}{|c|}{$\begin{array}{l}\text { 13. Clients I see find it acceptable for me to raise the following lifestyle issues routinely as part of the consultation: } \\
\text { ( } 1=\text { strongly disagree, } 5=\text { strongly agree })\end{array}$} \\
\hline \multicolumn{3}{|c|}{ Strongly Disagree } & \multicolumn{3}{|c|}{ Strongly Agree } & \\
\hline Smoking & 1 & 2 & 3 & 4 & 5 & do not discuss smoking \\
\hline Nutrition & 1 & 2 & 3 & 4 & 5 & do not discuss nutrition \\
\hline Alcohol & 1 & 2 & 3 & 4 & 5 & do not discuss alcohol consumption \\
\hline Physical Activity & 1 & 2 & 3 & 4 & 5 & do not discuss physical activity \\
\hline
\end{tabular}

14. Please rate how important you think the following lifestyle changes are for improving health ( $1=$ not at all important, $5=$ very important)

\begin{tabular}{lccccc}
\multicolumn{2}{c}{ Not at all important } & & & \multicolumn{2}{c}{ Very important } \\
Giving up smoking & 1 & 2 & 3 & 4 & 5 \\
Improving nutrition / eating habits & 1 & 2 & 3 & 4 & 5 \\
Reducing alcohol consumption & 1 & 2 & 3 & 4 & 5 \\
Becoming more physically active & 1 & 2 & 3 & 4 & 5
\end{tabular}

15. Please rate how important you think it is to address these lifestyle risk factors with the clients you see: ( $1=$ not at all important, $5=$ very important):

Not at all important

Very important

$\begin{array}{llllll}\text { Smoking cessation } & 1 & 2 & 3 & 4 & 5 \\ \text { Poor Nutrition } & 1 & 2 & 3 & 4 & 5 \\ \text { At risk alcohol consumption } & 1 & 2 & 3 & 4 & 5 \\ \text { Inadequate physical activity } & 1 & 2 & 3 & 4 & 5\end{array}$

16. How much of a work priority is it for your team/service to address lifestyle risk factors with clients as part of your normal clinical work $(1=$ very low priority, $5=$ very high priority):

Very low priority Very high priority

$\begin{array}{llllll}\text { Smoking cessation } & 1 & 2 & 3 & 4 & 5 \\ \text { Poor Nutrition } & 1 & 2 & 3 & 4 & 5 \\ \text { At risk alcohol consumption } & 1 & 2 & 3 & 4 & 5 \\ \text { Inadequate physical activity } & 1 & 2 & 3 & 4 & 5\end{array}$

\section{Education and training for risk factors}

17. In the past 12 months have you had education or training in the management of these risk factors or strategies for helping clients change their behaviour?

$\begin{array}{lll}\text { Smoking } & \text { Yes } & \text { No } \\ \text { Nutrition } & \text { Yes } & \text { No } \\ \text { Alcohol } & \text { Yes } & \text { No } \\ \text { Physical Activity } & \text { Yes } & \text { No } \\ \text { Motivational interviewing } & \text { Yes } & \text { No } \\ \text { Assessing Clients readiness to change } & \text { Yes } & \text { No }\end{array}$


18. If YES, please describe the type of education/ training you have received

19. Would you like additional education or training in these areas:

$\begin{array}{lll}\text { Assessing nicotine dependency } & \text { Yes, high priority } & \text { Yes, but not high priority } \\ \text { Smoking cessation recommendations } & \text { Yes, high priority } & \text { Yes, but not high priority } \\ \text { Assessing nutrition } & \text { Yes, high priority } & \text { Yes, but not high priority } \\ \text { Nutrition recommendations } & \text { Yes, high priority } & \text { Yes, but not high priority } \\ \text { Assessing for risk alcohol consumption } & \text { Yes, high priority } & \text { Yes, but not high priority } \\ \text { Recommendations for safe alcohol consumption } & \text { Yes, high priority } & \text { Yes, but not high priority } \\ \text { Assessing physical activity levels } & \text { Yes, high priority } & \text { Yes, but not high priority } \\ \text { Physical activity recommendations } & \text { Nes, high priority } & \text { Yes, but not high priority } \\ \text { Motivational interviewing } & \text { Nes, high priority } & \text { Yes, but not high priority } \\ \text { Assessing a client's readiness to change } & \text { Yes, high priority } & \text { Yes, but not high priority } \\ \text { Principles of adult education } & \text { Yes, high priority } & \text { Yes, but not high priority }\end{array}$

If you would like training, in what format would you like to receive it? (tick all that apply)

$\begin{array}{lll}\text { workshop } & \text { clinical supervision/mentoring } & \text { self-study materials } \\ \text { case studies } & \text { small group discussions } & \text { Other: }\end{array}$

case studies

small group discussions

Other:

20. . Any other comments:

Thank you for completing this questionnaire

Please place completed survey in the envelope provided and place in the survey box

Reprinted with permission from Mark Harris. In Harris, M., Davies, G. P., Williams, A., Eames-Brown, R., \& Amoroso, C. (n.d.). Lifestyle risk factor survey: Community health from http://cphce.unsw.edu.au/sites/default/files/uploads/Baseline_survey_pdf 


\title{
APPENDIX B. ANAL CANCER RISK FACTOR MANAGEMENT SURVEY
}

\author{
Anal Cancer Risk Factor Management Survey
}

\section{Instructions:}

This survey is being conducted as part of a dissertation project that assesses anal cancer risk factor management from the HIV primary care provider's perspective. The survey is confidential and voluntary. It will be analyzed by the principle investigator, PhDc-DNP student Crystal Walker, and will be reported as group findings- no individual responses will be reported. The survey should only take 15-20 minutes to complete. Please answer as accurately as possible. If you have any questions or concerns regarding this survey, please use the following contact information:

Crystal Walker, PhDc-DNP student

University of Tennessee Health Science Center

920 Madison Ave, \#544 Memphis, TN 38163

Phone: 601-415-3627

E-mail: cmarti47@uthsc.edu

Please check the appropriate response or answer the questions in the space provided.

\section{Clinician Details}

*Name:

*Name will be de-identified with a number assignment. Identification is needed if randomly chosen to participate in part 2 of the study: qualitative interviews.

\begin{tabular}{|c|c|c|}
\hline Sex: & & \\
\hline Age: & $18-24$ & $25-34$ \\
\hline
\end{tabular}

35-44 45-54


How many years have you worked in your profession?

How many years have you worked with persons infected with HIV/AIDs?

What zip code is your practice located in?

What is the name of your practice?

Clinician type: Advanced practice nurse

Medical doctor

Medical doctor/fellow

Physician assistant

\section{Management of Risk Factors}

1. Thinking of the new clients with HIV/AIDS that you have seen over the past $\mathbf{2}$ weeks, what percentage of these clients did you ask about the following risk factors for anal cancer:

$\begin{array}{lllllr}\text { Smoking } & \text { None } & 1-25 \% & 26-50 \% & 51-75 \% & >75 \% \\ \text { Unprotected anal sex } & \text { None } & 1-25 \% & 26-50 \% & 51-75 \% & >75 \% \\ \text { Non-adherence to ART } & \text { None } & 1-25 \% & 26-50 \% & 51-75 \% & >75 \% \\ \text { \# of lifetime sexual partners } & \text { None } & 1-25 \% & 26-50 \% & 51-75 \% & >75 \%\end{array}$

2. Thinking of the clients with HIV/AIDS that you have seen for review appointments over the past 2 weeks, what percentage of these clients did you ask about the following risk factors for anal cancer:

$\begin{array}{lllllr}\text { Smoking } & \text { None } & 1-25 \% & 26-50 \% & 51-75 \% & >75 \% \\ \text { Unprotected anal sex } & \text { None } & 1-25 \% & 26-50 \% & 51-75 \% & >75 \% \\ \text { Non-adherence to ART } & \text { None } & 1-25 \% & 26-50 \% & 51-75 \% & >75 \% \\ \text { \# of lifetime sexual partners } & \text { None } & 1-25 \% & 26-50 \% & 51-75 \% & >75 \%\end{array}$

3. Of the clients that you identified as having a lifestyle risk factor for anal cancer in the past $\mathbf{2}$ weeks, what percentage of these clients did you assess their readiness to change their behavior 
Smokers

Clients who practice unprotected anal sex

Clients who are non-adherent to ART

Clients with $\geq 15$ lifetime sexual partners*

$\begin{array}{lllll}\text { None } & 1-25 \% & 26-50 \% & 51-75 \% & >75 \% \\ \text { None } & 1-25 \% & 26-50 \% & 51-75 \% & >75 \% \\ \text { None } & 1-25 \% & 26-50 \% & 51-75 \% & >75 \% \\ \text { None } & 1-25 \% & 26-50 \% & 51-75 \% & >75 \%\end{array}$

*Literature states that men and women with $\geq 15$ lifetime sexual partners are at a higher risk of anal cancer, regardless of sexual orientation

4. Of the clients that you identified as having a lifestyle risk factor for anal cancer in the past 2 weeks, what percentage of these clients did you provide verbal advice to:

Smokers

$\begin{array}{lllll}\text { None } & 1-25 \% & 26-50 \% & 51-75 \% & >75 \% \\ \text { None } & 1-25 \% & 26-50 \% & 51-75 \% & >75 \% \\ \text { None } & 1-25 \% & 26-50 \% & 51-75 \% & >75 \% \\ \text { None } & 1-25 \% & 26-50 \% & 51-75 \% & >75 \%\end{array}$

Clients who practice unprotected anal sex

Clients who are non-adherent to ART
Clients with $\geq 15$ lifetime sexual partners

None

$1-25 \%$

5. Of the clients that you identified as having a lifestyle risk factor in the past $\mathbf{2}$ weeks, what percentage of these clients did you provide written advice (i.e. pamphlet):

\begin{tabular}{|c|c|c|c|c|c|}
\hline Smokers & None & $1-25 \%$ & $26-50 \%$ & $51-75 \%$ & $>75 \%$ \\
\hline Clients who practice unprotected anal sex & None & $1-25 \%$ & $26-50 \%$ & $51-75 \%$ & $>75 \%$ \\
\hline Clients who are non-adherent to ART & None & $1-25 \%$ & $26-50 \%$ & $51-75 \%$ & $>75 \%$ \\
\hline Clients with $\geq 15$ lifetime sexual partners & None & $1-25 \%$ & $26-50 \%$ & $51-75 \%$ & $>75 \%$ \\
\hline
\end{tabular}

6. Of the clients that you identified as having a lifestyle risk factor in the past $\mathbf{2}$ weeks, what percentage of these clients did you refer to other service providers/agencies or support groups for help in managing their risk factor:

\begin{tabular}{|c|c|c|c|c|c|}
\hline Smokers & None & $1-25 \%$ & $26-50 \%$ & $51-75 \%$ & $>75 \%$ \\
\hline Clients who practice unprotected anal sex & None & $1-25 \%$ & $26-50 \%$ & $51-75 \%$ & $>75 \%$ \\
\hline Clients who are non-adherent to ART & None & $1-25 \%$ & $26-50 \%$ & $51-75 \%$ & $>75 \%$ \\
\hline Clients with $\geq 15$ lifetime sexual partners & None & $1-25 \%$ & $26-50 \%$ & $51-75 \%$ & $>75 \%$ \\
\hline
\end{tabular}

7. When you provide advice about anal cancer risk factors, how much time do you estimate that you spend on average addressing each of the following: 


$\begin{array}{lllllll}\text { Smoking } & 1-2 \text { mins } & 3-5 \text { mins } & 6-10 \text { mins } & 11-15 \text { mins } & >15 \text { mins } & \text { did not provide advice } \\ \text { Unprotected anal sex } & 1-2 \text { mins } & 3-5 \text { mins } & 6-10 \text { mins } & 11-15 \text { mins } & >15 \text { mins } & \text { did not provide advice } \\ \text { Non-adherence to ART } & 1-2 \text { mins } & 3-5 \text { mins } & 6-10 \text { mins } & 11-15 \text { mins } & >15 \text { mins } & \text { did not provide advice } \\ \text { \# of lifetime sexual partners } & 1-2 \text { mins } & 3-5 \text { mins } & 6-10 \text { mins } & 11-15 \text { mins } & >15 \text { mins } & \text { did not provide advice }\end{array}$

8. For clients that you have given advice to about their risk factors for anal cancer, what percentage of these clients do you check their progress in subsequent visits (on average)?

Smokers

Clients who practice unprotected anal sex

Clients who are non-adherent to ART

Clients with $\geq 15$ lifetime sexual partners

$\begin{array}{llll}\text { None } & 1-25 \% & 26-50 \% & 51-75 \% \\ \text { None } & 1-25 \% & 26-50 \% & 51-75 \% \\ \text { None } & 1-25 \% & 26-50 \% & 51-75 \% \\ \text { None } & 1-25 \% & 26-50 \% & 51-75 \%\end{array}$

$>75 \%$ did not provide advice $>75 \%$ did not provide advice $>75 \%$ did not provide advice $>75 \%$ did not provide advice

9. How easy is it to find accessible outside services/agencies/support programs to refer your clients to for the following:

Smoking cessation

Adherence support/counseling

Risk reduction support/counseling

\begin{tabular}{ccccc}
\multicolumn{2}{c}{ Very Difficult } & \multicolumn{3}{c}{ Very Easy } \\
1 & 2 & 3 & 4 & 5 \\
1 & 2 & 3 & 4 & 5 \\
1 & 2 & 3 & 4 & 5
\end{tabular}

10. Please rate your KNOWLEDGE in relation to each of the following: (1=very poor, 5=excellent)

Assessing nicotine dependency

Smoking cessation recommendations

Assessing non-adherence to ART

Recommendations for improving adherence to ART

Assessing for risky sexual behaviors

Recommendations for reducing risky sexual behaviors

Motivational interviewing

Assessing a client's readiness to change

Principles of adult education

$\begin{array}{ccccc}\text { Very Poor } & & & & \text { Excellent } \\ 1 & 2 & 3 & 4 & 5 \\ 1 & 2 & 3 & 4 & 5 \\ 1 & 2 & 3 & 4 & 5 \\ 1 & 2 & 3 & 4 & 5 \\ 1 & 2 & 3 & 4 & 5 \\ 1 & 2 & 3 & 4 & 5 \\ 1 & 2 & 3 & 4 & 5 \\ 1 & 2 & 3 & 4 & 5 \\ 1 & 2 & 3 & 4 & 5\end{array}$


11. Please rate how CONFIDENT you are in undertaking the following activities with clients: ( $1=$ not at all confident, $5=$ very confident)

Assessing nicotine dependency

Smoking cessation recommendations

Assessing non-adherence to ART

Recommendations for improving adherence to ART

Assessing for risky sexual behaviors

Recommendations for reducing risky sexual behaviors

Motivational interviewing

Assessing a client's readiness to change

Principles of adult education

Not at ans

$\begin{array}{cc}\text { all confident } \\ 1 & 2 \\ 1 & 2 \\ 1 & 2 \\ 1 & 2 \\ 1 & 2 \\ 1 & 2 \\ 1 & 2 \\ 1 & 2 \\ 1 & 2\end{array}$

$\begin{array}{llc} & & \text { Very Confident } \\ 3 & 4 & 5 \\ 3 & 4 & 5 \\ 3 & 4 & 5 \\ 3 & 4 & 5 \\ 3 & 4 & 5 \\ 3 & 4 & 5 \\ 3 & 4 & 5 \\ 3 & 4 & 5 \\ 3 & 4 & 5\end{array}$

12. Please rate how effective you think your advice is in helping clients to: ( $1=$ not at all effective, $5=$ very effective)

Give up smoking

Improve ART adherence

Reduce risky sexual behaviors

\begin{tabular}{ccccc}
\multicolumn{2}{c}{ Not at all effective } & \multicolumn{3}{r}{ Very Effective } \\
1 & 2 & 3 & 4 & 5 \\
1 & 2 & 3 & 4 & 5 \\
1 & 2 & 3 & 4 & 5
\end{tabular}

13. Clients I see find it acceptable for me to raise the following lifestyle issues routinely as part of the care:

Smoking

Unprotected anal sex

Non-adherence to ART

\# of lifetime sexual partners

\begin{tabular}{ccccc}
\multicolumn{2}{c}{ Strongly disagree } & \multicolumn{3}{c}{ Strongly Agree } \\
1 & 2 & 3 & 4 & 5 \\
1 & 2 & 3 & 4 & 5 \\
1 & 2 & 3 & 4 & 5 \\
1 & 2 & 3 & 4 & 5
\end{tabular}

14. Please rate how important you think the following lifestyle changes are for improving health ( $1=$ not at all important, $5=$ very important): 
Give up smoking

Improve ART adherence

Reduce risky sexual behaviors

Not at all important

$\begin{array}{lllll}1 & 2 & 3 & 4 & 5 \\ 1 & 2 & 3 & 4 & 5 \\ 1 & 2 & 3 & 4 & 5\end{array}$

15. Please rate how important you think it is to address these anal cancer risk factors with the clients you see $(1=$ not at all important, $5=$ very important):

\title{
Smoking cessation
}

Non-adherence to ART

Reduce risky sexual behaviors

\begin{abstract}
Not at all important
\end{abstract}

$\begin{array}{lllll}1 & 2 & 3 & 4 & 5 \\ 1 & 2 & 3 & 4 & 5 \\ 1 & 2 & 3 & 4 & 5\end{array}$

16. How much of a work priority is it for your team/service to address anal cancer risk factors with clients as part of your normal clinical work ( $1=$ very low priority, $5=$ very high priority):

Smoking cessation

Non-adherence to ART

Very low priority

Reduce risky sexual behaviors

$\begin{array}{lllll}1 & 2 & 3 & 4 & 5 \\ 1 & 2 & 3 & 4 & 5 \\ 1 & 2 & 3 & 4 & 5\end{array}$

\section{Education and training for risk factors}

17. In the past 12 months have you had education or training in the management of these risk factors or strategies for helping clients change their behaviors?

$\begin{array}{lcc}\text { Smoking } & \text { Yes } & \text { No } \\ \text { Non-adherence to ART } & \text { Yes } & \text { No } \\ \text { Risky sexual behaviors } & \text { Yes } & \text { No } \\ \text { Motivational interviewing } & \text { Yes } & \text { No } \\ \text { Assessing clients' readiness to change } & \text { Yes } & \text { No } \\ \text { Client Education } & \text { Yes } & \text { No }\end{array}$

18. If you answered yes, please describe the type of education/training you have received: 
19. Would you like additional education or training in these areas:

$\begin{array}{ll}\text { Assessing nicotine dependency } & \text { Yes, high priority } \\ \text { Smoking cessation recommendations } & \text { Yes, high priority } \\ \text { Assessing non-adherence to ART } & \text { Yes, high priority } \\ \text { Recommendations for improving adherence to ART } & \text { Yes, high priority } \\ \text { Assessing for risky sexual behaviors } & \text { Yes, high priority } \\ \text { Recommendations for reducing risky sexual behaviors } & \text { Yes, high priority } \\ \text { Motivational interviewing } & \text { Yes, high priority } \\ \text { Assessing a client's readiness to change } & \text { Yes, high priority } \\ \text { Principles of adult education } & \text { Yes, high priority }\end{array}$

Yes, but not high priority

Yes, but not high priority

Yes, but not high priority

Yes, but not high priority

Yes, but not high priority

Yes, but not high priority

Yes, but not high priority

Yes, but not high priority

Yes, but not high priority

If you would like training, in what format would you like to receive it? (circle all that apply)

\section{Conference}

Clinical supervision/mentoring

Small group discussions

Interactive web programs

Archived web programs

Other:

20. Any other comments:

Thank you for completing this survey

Modified with permission from Mark Harris. In Harris, M., Davies, G. P., Williams, A., Eames-Brown, R., \& Amoroso, C. (n.d.). Lifestyle risk factor survey: Community health from http://cphce.unsw.edu.au/sites/default/files/uploads/Baseline_survey_.pdf 


\section{APPENDIX C. INSTITUTIONAL REVIEW BOARD APPROVAL}

\begin{tabular}{lr}
\hline THE UNIVERSITY OF TENNESSEE \\
Health Science Center
\end{tabular}

December 31, 2013

Crystal Martin Walker, MSN

UTHSC - CON - Nursing- Academic Programs

Alexander Building

877 Madison Avenue

Memphis, TN 38163--2186

Re: 13-02876-XP

Study Title: Prevalence, barriers, and facilitators of anal cancer risk factor management from the HIV primary care provider's prospective

Dear Dr. Walker:

The Administrative Section of the UTHSC Institutional Review Board (IRB) has received your written acceptance of and/or responses dated 12/26/2013 and 12/18/2013 to the provisos outlined in our correspondence of 12/20/2013 and 12/16/2013 concerning the above referenced project. The IRB determined that your application is eligible for expedited review under 45 CFR 46.110(b)(1), categories (6) and (7). The IRB has reviewed these materials and determined that they do comply with proper consideration for the rights and welfare of human subjects and the regulatory requirements for the protection of human subjects. Therefore, this letter constitutes full approval by the IRB of your application, Version 1.3, as submitted including:

- Anal cancer risk factor management survey, dated 11/1/2013 (stamped IRB approved $12 / 31 / 2013$ )

- Survey Consent Script, dated 12/31/2013 (stamped IRB approved 12/31/2013

- Main consent form, dated 12/31/2013, (stamped IRB approved 12/31/2013)

Approval of this study will be valid from 12/31/2013 to $12 / 4 / 2014$.

The IRB has determined that the informed consent form, incorporating the authorization of subjects to use their protected health information in research, complies with the federal privacy regulations as specified in 45 CFR 160 and 45 CFR 164.

In accord with 45 CFR 46.116(d), informed consent may be altered, with the cover statement used in lieu of an informed consent interview for the electronic survey process. The requirement to secure a signed consent form is waived under 45 CFR 46.117(c)(2). Willingness of the subject to participate will constitute adequate documentation of consent.

In accord with 45 CFR 46.116(d), informed consent may be altered for the one-on-one interviews. For the phone interviews, the PI may either e-mail or fax the main informed consent 
to the subjects. After the subject receives the copy of the consent form, the PI will have a telephone consent discussion where any questions that the subject has about study participation are answered prior to signing the consent form. The subject may fax or e-mail the signed consent to the PI. The one-on-one interview may commence once the signed consent form has been received by the PI. Subjects that elect to have a face-to-face interview may sign the consent form in-person.

In the event that subjects are to be recruited using solicitation materials, such as brochures, posters, web-based advertisements, etc., these materials must receive prior approval of the IRB. Any revisions in the approved application must also be submitted to and approved by the IRB prior to implementation. In addition, you are responsible for reporting any unanticipated serious adverse events or other problems involving risks to subjects or others in the manner required by the local IRB policy.

Finally, re-approval of your project is required by the IRB in accord with the conditions specified above. You may not continue the research study beyond the time or other limits specified unless you obtain prior written approval of the IRB.

Sincerely,

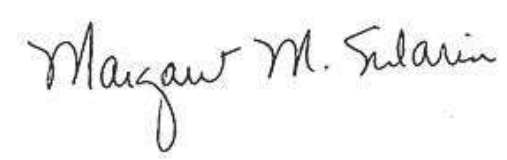

Signature applied by Margaret M Sularin on 12/31/2013 01:10:27 PM CST

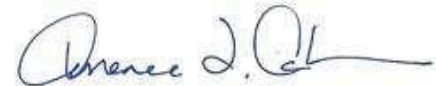

Signature applied by Terrence F Ackerman on 12/31/2013 01:11:06 PM CST

Margaret M. Sularin, LMSW, RD, LDN, CCRP

Regulatory Specialist

UTHSC IRB
Terrence F. Ackerman, Ph.D.

Chairman

UTHSC IRB 


\section{APPENDIX D. ONLINE SURVEY CONSENT FORM}

\section{Survey Introduction and Consent}

You are being given the opportunity to participate in this research study conducted by Crystal Walker, RN, MSN-CN and Wendy Likes, PhD, DNSc, APRN-Bc at the University of Tennessee Health Science Center, College of Nursing

The purpose of this study is to assess HIV primary care providers' self reported level of anal cancer risk factor management (ACRFM) and to explore the facilitators and barriers of incorporating ACRFM into HIV primary care. The study will consist of two parts: The first part is completion of an electronic survey, and the second part includes a one-on one interview in which survey subjects are randomly selected to participate in the interviews. If you are chosen and you would like to participate in the one-on-one interview you may participate by telephone or by coming to the College of Nursing at the University of Tennessee Health Science Center. The electronic survey will take approximately 15-20 minutes to complete. The one-on-one interviews will take $30-60$ minutes.

As a result of your participation in this study potential risks, though minimal, include social harm related to loss of confidentiality and psychological harm related to the interview process if you are chosen to participate in one-on-one interviews. Your participation in this study will remain confidential, and your identity will not be stored with your responses. Your responses will be assigned a code number, and the master list with your name and code number will be accessed by the principle investigator only. Responses will be stored in a locked room and destroyed upon collecting and analyzing the data. Your study responses will be handled as confidentially as possible, but there is always a risk in the breach of confidentiality with research studies which could cause social harm such as embarrassment within social groups/business groups. There is a potential risk of psychological harm with the one-on-one interviews as you may feel a sense of embarrassment, guilt, and stress when responding to the interview questions. If you are chosen to participate in the one-on-one interviews, and you agree to participate, this identifying information will also be de-identified with a code number, stored in a locked room, and destroyed upon collecting and analyzing your responses. None of your responses from this research study will be shared with your employer/s and linked to your participation, so there is minimal risk associated with loss of employment.

Since there is the potential risk of loss of confidentiality, every effort will be made to keep your information confidential; however, this cannot be guaranteed. There is no benefit to you for participation in this study. To date there is only one study that explores anal health in the HIV primary care setting. This research will help to expand the current knowledge in this field, and it could help to improve anal health in the HIV primary care setting

You do not have to participate in this study. Participation in both parts of this research study is voluntary and failure to participate in either part of the study will not adversely affect any opportunities that you would have otherwise. If you have questions, concerns, or complaints about your participation or about the research study in general, please contact: Crystal Walker, PhD candidate,601-415-3672/cmarti47@uthsc.edu

If you complete the electronic survey, your name will be entered in one drawing for a $\$ 75$ gift card. If you are chosen, this card will be mailed to you after all of the survey responses are collected and analyzed. If you are randomly chosen to participate in the one-on-one interviews, you will receive a $\$ 75$ gift card at the completion of the interview.

You have read the description of the research study as outlined above. If you wish to participate in the study, accept by choosing the "agree" button on. If you do not wish to participate in the study, decline by choosing the "disagree" button.

\section{I agree to participate in this research study}

Agree

Disagree 


\section{APPENDIX E. MAIN CONSENT FORM}

\begin{tabular}{ll} 
Main Consent Form & $\begin{array}{l}\text { THEUNIVERSITYof } \\
\text { TENNESSEE }\end{array}$ \\
\hline
\end{tabular}

TITLE: Practices, barriers, and facilitators of anal cancer risk factor management from the HIV primary care provider's prospective

PRINCIPAL INVESTIGATOR: $\quad$ Crystal Martin Walker, RN, MSN-CNL

920 Madison Ave \#544

Memphis, TN 38163

CO-INVESTIGATOR(S): $\quad$ Wendy Likes, PhD, DNSc, APRN-Bc

\section{INTRODUCTION:}

You are being given the opportunity to participate in this research study. The purpose of this consent form is to help you decide if you want to be in the research study. This consent form may contain words that you do not understand. Please ask the study doctor or study staff to explain any words or information that you do not clearly understand. We encourage you to talk with your family and friends before you decide to take part in this research study.

Please tell the study doctor or study staff if you are taking part in another research study.

The purpose of this study is to explore the facilitators and barriers of incorporating anal cancer risk factor management into HIV primary care, and will include one-on-one interviews in which you were randomly selected to participate in.

After consenting to participate in this study, you will be asked to participate in a one-on-one interview with the principle investigator, and the interview will take place in your HIV primary care setting, at The University of Tennessee Health Science Center college of nursing, or by telephone. The interview will take approximately 30-60 minutes, and after completion of your interview, this will end your participation in the study.

\section{PROCEDURES TO BE FOLLOWED:}

- Complete a one-on-one interview (30-60 minutes)

The topic of the questions for the one-on-one interviews includes understanding the facilitators and barriers of discussing anal health in the HIV primary care setting. One-onone interviews will be conducted face to face at a time convenient for the participant or by telephone. All interviews will be voice recorded. The interview is for research purposes only. 


\section{RISKS ASSOCIATED WITH PARTICIPATION:}

As a result of your participation in this study potential risks, though minimal, include social harm related to loss of confidentiality and psychological harm related to the interview process if you are chosen to participate in one-on-one interviews. Your participation in this study will remain confidential, and your identity will not be stored with your responses. Your responses will be assigned a code number, and the master list with your name and code number will be accessed by the principle investigator only, and it will be stored in a locked room and destroyed upon collecting and analyzing your responses. Your study responses will be handled as confidentially as possible, but there is always a risk in the breach of confidentiality with research studies, which could cause social harm such as embarrassment within social groups/business groups. There is a potential risk of psychological harm with the one-on-one interviews as you may feel a sense of embarrassment, guilt, and stress when responding to the interview questions. None of your responses from this research study will be shared with your employer/s and linked to your participation, so there is minimal risk associated with loss of employment.

Since there is the potential risk of loss of confidentiality, every effort will be made to keep your information confidential; however, this cannot be guaranteed.

The research may involve risks to you, which are currently unforeseeable. You will be told about any new information that might change your decision to be in this study. You may be asked to sign a new consent form if this occurs.

\section{BENEFITS ASSOCIATED WITH PARTICIPATION:}

There are not benefits to you for participating in this study. To date there is only one study that explores anal health in the HIV primary care setting. This research will help to expand the current knowledge in this field, and it could help to improve anal health in the HIV primary care setting.

\section{ALTERNATIVES TO PARTICIPATION:}

You do not have to participate in this study.

You will not have to undergo the following procedures if you do not take part in this study: 


\section{CONFIDENTIALITY:}

If any paper research records are gathered such as interview notes, they will be stored in locked file cabinets and will be accessible only to research personnel.

All of your electronic research records will be computer password protected and accessible only to research personnel.

Presentations/Publications

You will not be identified in any presentations or publications based on the results of this research study.

\section{COMPENSATION AND TREATMENT FOR INJURY:}

You are not waiving any legal rights or releasing the University of Tennessee or its agents from liability for negligence. In the event of physical injury resulting from research procedures, the University of Tennessee does not have funds budgeted for compensation for medical treatment. Therefore, the University of Tennessee does not provide for treatment or reimbursement for such injuries.

If you are injured or get sick as a result of being in this study, you and/or your insurance will be billed for the costs associated with this research study.

No compensation will be available to you for any extra expenses that you may have as the result of research related physical injuries, such as additional hospital bills, lost wages, travel expenses, etc.

No compensation will be available to you for any non-physical injuries that you may have as a result of research participation, such as legal problems, problems with your finances or job, or damage to your reputation.

\section{QUESTIONS:}

Contact Crystal Walker at 601-415-3672 if you have questions about your participation in this study or if you have questions, concerns, or complaints about the research.

If you feel you have had a research-related injury, contact Crystal Walker at 601-415-3672. This is a 24-hour/7-day cell phone number.

You may contact Terrence F. Ackerman, Ph.D., UTHSC IRB Chairman, at 901-448-4824 or visit the IRB website at http://www.uthsc.edu/research/research_compliance/IRB/participant_complaint.php if you 


\section{Main Consent Form}

have any questions about your rights as a research subject or if you have questions, concerns, or complaints about the research.

\section{PAYMENT FOR PARTICIPATION:}

You will receive a $\$ 75$ gift card by mail after completion of the interview.

\section{COSTS OF PARTICIPATION:}

There are no costs to you for participating in this study.

\section{VOLUNTARY PARTICIPATION AND WITHDRAWAL:}

Your participation in this research study is voluntary. You may decide not to participate or you may leave the study at any time. Your decision will not result in any penalty or loss of benefits to which you are entitled.

If you are an employee of The University of Tennessee Health Science Center, participating or not participating in this study will not affect your employment status.

If you decide to stop being part of the study, information that you have already provided will be kept in a confidential manner.

Your participation in this research study may be stopped by the study doctor or study staff without your consent for any of the following reasons:

- If you do not show up for visits; or

- If you do not follow the study doctor's or study staffs' instructions 


\section{CONSENT OF SUBJECT}

You have read or have had read to you a description of the research study as outlined above. The investigator or his/her representative has explained the study to you and has answered all the questions you have at this time. You knowingly and freely choose to participate in the study. A copy of this consent form will be given to you for your records.

Signature of Research Subject (18 years + )

Printed Name of Adult Research Subject

\section{Date}

Date

\section{Time}

Time

\section{Printed Name of Person Obtaining Consent}

In my judgment, the subject has voluntarily and knowingly given informed consent and possesses the legal capacity to give informed consent to participate in this research study.

$\overline{\text { Date }} \quad \overline{\text { Time }}$




\section{VITA}

Mrs. Crystal Martin Walker was born in Vicksburg, MS in 1986. She graduated with a Bachelor of Science degree in Biology from The University of Mississippi in 2009 followed by a Masters of Science degree in nursing with a Clinical Nurse Leader certification from The University of Tennessee Health Science Center in 2011. She entered the dual D.N.P-Ph.D. program at The University of Tennessee Health Science Center in Fall 2011 and also began her nursing career as an oncology nurse at Methodist University Hospital. While in the dual program, she worked as a graduate teaching assistant in the University of Tennessee Health Science Center's college of nursing. She has presented her research on anal cytology and anal health at various national and local conferences and meetings. She has served as a volunteer instructor at Friends for Life, a non-profit HIV/AIDS organization, and she volunteers with the Tennessee Achieves program as a mentor to high school students. She is a member of Sigma Theta Tau and the Southern Nursing Research Society. She plans to finish the D.N.P portion of the dual degree Spring 2016. 